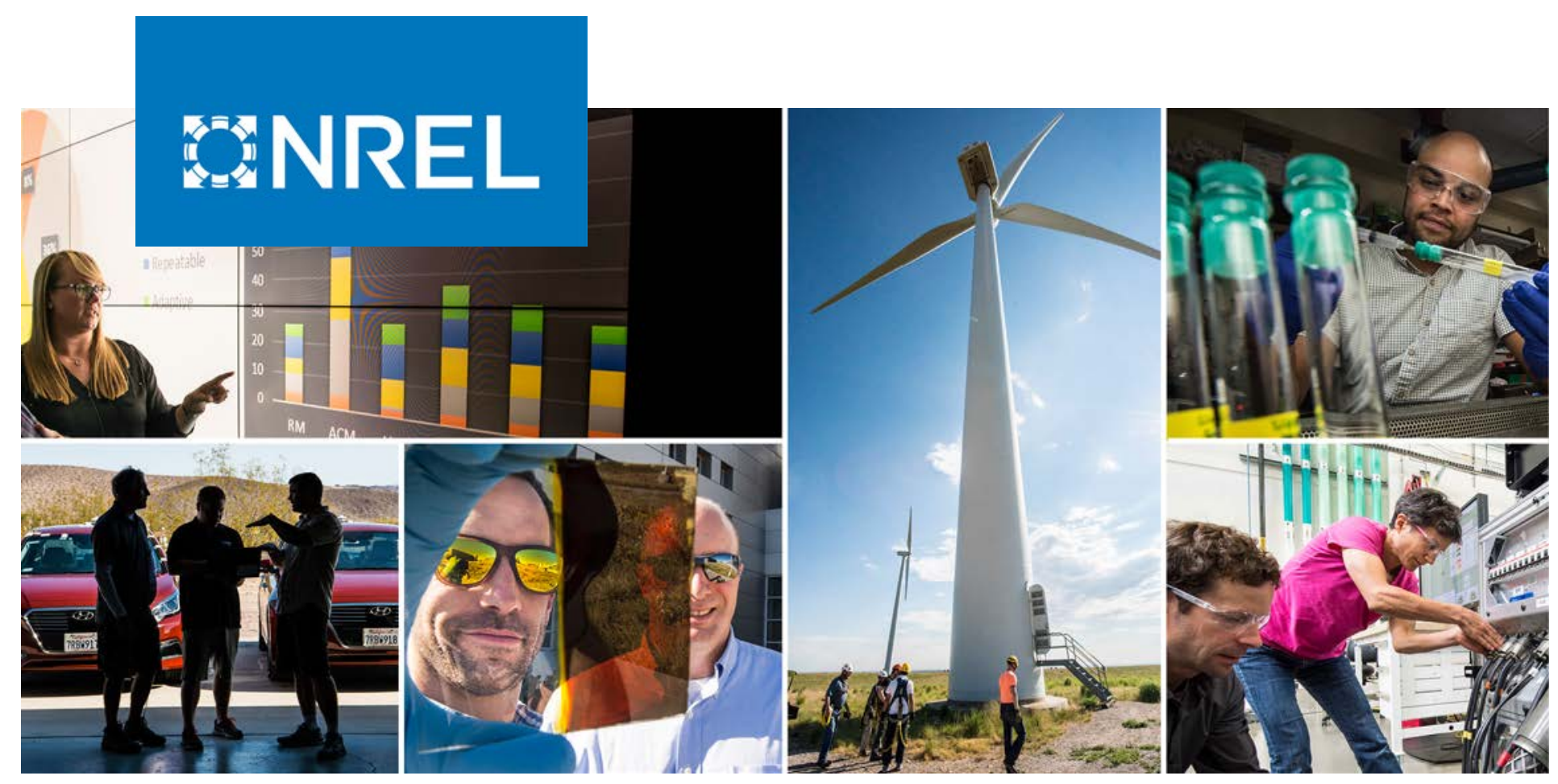

\title{
The Cost and Feasibility of Floating Offshore Wind Energy in the O'ahu Region
}

Matt Shields, Patrick Duffy, Walt Musial, Michael Laurienti, Donna Heimiller, Rob Spencer, and Mike Optis

National Renewable Energy Laboratory

NREL is a national laboratory of the U.S. Department of Energy Office of Energy Efficiency \& Renewable Energy

Operated by the Alliance for Sustainable Energy, LLC

This report is available at no cost from the National Renewable Energy Laboratory (NREL) at www.nrel.gov/publications.
Technical Report

NREL/TP-5000-80808

October 2021 


\title{
BNREL
}

\section{The Cost and Feasibility of Floating Offshore Wind Energy in the O'ahu Region}

\author{
Matt Shields, Patrick Duffy, Walt Musial, Michael Laurienti, \\ Donna Heimiller, Rob Spencer, and Mike Optis
}

National Renewable Energy Laboratory

\section{Suggested Citation}

Shields, Matt, Patrick Duffy, Walt Musial, Michael Laurienti, Donna Heimiller, Rob Spencer, and Mike Optis. 2021. The Cost and Feasibility of Floating Offshore Wind Energy in the O'ahu Region. Golden, CO: National Renewable Energy Laboratory. NREL/TP5000-80808. https://www.nrel.gov/docs/fy220sti/80808.pdf.

This report is available from the Bureau of Ocean Energy Management by referencing OCS Study BOEM 2021-070. The report may be downloaded from BOEM's Recently Completed Environmental \& Technical Studies - Pacific webpage at http://www.boem.gov/Pacific-Completed-Studies.

This study was funded by the U.S. Department of the Interior, Bureau of Ocean Energy Management through Interagency Agreement M19PG00025 with the U.S. Department of Energy.

NREL is a national laboratory of the U.S. Department of Energy Office of Energy Efficiency \& Renewable Energy Operated by the Alliance for Sustainable Energy, LLC

This report is available at no cost from the National Renewable Energy Laboratory (NREL) at www.nrel.gov/publications.

Contract No. DE-AC36-08GO28308
Technical Report NREL/TP-5000-80808 October 2021

National Renewable Energy Laboratory 15013 Denver West Parkway Golden, CO 80401 303-275-3000 • www.nrel.gov 


\section{NOTICE}

This work was authored by the National Renewable Energy Laboratory, operated by Alliance for Sustainable Energy, LLC, for the U.S. Department of Energy (DOE) under Contract No. DE-AC36-08GO28308. Funding provided by the U.S. Department of the Interior, Bureau of Ocean Energy Management through Interagency Agreement M19PG00025 with the U.S. Department of Energy. The views expressed herein do not necessarily represent the views of the DOE or the U.S. Government.

This report is available at no cost from the National Renewable Energy Laboratory (NREL) at www.nrel.gov/publications.

U.S. Department of Energy (DOE) reports produced after 1991 and a growing number of pre-1991 documents are available free via www.OSTI.gov.

Cover Photos by Dennis Schroeder: (clockwise, left to right) NREL 51934, NREL 45897, NREL 42160, NREL 45891, NREL 48097, NREL 46526.

NREL prints on paper that contains recycled content. 


\section{Executive Summary}

In 2008, the State of Hawai' $i$ and the United States Department of Energy signed a Memorandum of Understanding to transform the state's energy portfolio from $95 \%$ dependency on imported oil to an economy based primarily on renewable generation (Hawai 'i State Energy Office 2018). This agreement was strengthened in 2015 when the state set a target to achieve a 100\% Renewable Portfolio Standard (RPS) by 2045 in House Bill 623 (Hawai'i House of Representatives 2015b). The Hawai'i Clean Energy Initiative (HCEI) is the framework of legislation that enables this transition to a clean energy economy. The HCEI has stated objectives of developing infrastructure, fostering innovation, creating economic opportunity, sharing their approach with other island communities, and building a workforce with new skills (Hawai' $i$ State Energy Office 2018). Hawai' $i$ has made significant progress already towards the RPS, generating over 34\% of the state's electric utility needs from renewable sources in 2020 (Hawaiian Electric 2021).

Hawai ${ }^{\prime} \mathrm{i}$ is well suited to become the first state to achieve a 100\% RPS. It has a relatively small load, high current electricity prices, heavy reliance on imported fossil fuels, and favorable conditions for wind and solar energy production (Energy Information Agency 2021). Offshore wind has the potential to contribute significantly to this RPS as Hawai $i$ is an island community with a strong wind resource and a population (and corresponding electricity demand) concentrated along the coastline. To date, no offshore wind development has taken place in the Hawaiian Islands. In 2015 and 2016, the Bureau of Ocean Energy Management (BOEM) received three unsolicited applications to develop

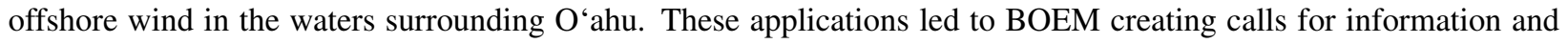
nominations at two Call Areas, one on the northwest side of the island and the other on the south side. BOEM is no longer reviewing these project applications. Moreover, there is currently no timeline or specific plan to develop the first offshore wind project in Hawai 'i waters.

The Hawai' $i$ State Energy Office (HSEO) is the organization that leads the HCEI and is interested in better understanding the value proposition of offshore wind. HSEO collaborated with BOEM to develop the scope of this cost and feasibility study with the intent of providing information to decision makers on Hawai' $i$ as they consider the makeup of the $100 \%$ RPS. HSEO requested that the analysis focus on $\mathrm{O}^{\prime}$ ahu as it has the highest energy demand of the Hawaiian Islands. The study is intended to:

- Provide estimates of the Levelized Cost of Energy (LCOE) of offshore wind in the region surrounding O'ahu. This information will be used by local decision makers and interested parties on Hawai' $i$, including HSEO and Hawaiian Electric (HE) to inform the Integrated Grid Planning process.

- Consider potential technologies, ports, grid connections, and logistics that may impact the costs of offshore wind.

- Produce visualization materials that demonstrate land-use tradeoffs between onshore and offshore renewable generation sources.

- Compile preliminary feedback and information from local stakeholders on the benefits and drawbacks of offshore wind. This information was used to inform the cost modeling approach where possible.

- Suggest future studies and activities that are needed to inform decision makers about offshore wind in the $\mathrm{O}$ 'ahu region.

The study is not a marine spatial planning exercise and does not propose or seek to develop an actual project. Further information will need to be developed to understand the environmental, social, cultural, and workforce impacts of offshore wind so that projects can be developed holistically as a partnership with Hawaiian perspectives. ${ }^{1}$

We conducted a geospatial cost study to model the spatial and temporal variations in the LCOE of offshore wind for the region surrounding $\mathrm{O}^{\prime}$ ahu. LCOE is a metric that encompasses the development, capital, operational, and financing costs of a generation asset along with the annual energy production of the power plant. It is essentially the net present

\footnotetext{
${ }^{1}$ In this report we use the term "Hawaiian"" to refer to people of Hawaiian descent. We use the broader term "Hawai ${ }^{i} \mathrm{i}$ residents" or "Hawai ${ }^{\circ} \mathrm{i}$ stakeholders" to include all local community members who may or may not be of Hawaiian descent.
} 
value of all project expenditures scaled by the net present value of the lifetime energy production. LCOE can be used to compare the costs of offshore wind with other generation technologies (or compare the costs of different offshore wind projects) although one must take care to standardize the assumptions used with the different calculations. We provide a detailed explanation of the individual terms and assumptions used in the LCOE calculation in this study in Section 7.

We defined an analysis domain which begins 3 nautical miles offshore the coast of $\mathrm{O}$ 'ahu and expands to locations with a water depth of $1,300 \mathrm{~m}$, excluding marine sanctuaries in the area. We collected relevant geospatial layers, such as bathymetry, metocean conditions (meteorological and ocean, including wind speed and wave height), and infrastructure, to inform the cost study. A new, state-of-the-art offshore wind resource data set was available at the time of this study. The new data set, developed by the National Renewable Energy Laboratory (NREL) using methodologies outlined in Optis et al. (2020), shows that the annual average wind speeds in the $\mathrm{O}^{\prime}$ ahu region are typically $2 \mathrm{~m} / \mathrm{s}$ higher than the data sets previously used by NREL (Musial et al. 2016). We report more detailed costs from three Study Areas ( $\mathrm{O}^{\prime}$ ahu North, $\mathrm{O}$ 'ahu South, and $\mathrm{O}^{\prime}$ ahu East) in different regions within the analysis domain as a way to convey the geographic diversity in costs in the region. The first two Study Areas have the same boundaries as the BOEM Call Areas, and we defined the boundaries of the third area for the purposes of this study. Again, this study is not a marine spatial planning exercise; as a result, we did not vet the Study Area boundaries with stakeholder groups, and only use these areas as a way to compare cost and performance in the region. We did solicit preliminary feedback from stakeholder groups and compiled public comments on offshore wind development in the region from previous outreach activities conducted by BOEM. These discussions highlighted the importance of including Hawaiian perspectives throughout the entire offshore wind development process to understand cultural and environmental sensitivities with potential project sites. This may be best accomplished by involving Hawai 'i stakeholders in integral roles from the outset of the project.

We used NREL's Offshore Regional Cost Analyzer (ORCA) model to evaluate costs throughout the analysis domain. ORCA is a deterministic cost model that evaluates the LCOE of offshore wind projects uniformly located throughout the domain. ${ }^{2}$ We assigned a high resolution grid (highest currently available in ORCA) of approximately $1 \mathrm{~km} \times 1$ $\mathrm{km}$ with a 600-MW offshore wind power plant centered on each node, corresponding to 5,057 sites within the analysis domain. We selected this resolution to provide smoother maps of the spatial variance in cost; although it means that the modeled projects overlap, this does not impact the cost results. We selected a 600-MW plant capacity in collaboration with Hawaiian Electric (HE) to reflect the largest project that could reasonably be built in the $\mathrm{O}^{\text {' }}$ ahu region. Decreasing the project size would likely increase LCOE relative to the results presented in this report as economies of scale are not fully realized. ORCA calculates the Capital Expenditures (CapEx), Operational Expenditures (OpEx), and Annual Energy Production (AEP) at each site location, and aggregates these to compute the LCOE at each point. CapEx includes costs for site control, permitting, environmental and site surveys, and financing. Although significant infrastructure development would be required to develop offshore wind in the $\mathrm{O}^{`}$ ahu region, such as port upgrades, these expenses are exogenous to LCOE and are therefore not modeled in this study. LCOE is computed for a project with a Commercial Operation Date (COD) of 2019, and then the costs of projects with CODs of 2022, 2027, and 2032 are projected from the baseline result based on the impact of learning curves and technological advancements. We present the full sequence of results to demonstrate the potential trajectory of floating offshore wind costs, although the timeframes required to plan, permit, and install a commercial-scale offshore wind project make it unlikely that any project would be constructed in the O'ahu region before 2030 .

We derived a set of customized assumptions for the ORCA model that are specific to the $\mathrm{O}$ 'ahu region. The water depths in the analysis domain require floating wind turbines, and we identify a semisubmersible platform as a likely technology choice. Each COD has a specific turbine rating assigned to it that reflects current and anticipated industry trends toward larger turbines (Musial et al. 2021). Larger turbines enable projects to reduce costs as they require fewer machines and support structures to generate a given capacity (Shields et al. 2021). The analysis we conduct for this study accounts for both the CapEx and OpEx savings associated with the different turbine ratings as well as the specific wake losses and energy production for each scenario. We assign a $10 \%$ cost premium to the wind turbines to account for backup systems that would allow them to safely control themselves in the event of a loss of grid connection during

${ }^{2}$ ORCA itself is not a publicly available model, although the underlying cost equations used within this study are published within the National Renewable Energy Laboratory Wind Analysis Library (NREL 2021e), which can be accessed at https://github.com/NREL/NRWAL. 
a hurricane. A final technology constraint is that the capacity of the export cables is capped at $135 \mathrm{MW}$ instead of the more common 300-400 MW. This requirement was imposed by the Hawaiian Electric Company to accommodate their grid resiliency planning specifications. Although the smaller cables are cheaper, the lower capacity means that more are required per project, which increases the overall export cable costs by around $75 \%$. A summary of the major technology assumptions used in this study is provided in Table A.

Table A. Technology assumptions for offshore wind in the O'ahu region between 2019 and 2032.

\begin{tabular}{cccccc}
\hline & & \multicolumn{4}{c}{ Commercial Operation Date } \\
Property & Unit & 2019 & 2022 & 2027 & 2032 \\
\hline Turbine rated power & MW & 8 & 10 & 12 & 15 \\
Turbine rotor diameter & $\mathrm{m}$ & 175 & 196 & 215 & 240 \\
Turbine hub height & $\mathrm{m}$ & 118 & 128 & 138 & 150 \\
Substructure type & & \multicolumn{4}{c}{ Semisubmersible } \\
Wind power plant capacity & MW & \multicolumn{4}{c}{600} \\
Wind turbine spacing & Rotor diameters & \multicolumn{4}{c}{135} \\
Export cable capacity & MW & \multicolumn{4}{c}{$91-1,300$} \\
Range of water depths & $\mathrm{m}$ & \multicolumn{5}{c}{} \\
\hline
\end{tabular}

In addition to the technology assumptions, we selected potential infrastructure resources that would be appropriate for developing commercial-scale floating wind. We identified the Kalaeloa/Barber's Point Harbor (KBPH) as a likely construction and operations port on $\mathrm{O}^{`}$ ahu as it is less congested than the main port at Honolulu, has available upland area that could be repurposed for manufacturing or storage of offshore wind components, and is actively seeking out new business opportunities as part of their 2040 Master Plan (Transportation Harbors Division 2015). Furthermore, we selected the Iwilei and Ko'olau transmission level substations as the most realistic points of interconnection as they are the most straightforward locations to upgrade to accommodate an injection of several hundred megawatts of offshore wind power, and their location on the eastern side of the island will improve power flows by sending electricity west toward load centers near Honolulu (currently, most of the power flows on O'ahu move from west to east). We assume that major components are sourced from a mature supply chain developed on the mainland United States, which would require significant investment to develop the necessary capabilities to support offshore wind deployment in the timeframes considered in this study. We conducted a preliminary assessment into sourcing components from international supply chains located in Southeast Asia; although we do not incorporate any cost differences into the results of this study, a closer evaluation into the availability of alternate suppliers may represent a pathway to additional cost reductions. The consequence of sourcing components internationally would be a reduction in the overall economic impacts of a domestic supply chain, although neither manufacturing on the U.S. mainland nor Southeast Asia would contribute to local content requirements on $\mathrm{O}^{`}$ ahu. As offshore wind projects in the $\mathrm{O}^{`}$ ahu region would be located a significant distance away from a mature supply chain on the U.S. mainland, we computed an additional transportation cost premium of around \$1.8 million per barge trip to shuttle components to KBPH.

Our modeling approach indicates that the LCOE for offshore wind in the $\mathrm{O}^{\prime}$ ahu analysis domain ranges from around $\$ 83 / \mathrm{MWh}-\$ 194 / \mathrm{MWh}$ for a COD in 2019 and decreases to $\$ 48 / \mathrm{MWh}-\$ 109 / \mathrm{MWh}$ by 2032 as a result of maturing global supply chains, increasing turbine rating, and the incorporation of technological innovations. Heat maps showing the spatial distribution of these costs are provided in Figure A. The lowest values of LCOE correspond to areas with low CapEx and OpEx and high values of AEP. These sites are typically close to the construction and operations port, close to the interconnection point, and experience an unobstructed wind resource.

The average LCOE within the three Study Areas is shown in Figure B. The O'ahu East Study Area exhibits the lowest average LCOE as it is close to the grid connection in Ko'olau and has the strongest wind resource. The long export cable distances required for the $\mathrm{O}^{\prime}$ ahu North Study Area result in the highest overall costs. The average LCOE in the three Study Areas ranges from \$96/MWh-\$113/MWh for a COD in 2019 to $\$ 56 / \mathrm{MWh}-\$ 66 / \mathrm{MWh}$ for a COD in 2032 . 

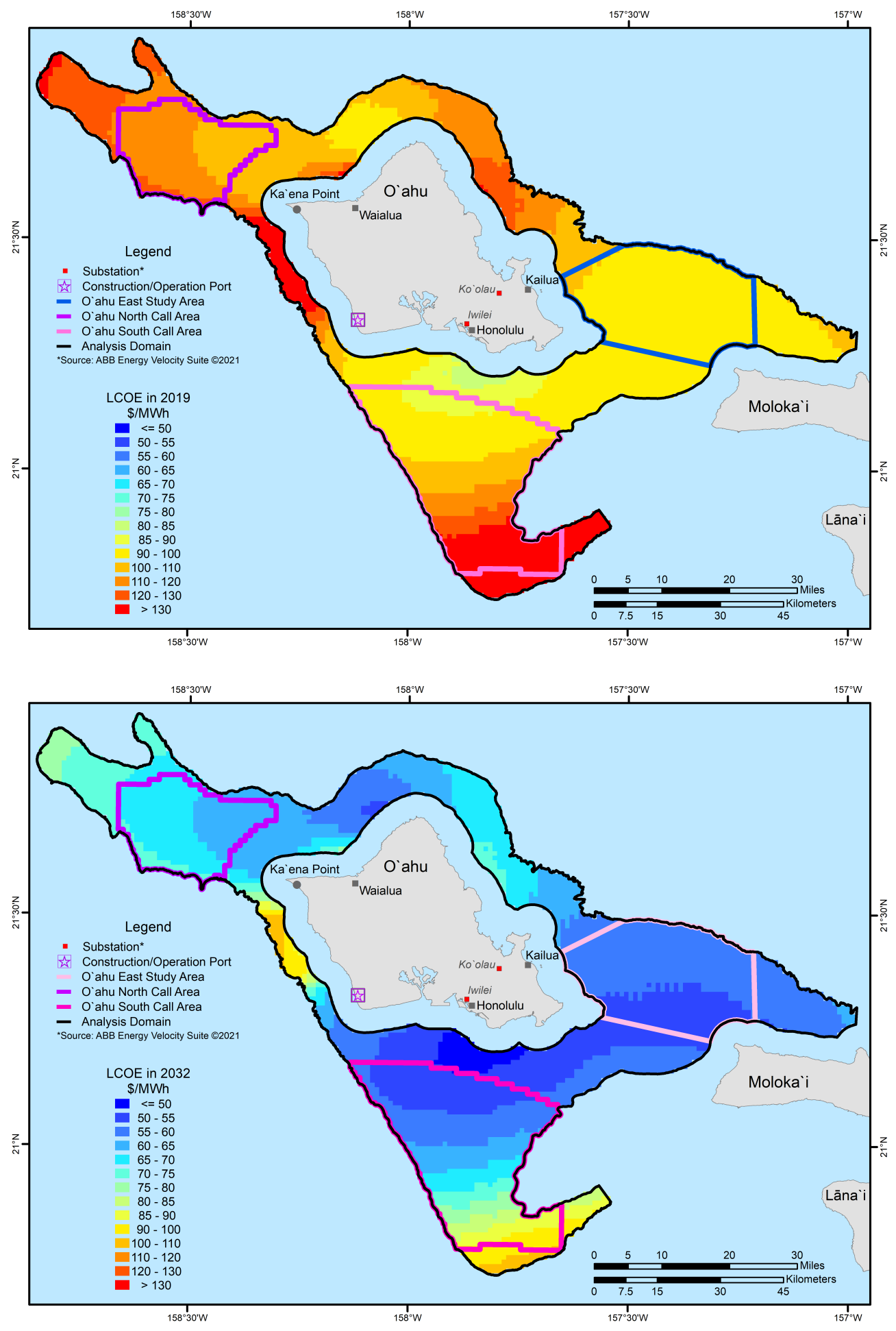

Figure A. Heat maps of LCOE in the O'ahu region for CODs in 2019 (top) and 2032 (bottom). 


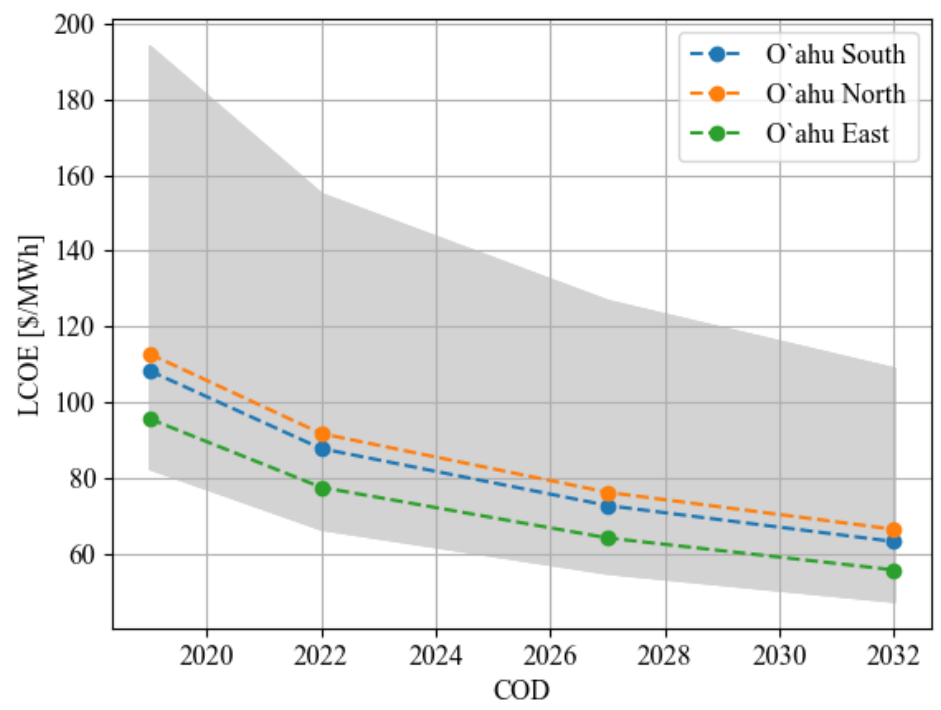

Figure B. LCOE projections for CODs between 2019 and 2032 for the three Study Areas (spatial averages). Gray shading indicates the range between minimum and maximum values over the analysis domain.

The values of LCOE that we estimate for the analysis domain show that offshore wind costs in the $\mathrm{O}$ 'ahu region can potentially be competitive with projected global costs. Despite the logistical complexities of installing projects far from existing supply chains, the quality of the wind resource, close proximity to the infrastructure on land, and the relatively benign metocean climate compensate for the additional cost requirements (NREL 2021c). This finding is

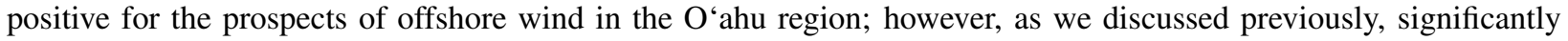
more information is required to understand the comprehensive impact of developing these projects. There are several caveats to the results of this study:

- We did not conduct detailed environmental impact assessments or stakeholder engagement activities (although we did solicit preliminary feedback from stakeholder groups). When these studies and outreach efforts are conducted, the findings may suggest alternative technology, infrastructure, or logistics options to the assumptions we use in this report. This would likely have an impact on LCOE.

- We do not consider the impact of offshore wind development on Hawaiian traditional and customary practices (such as fishing) which are protected under the state constitution. Actual projects may incur additional costs to mitigate potential effects on Native Hawaiian customs.

- We do not consider the effects of public policy on the costs of offshore wind. State or federal policies such as tax credits, green bonds, or offshore renewable energy credits have the potential to benefit project economics.

- The basis for this study is a 600-MW floating wind power plant. Currently, there are only demonstration-scale floating projects (less than $50 \mathrm{MW}$ ) that have been deployed worldwide (Musial et al. 2021). Obtaining the costs that we report in this study will require continued turbine and plant upsizing along with further technological innovation.

- We assume that a mature floating wind supply chain exists in the mainland United States that has sufficient throughput capacity to support offshore wind in the $\mathrm{O}$ 'ahu region. This supply chain would include component manufacturing facilities, transportation vessels, and a well-trained workforce. We do not consider the costs or challenges associated with developing this supply chain, which will be significant but would not be part of the individual project LCOE reported in this study.

- The modeled operation and maintenance costs assume that sufficient infrastructure exists on $\mathrm{O}$ 'ahu to repair and 
replace components without accruing substantial downtime or cost to mobilize vessels, spare parts, or qualified workers. If these capabilities are not developed on O'ahu, the LCOE may be significantly higher than the values reported here; however, this also represents an opportunity to invest in a sustainable industry on the island.

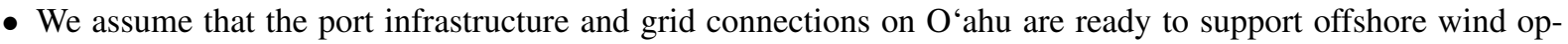
erations for all modeled CODs. In reality, several years of lead time would be required to plan, permit, and upgrade these facilities, which has presented a challenge for fixed-bottom wind on the Atlantic Coast and has led to states such as Massachusetts, Connecticut, and New Jersey investing in port infrastructure development. We do not consider the costs associated with port, substation, or bulk transmission upgrades in this study.

- The cost and deployment analysis is based on the use of semisubmersible floating platforms, but different designs could also be realized over the analyzed time frame and would subsequently impact cost and logistics decisions.

- We report deterministic cost projections to demonstrate the trajectory of offshore wind LCOE over time and the spatial variation throughout the $\mathrm{O}^{\text {' }}$ ahu region. The assumptions made in this study introduce some uncertainty in these results, which we discuss qualitatively and through sensitivity analyses. A more comprehensive uncertainty quantification of individual cost parameters or technology futures is outside the scope of this study.

- The floating wind industry is evolving rapidly, which has the potential to dramatically impact costs, technology, logistics, and stakeholder perspectives within the span of only a few years. As stakeholders on Hawai' $i$ have strong cultural, social, and environmental ties to the land and surrounding ocean, collaborations between project developers and local community members will be required to identify the best technology choices for offshore wind. The results in this study should be regularly refined and updated to reflect the growth of the industry and any ongoing collaborations with stakeholders on Hawai' $i$. 


\section{Acknowledgments}

The authors would like to thank the many people who contributed to the content of this report, including Bureau of Ocean Energy Management staff members Parker McWilliams, Sara Guiltinan, Necy Sumait, and Doug Boren and National Renewable Energy Laboratory staff member Tom Harris. The peer reviewers for this report included Jim Tolan (EDF Renewables), Christopher Lau (Hawaiian Electric), Kurt Tsue (Hawaiian Electric), Dan Beals (Department of Energy), Maxx Philipps (Hawaiian Islands National Humpback Whales Marine Sanctuary Advisory Council), Michael Schwing (Hawai 'i State Energy Office), Monique Schafer (Hawai 'i State Energy Office), Derek Chow (Hawai 'i Department of Transportation, Harbors Division), Noe Kalipi (Progression Energy), Wren Wescoatt (Progression Energy), Mark Jensen (Bureau of Ocean Energy Management), Dave Ball (Bureau of Ocean Energy Management), Parker McWilliams (Bureau of Ocean Energy Management), Aaron Smith (Principle Power), Luisa Amorim (Principle Power), and Letani Peltier (Office of Hawaiian Affairs). We would also like to acknowledge helpful conversations that we conducted with the Hawaiian Islands National Humpback Whales Marine Sanctuary Advisory Council and the Hawaiian Electric Solution Evaluation and Optimization Working Group during the course of the study. 


\section{List of Acronyms}

AEP Annual Energy Production.

BOEM Bureau of Ocean Energy Management.

BOS balance-of-system.

CapEx Capital Expenditures.

COD Commercial Operation Date.

DEA drag embedment anchors.

DOT-H Hawai ‘i Department of Transportation, Harbors Division.

FCR fixed change rate.

GCF Gross Capacity Factor.

HCEI Hawai 'i Clean Energy Initiative.

HE Hawaiian Electric.

HSEO Hawai'i State Energy Office.

IEC International Electrotechnical Commission.

KBPH Kalaeloa/Barber's Point Harbor.

LCOE Levelized Cost of Energy.

NCF Net Capacity Factor.

NREL National Renewable Energy Laboratory.

OpEx Operational Expenditures.

ORBIT Offshore Renewables Balance-of-system and Installation Tool.

ORCA Offshore Regional Cost Analyzer.

OSW offshore wind.

POI Point(s) of Interconnection.

PSLT port, staging, logistics, and transport.

PV photovoltaic.

RPS Renewable Portfolio Standard.

USACE United States Army Corps of Engineers. 
WACC Weighted-average cost of capital.

WIND Wind Integration National Dataset.

WRF Weather Research and Forecasting numerical weather prediction model.

WTIV Wind Turbine Installation Vessels.

WTK-LED WIND Toolkit Long-term Ensamble Dataset. 


\section{Contents}

Executive Summary $\ldots \ldots \ldots \ldots \ldots \ldots \ldots \ldots \ldots \ldots \ldots \ldots \ldots$

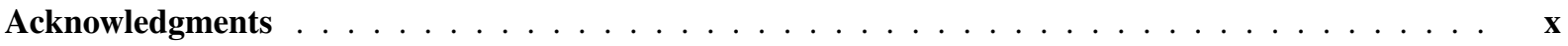

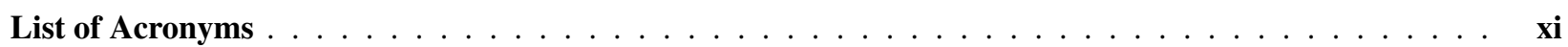

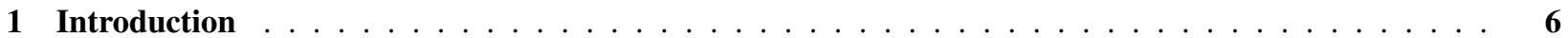

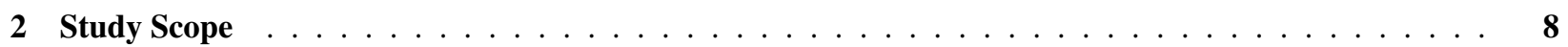

2.1 The $\mathrm{O}$ 'ahu Analysis Domain $\ldots \ldots \ldots \ldots \ldots$

2.2 Study Goals . . . . . . . . . . . . . . . . . . . . . . . . . . . . . . . . 9

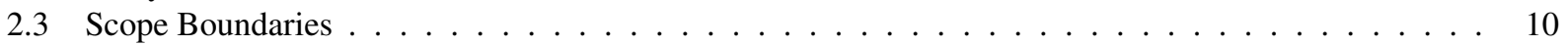

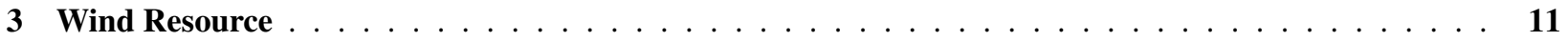

3.1 Study Area Wind Resource Characteristics . . . . . . . . . . . . . . . . . . . . . . . . . 12

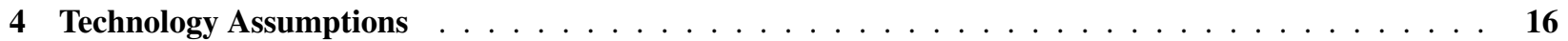

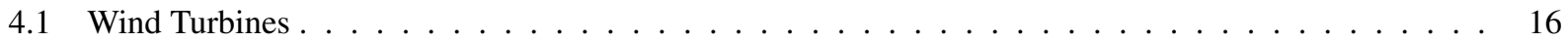

4.1.1 Wind Turbine Technology Trends . . . . . . . . . . . . . . . . . . . . . . . 16

4.1 .2 Wind Turbine Design Parameters . . . . . . . . . . . . . . . . . . 17

4.1 .3 Designing for Hurricane Resiliency $\ldots \ldots \ldots \ldots \ldots \ldots \ldots$

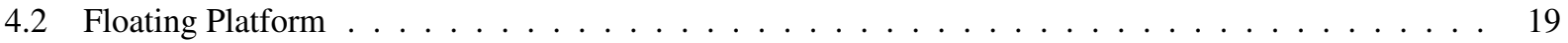

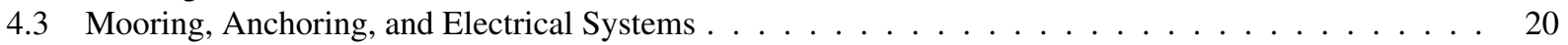

5 Wind Power Plant Model $\ldots \ldots \ldots \ldots \ldots$

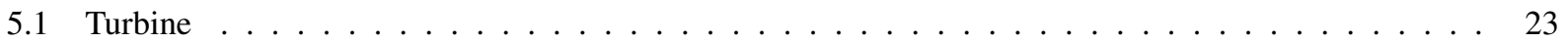

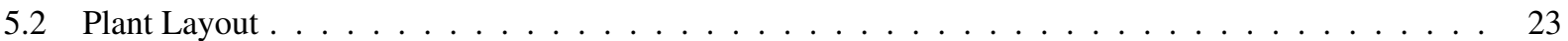

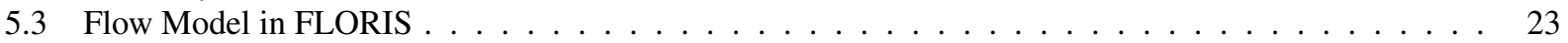

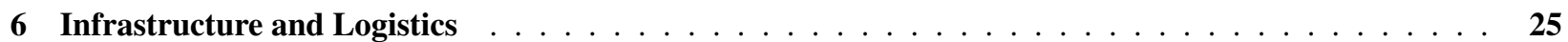

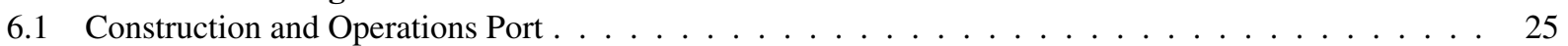

6.1.1 Requirements for a Floating Wind Port . . . . . . . . . . . . . . . . . . . . 25

6.1.2 Description of the Kalealoa Barber's Point Harbor . . . . . . . . . . . . . . . . . 26

6.2 The Electricity Grid and Points of Interconnection . . . . . . . . . . . . . . . . . . . . . . 27

6.3 Supply Chain Assessment . . . . . . . . . . . . . . . . . . . . . . . . . . . . . . . . . 29

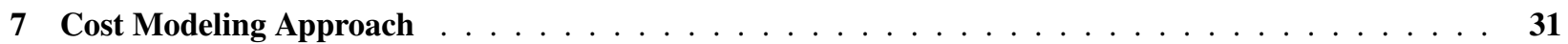

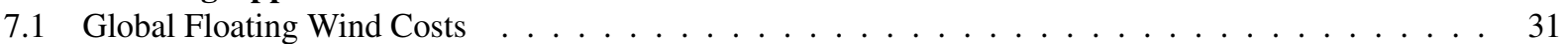

7.2 Offshore Regional Cost Analyzer . . . . . . . . . . . . . . . . . . . . . . . . . . . . 32

7.3 Modeling Assumptions . . . . . . . . . . . . . . . . . . . . . . . . . . 34

7.3 .1 Turbine Ratings and Costs $\ldots \ldots \ldots \ldots \ldots \ldots \ldots \ldots$

7.3 .2 Lease Price . . . . . . . . . . . . . . . . . . . . . . . . . . . . . 34

7.3.3 Floating Platform and Support Structure Costs . . . . . . . . . . . . . . . . . . 34

7.3 .4 Electrical Infrastructure Costs . . . . . . . . . . . . . . . . . . . . . . 35

7.3.5 Transportation, Installation, Operations, and Maintenance Costs $\ldots \ldots \ldots \ldots$ 
7.3.6 Wind Power Plant Size and Economies of Scale . . . . . . . . . . . . . . . . 37

7.3 .7 Annual Energy Production . . . . . . . . . . . . . . . . . . . . . 37

7.3 .8 Gross Capacity Factor $\ldots \ldots \ldots$. . . . . . . . . . . . . . . . . . . 38

7.3 .9 Energy Losses . . . . . . . . . . . . . . . . . . . . . . . . . . . 38

7.3 .10 Financial Parameters . . . . . . . . . . . . . . . . . . . . 40

7.3.11 Cost Projections and Floating Wind Learning Curves . . . . . . . . . . . . . . . 40

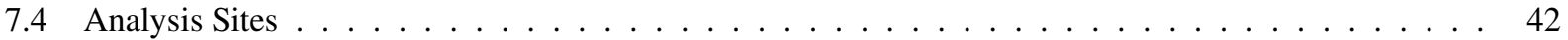

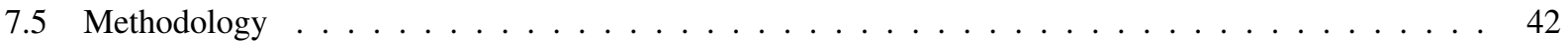

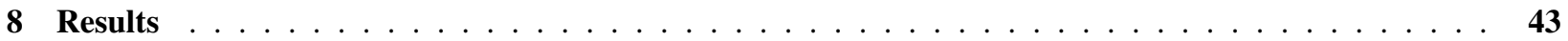

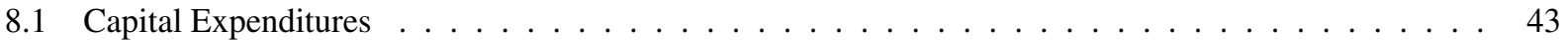

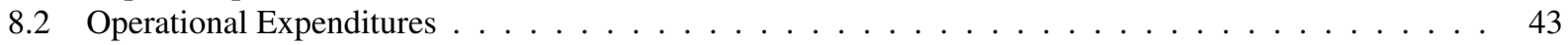

8.3 Capacity Factors and Energy Production $\ldots \ldots \ldots \ldots \ldots \ldots \ldots$

8.4 Levelized Cost of Energy $\ldots \ldots \ldots \ldots \ldots$

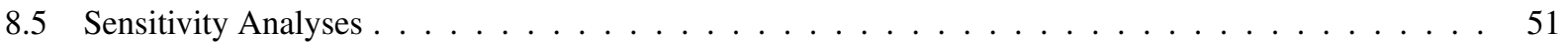

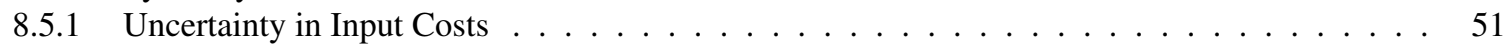

8.5 .2 Alternate Supply Chain . . . . . . . . . . . . . . . . . . . . . . . 52

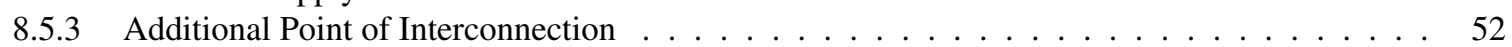

8.6 Visualization of Land-Use Tradeoffs _ . . . . . . . . . . . . . . . . . . . . . . . . . . 53

9 Summary of Stakeholder Feedback $\ldots \ldots \ldots \ldots \ldots \ldots \ldots \ldots \ldots$

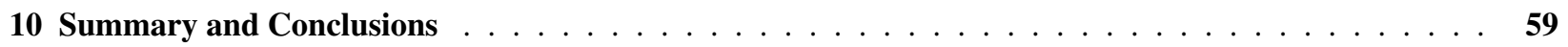

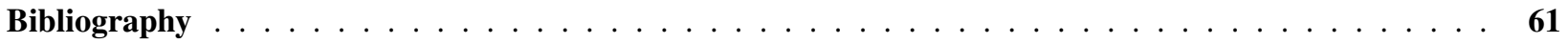

A Assessing the Need for Typhoon-Class Turbines $\ldots \ldots \ldots \ldots \ldots \ldots$

B Sizing Export Cables $\ldots \ldots \ldots \ldots \ldots \ldots \ldots \ldots \ldots \ldots$

C Full Page Heat Maps $\ldots \ldots \ldots \ldots \ldots \ldots \ldots \ldots \ldots \ldots \ldots \ldots \ldots$

\section{List of Figures}

Figure A. Heat maps of LCOE in the $\mathrm{O}^{\prime}$ ahu region for CODs in 2019 (top) and 2032 (bottom). . . . . . v vii

Figure B. LCOE projections for CODs between 2019 and 2032 for the three Study Areas (spatial averages).

Gray shading indicates the range between minimum and maximum values over the analysis domain. . . . viii

Figure 1. Topographic and bathymetric map of the island of $\mathrm{O}^{`}$ ahu and surrounding region. . . . . . . . . 8

Figure 2. Map of 20-yr mean wind speeds at $120 \mathrm{~m}$ offshore $\mathrm{O}^{\prime}$ ahu from HI20 data set. . . . . . . . . . . 11

Figure 3. Map comparing HI20 and AWS Truepower data set mean wind speeds at $90 \mathrm{~m}$ offshore $\mathrm{O}$ 'ahu. . . 12

Figure 4. 20-yr mean vertical wind shear profiles at the $\mathrm{O}{ }^{`}$ ahu Study Area centroids. . . . . . . . . . . . 13

Figure 5. 20-yr wind speed distributions at $120 \mathrm{~m}$ at the centroids of O'ahu South (top left), O'ahu North

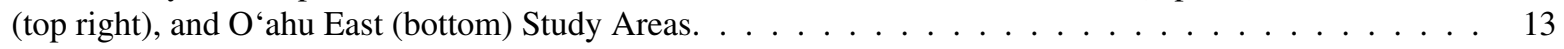

Figure 6. Wind roses at the centroids of O'ahu South (top left), O'ahu North (top right), and O'ahu East

(bottom) Study Areas. . . . . . . . . . . . . . . . . . . . . . . . . . 14 
Figure 7. Seasonal diurnal profiles at $120 \mathrm{~m}$ for (clockwise from top left) winter, spring, summer, and fall seasons at the $\mathrm{O}$ `ahu Study Areas. . . . . . . . . . . . . . . . . . . . .

Figure 8. The International Energy Agency 15-MW reference offshore wind turbine (Gaertner et al. 2020) on a floating semisubmersible platform. Illustration by Josh Bauer, NREL. . . . . . . . . . . . . . . . . .

Figure 9. Power curves for the reference wind turbines used in this study (Beiter et al. 2020). The 8-MW, 10-MW, 12-MW, and 15-MW wind turbines correspond to CODs of 2019, 2022, 2027, and 2032,

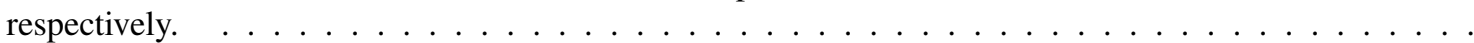

Figure 10. Substructure archetypes for floating offshore wind systems, including the spar-buoy, the semisubmersible, and the tension leg platform. Illustration by Josh Bauer, NREL. . . . . . . . . . . . . . 20

Figure 11. Turbine platform motion within the confines of a watch circle. Illustration by Josh Bauer, NREL. . . 21

Figure 12. Cross sectional view of the water column with mooring lines and electrical cables for 4 turbines spaced 5 rotor diameters apart. The radius of the mooring line is approximately twice the water depth. Illustration by Josh Bauer, NREL. . . . . . . . . . . . . . . . . . . . . . . . . . . . .

Figure 13. Drag embedment anchor and catenary mooring line. Illustration by Josh Bauer, NREL. . . . . . . . . 22

Figure 14. Conceptual rendering of a commercial-scale offshore wind plant using 15-MW wind turbines located within the $\mathrm{O}$ `ahu East Study Area. Illustration by Josh Bauer, NREL. . . . . . . . . . . . . . . . . . 24

Figure 15. Proposed land use for the Kalealoa Barber's Point Harbor in 2040 (Transportation Harbors

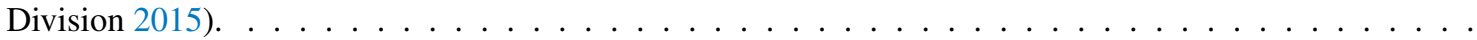

Figure 16. Topographic and bathymetric map of the island of $\mathrm{O}^{\prime}$ ahu and surrounding region. Some sections of the transmission lines are underground cables, although these are not delineated on this map. . . . . 28

Figure 17. Global LCOE estimates of floating wind technology (Musial et al. 2021). . . . . . . . . . . . . . 32

Figure 18. ORCA input-output flow diagram. . . . . . . . . . . . . . . . . . . . . . 34

Figure 19. Expected economies of scale for individual cost categories (left) and overall CapEx (right) for increasing wind power plant capacities. . . . . . . . . . . . . .

Figure 20. Modeled CapEx, OpEx, and AEP cost reductions from the baseline year. Changes in CapEx are the sum of learning curve and turbine upsizing effects, and changes in OpEx and AEP are derived from

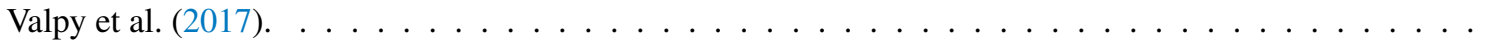

Figure 21. CapEx estimates in the $\mathrm{O}^{`}$ ahu analysis domain for the baseline study year (COD 2019). . . . . . 45

Figure 22. CapEx projections for CODs between 2019 and 2032 for the three Study Areas. Gray shading indicates range between minimum and maximum values over the analysis domain. . . . . . . . . . . 45

Figure 23. OpEx estimates in the O`ahu analysis domain for the baseline study year (COD 2019). . . . . . . 46

Figure 24. OpEx projections for CODs between 2019 and 2032 for the three Study Areas. Gray shading indicates the range between minimum and maximum values over the analysis domain. . . . . . . . . 46

Figure 25. NCF estimates in the O`ahu region for the baseline study year (COD 2019). . . . . . . . . . 48

Figure 26. Line plots showing spatially averaged gross (left) and net (right) capacity factors in time across each Study Area. Gray shading indicates the range between minimum and maximum values over the analysis domain. . . . . . . . . . . . . . . . . . . . . . . . . . . . . . . . . . . . . .

Figure 27. Heat maps of LCOE in the O'ahu region for CODs in 2019 (top) and 2032 (bottom). . . . . . . . 50

Figure 28. LCOE projections for CODs between 2019 and 2032 for the three Study Areas (spatial average of all analysis nodes within Study Area boundaries). Gray shading indicates the range between minimum and maximum values over the analysis domain. . . . . . . . . . . . . . . . . . . . . . .

Figure 29. LCOE sensitivity to main cost variables. . . . . . . . . . . . . . . . . . . . . . 52 


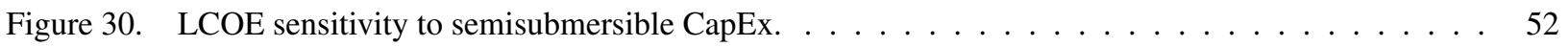

Figure 31. Percent change in export cable costs if the Kahe power plant is available as an interconnection point. 53

Figure 32. Land and ocean footprints for 100\% renewable generation scenarios in 2045 corresponding to no offshore wind buildout (top left), $600 \mathrm{MW}$ of offshore wind buildout (top right), and 1,200 MW of

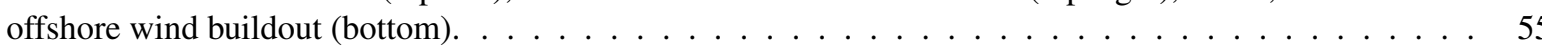

Figure A.1. Wind speed recurrence intervals in Hawai' $i$ with the return period shown on the $x$-axis and the magnitude of the 3-s gust at $10 \mathrm{~m}$ height on the y-axis. Data taken from Martin \& Chock (2013) . . . . 66

Figure C.1. 2019 CapEx heat map. . . . . . . . . . . . . . . . . . . . . . . . . . . . . . 71

Figure C.2. 2022 CapEx heat map. . . . . . . . . . . . . . . . . . . . . . . . . . . . 72

Figure C.3. 2027 CapEx heat map. . . . . . . . . . . . . . . . . . . . . . . . . . . . . . 73

Figure C.4. 2032 CapEx heat map. . . . . . . . . . . . . . . . . . . . . . . . . . . 74

Figure C.5. 2019 OpEx heat map. . . . . . . . . . . . . . . . . . . . . . . . . . . 75

Figure C.6. 2022 OpEx heat map. . . . . . . . . . . . . . . . . . . . . . . . . . . . . 76

Figure C.7. 2027 OpEx heat map. . . . . . . . . . . . . . . . . . . . . . . . . . . . 77

Figure C.8. 2032 OpEx heat map. . . . . . . . . . . . . . . . . . . . . . . . . . 78

Figure C.9. 2019 NCF heat map. . . . . . . . . . . . . . . . . . . . . . . . . . . . . . . . 79

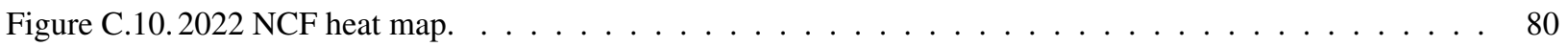

Figure C.11.2027 NCF heat map. . . . . . . . . . . . . . . . . . . . . . . . . . . 81

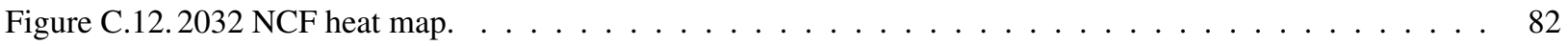

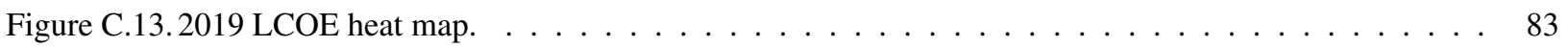

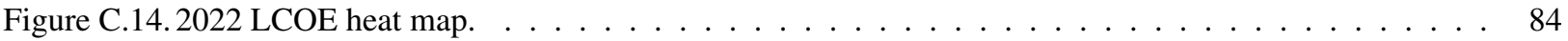

Figure C.15.2027 LCOE heat map. . . . . . . . . . . . . . . . . . . . . . . . . . . . 85

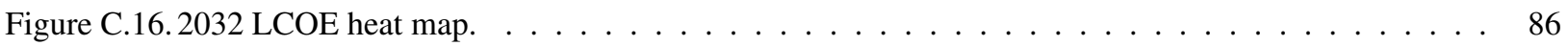

Figure C.17. 2019 POI sensitivity \% change in export cable CapEx heat map. . . . . . . . . . . . . . . . . 87

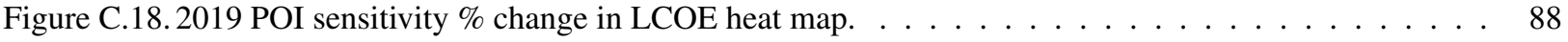

\section{List of Tables}

Table A. Technology assumptions for offshore wind in the $\mathrm{O}^{\prime}$ ahu region between 2019 and 2032 . . . . . vi

Table 1. Average site-specific characteristics of the three $\mathrm{O}$ 'ahu Study Areas. . . . . . . . . . . . . . 9

Table 2. Technology assumptions for the $\mathrm{O}$ 'ahu reference wind turbines $\ldots \ldots \ldots \ldots$

Table 3. Capacity of existing fossil fuel power plants on $\mathrm{O}$ 'ahu with over $100 \mathrm{MW}$ of generation capacity

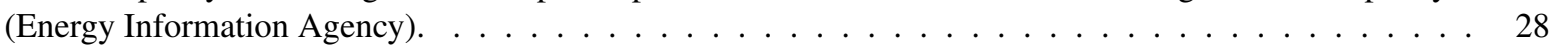

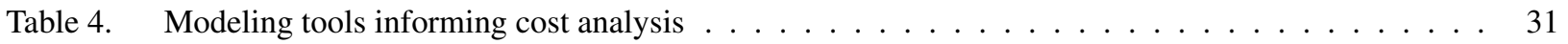

Table 5. Summary of ORCA modeling approaches for different cost and performance terms. . . . . . . . 33

Table 6. Transportation barge specifications and required area per component. . . . . . . . . . . . 36

Table 7. Commercial-scale floating offshore wind financing assumptions. . . . . . . . . . . . . . . 40 
Table 8. Spatially averaged 2019 CapEx line item values across the Study Areas, \$/kW. Note: Values are rounded to the nearest $\$ / \mathrm{kW} \ldots \ldots \ldots \ldots \ldots \ldots$

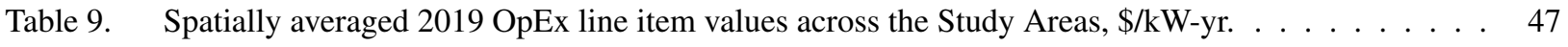

Table 10. Losses for O`ahu Study Areas for COD 2019. . . . . . . . . . . . . . . . . . . . . . . . . 47

Table 11. Gross and net capacity factors with losses over time for each Study Area. . . . . . . . . . . . . . . 49

Table 12. 2019 analysis domain average cost parameters . . . . . . . . . . . . . . . . . . 51

Table 13. Offshore wind and solar PV buildout scenarios in 2045. The offshore wind buildout is prescribed, and the required amount of solar PV is calculated by the Engage model. . . . . . . . . . . . . 54

Table 14. Categories of stakeholder concerns regarding offshore wind in the $\mathrm{O}$ 'ahu region. . . . . . . . . 57

Table A.1. 3-s gust scaling parameters and values at hub height for Hawai'i adapted from Vickery et al. (2009). 67

Table B.1. Scaled parameters for a 135-MW export cable. ABB cable data taken from ABB. . . . . . . . . 68

Table B.2. Scaling factors for export cable procurement and installation as a function of distance to shore for 530 A export cables relative to the default cable type. . . . . . . . . . . . . . . . . . . . . 69 


\section{Introduction}

In 2015, Hawai 'i mandated under HB623 that it shall establish a renewable portfolio standard of $100 \%$ of net electricity sales by the end of 2045 (Hawai'i House of Representatives 2015b, 2015a). This transition to a renewable energy economy will require further development of energy efficiency, storage, and a diverse range of renewable energy, zero-carbon emissions, and transmission technologies, including potential requirements for offshore wind (OSW). The OSW resource off the coast of $\mathrm{O}^{\prime} \mathrm{ahu}$, where around $72 \%$ of the state's electricity consumption takes place (Hawai $i$ Department of Business, Economic Development \& Tourism 2021), has the potential to meet a significant portion of the future electricity demand on Hawai ' $i$. The OSW technical resource ${ }^{3}$ was assessed by NREL in 2016 to be $29 \mathrm{GW}$, and OSW deployment scenarios studied by NREL suggest that a build-out of $800 \mathrm{MW}$ could provide up to 40\% of O'ahu's electricity (Musial et al. 2016; Musial, Robichaud, and Tegen 2016). In 2015 and 2016, the U.S. Department of the Interior's Bureau of Ocean Energy Management (BOEM) received three unsolicited applications for commercial-scale floating offshore wind projects in Hawai' $\mathrm{i}$, each about 400-MW in size. Competitive interest was indicated at the locations of the unsolicited projects. Subsequently, BOEM defined two Call Areas, which fully enclosed the unsolicited projects. BOEM is no longer reviewing the unsolicited projects.

This study considers the cost of development at all offshore O'ahu sites that are technically feasible under current technology. Moreover, the economic analysis conducted here is not a marine spatial planning exercise; many of the sites evaluated herein could be infeasible due to siting issues that are beyond the scope of this study. Most of Hawai' 'i's offshore wind resource is in water depths that are suitable only for floating offshore wind technology development. Floating wind turbine technology is at a nascent stage of development, but the potential for floating wind turbines to contribute to the nation's energy future as well as Hawai' $i$ is significant, with $58 \%$ of the technical offshore wind resource potential over waters with depths greater than 60 meters (m) but less than 1,300 m (Beiter et al. 2016). The upper bound of water depth was set at 1,300 m based on input from BOEM and industry practitioners, reflecting the potential limits of mooring system designs for floating wind turbines. In Hawai' $\mathrm{i}$, depths between 500-m and 1300-m are common at all sites where development might be considered.

Industry market signals suggest that floating offshore wind technology is rapidly moving toward a commercial phase. The present rate of technology advancements globally suggests that commercial floating arrays may be available to Hawai'i's energy markets as early as the mid-2020s. NREL has been conducting research in offshore wind for many years, and recent NREL economic studies in 2019 and 2020 that examine floating offshore wind costs in Oregon, Maine and California, respectively (Musial et al. 2019a; Musial, Beiter, and Nunemaker 2020; Beiter et al. 2020), indicate that offshore wind has the potential for future cost competitiveness, enhanced power system value, more efficient land use, and positive economic development benefits. This offshore wind cost study builds on NREL's prior work to explore the unique possibilities that may give Hawai ' $i$ an opportunity to increase its renewable energy supply while diversifying its renewable energy mix.

NREL's techno-economic modeling team focused on key regional issues of Hawaii, anticipating technology trends relevant to locations off $\mathrm{O}^{\prime}$ ahu. The cost model and its outputs used the most up-to-date floating balance-of-station inputs, incorporated new methods for local wake loss and AEP calculations, introduced a newly developed 20-year wind resource data set for Hawai ${ }^{~} i$, and considered wind turbines up to $15 \mathrm{MW}$ in size out to a commercial operations year of 2032. The study is unique to Hawai' $i$ because it investigates a range of local impacts including:

- Limited points of interconnection to the electricity grid on $\mathrm{O}^{\prime} \mathrm{ahu}$

- Unique construction and operations and maintenance (O\&M) strategies necessary because of the remote location relative to global supply chains and relative proximity to Asian Supply Chains

- Local port options

- Milder climate for operations and service logistics

- Potential for major hurricanes and mitigation strategies, and

\footnotetext{
3"Technical resource" is defined as the subset of total resource potential that can be considered recoverable under available technological and turbine performance conditions and after exclusion of land-use and environmental siting constraints (Musial et al. 2016).
} 
- Land use tradeoffs with other renewable energy contenders.

We intend that this report can inform decision-making at relevant state agencies and utilities. The following sections

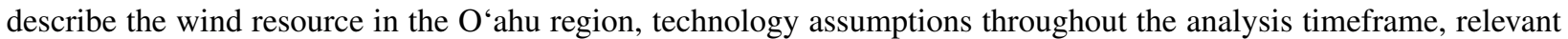
infrastructure and logistics on $\mathrm{O}^{\prime}$ ahu that would be required to construct an offshore wind project, cost modeling results, and a preliminary collection of stakeholder perspectives on offshore wind. 


\section{Study Scope}

\subsection{The O'ahu Analysis Domain}

$\mathrm{O}$ 'ahu is the third largest Hawaiian island and is home to roughly two-thirds of the state population as well as the state capital, Honolulu (Hawai 'i Department of Business, Economic Development \& Tourism 2020). The island has an area of 1,545 $\mathrm{km}^{2}$, including the Wai'anae and Ko'olau mountain ranges on the west and east sides, respectively. A topographic map of the island is shown in Figure 1, which also includes selected cities, transmission lines, ports, substations, and power plants that are relevant to this study and will be discussed further in later chapters.

The volcanic nature of the island leads to steep increases in water depth in the nearshore region, particularly on the north, east, and west sides. The bathymetry is reasonably uniform in the Ka'iwi Channel between O'ahu and Moloka 'i, although the depth is typically greater than $500 \mathrm{~m}$. The bathymetry of the seafloor surrounding $\mathrm{O}$ 'ahu is also shown in Figure 1.

In this analysis, we derive the relative costs of offshore wind in the region surrounding $\mathrm{O}^{`}$ ahu. The analysis domain begins at the boundary of state and federal waters 3 nautical miles offshore and extends to the $1,300 \mathrm{~m}$ water depth contour; both of these features are shown in Figure 1. Because of the non-uniform drop-offs in water depth, the distance of this outer boundary from the island varies spatially. The analysis domain excludes the waters north of Moloka' $i$ and the Hawaiian Island Humpback Whale National Marine Sanctuary off the coast of Moloka'i. At the request of the Bureau of Ocean Energy Management (BOEM), we have not considered any exclusions related to commercial,

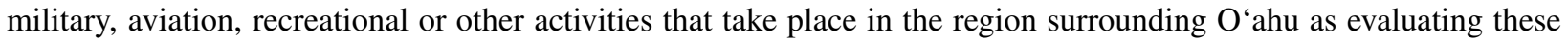
restrictions is out of scope for this study. Nevertheless, an actual offshore wind project in the region would have to address these competing uses as part of the planning and permitting process.

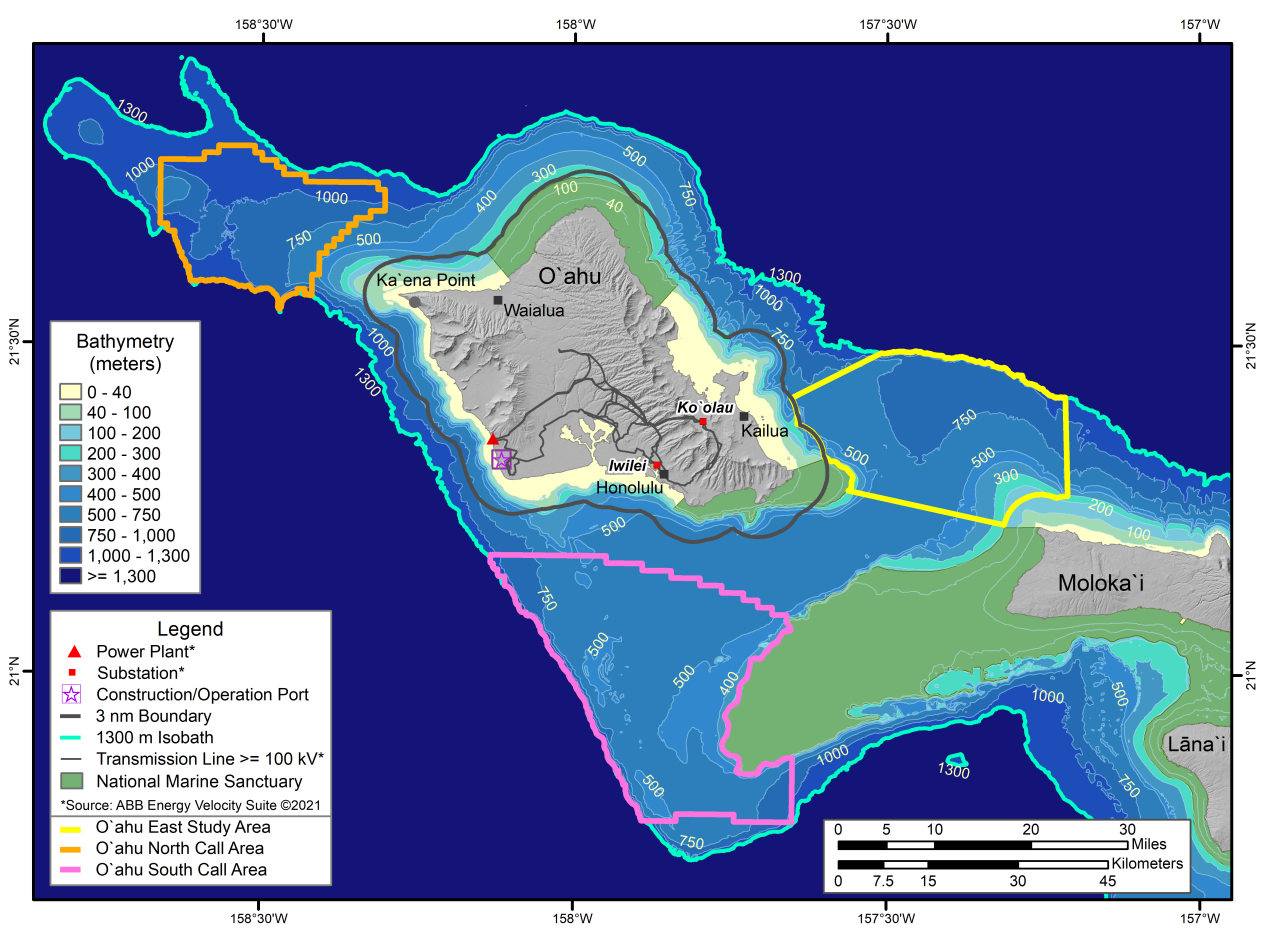

Figure 1. Topographic and bathymetric map of the island of $O$ 'ahu and surrounding region.

In addition to evaluating offshore wind costs throughout the entire analysis domain, we develop more highly resolved results in three Study Areas, which are referred to as O'ahu East, O'ahu North, and O'ahu South. The boundaries of these Study Areas are provided in Figure 1. O'ahu North and O'ahu South correspond to the Call Areas identified 
by BOEM in response to three development requests in 2016 (BOEM 2021). We defined the O'ahu East Study Area for this report to provide additional geographic diversity to the comparison of relative costs in different regions surrounding the island. Although the western boundary of the East Study Area is set by the 3 nautical mile contour (whereas the North and South Study Areas are offset from this contour), this does not imply that an actual project located in this region would be built closer to shore than a project in one of the other two Study Areas. All of the Study Areas are substantially larger than the footprint of a single offshore wind project, and any lease areas proposed by BOEM would be located sufficiently far from shore to mitigate concerns about visual impact.

These Study Areas do not correspond to actual project boundaries or proposed development locations; they are merely used for comparative purposes to convey the relative characteristics of offshore wind at different locations in the analysis domain. A summary of the average site characteristics of each Study Area is provided in Table 1. The determination of wind speeds and infrastructure locations are described in Sections 3 and 6, respectively.

Table 1. Average site-specific characteristics of the three O'ahu Study Areas.

\begin{tabular}{ccccc}
\hline Property & Unit & O'ahu South & O'ahu North & O'ahu East \\
\hline Area & $\mathrm{km}^{2}$ & 1,289 & 609 & 941 \\
Assumed capacity density & $\mathrm{MW} / \mathrm{km}^{2}$ & 3 & 3 & 3 \\
Technical potential & $\mathrm{MW}$ & 3,867 & 1,827 & 2,823 \\
20-year mean wind speed at 150 m height & $\mathrm{m} / \mathrm{s}$ & 8.80 & 9.13 & 9.82 \\
Water depth & $\mathrm{m}$ & 584 & 946 & 665 \\
Significant wave height & $\mathrm{m}$ & 1.38 & 1.58 & 1.48 \\
Distance from site to cable landfall & $\mathrm{km}$ & 39.2 & 89.3 & 47.2 \\
Distance from site to port & $\mathrm{km}$ & 48.7 & 59.8 & 83.5 \\
\hline
\end{tabular}

\subsection{Study Goals}

This scope of this analysis was collaboratively developed by BOEM and the Hawai 'i State Energy Office (HSEO) to provide information to stakeholders and decision makers on Hawai ${ }^{\prime} i$ as they consider the relative merits of different renewable generation sources that could support $100 \%$ of net electricity sales by 2045 to align with the Hawai' $i$ Clean Energy Initiative (HCEI) goals (Hawai'i State Energy Office 2018). This study provides estimates of how much it would cost to build offshore wind in the waters surrounding $\mathrm{O}$ 'ahu, along with descriptions and visualizations of likely technology solutions. This is not intended to provide a comprehensive understanding of the full impact of offshore wind development, and future work will be required to compile all of the necessary information needed to determine if offshore wind deployment will actually take place.

The primary outcomes of this analysis are to:

- Provide estimates of the Levelized Cost of Energy (LCOE) of offshore wind in the region surrounding O'ahu. This information will be used by Hawaiian decision makers, including HSEO and Hawaiian Electric (HE) to inform the Integrated Grid Planning process.

- Consider potential technologies, ports, grid connections, and logistics that may impact the costs of offshore wind.

- Produce visualization materials that demonstrate land-use tradeoffs between onshore and offshore renewable generation sources.

- Compile preliminary feedback and information from local stakeholders on the benefits and drawbacks of offshore wind. This information was used to inform the cost modeling approach where possible.

- Suggest future studies and activities that are needed to inform decision makers about offshore wind in the $\mathrm{O}$ 'ahu region. 


\subsection{Scope Boundaries}

This study focuses primarily on a comparative analysis of LCOE throughout the analysis domain. This analysis is intended to provide information to decision-makers as they consider offshore wind for $\mathrm{O}$ ‘ahu's energy portfolio, but it is not part of a formal project planning or development process. Future work will be required to complement the results produced in this report to investigate the holistic impacts of offshore wind on the human, environmental, and energy systems on $\mathrm{O}^{\prime}$ ahu. This study does not:

- Propose or develop a specific project.

- Replace a planning process for actual offshore wind development.

- Identify or suggest specific areas in which a project will be built.

- Conduct detailed environmental, social, cultural, or workforce development studies.

- Identify preferred vendors, suppliers, operators, or labor for potential offshore wind projects.

- Estimate the impact of offshore wind on ratepayers relative to the current price of electricity.

The following sections describe the unique conditions in the $\mathrm{O}$ 'ahu region that are relevant to offshore wind and the subsequent modeling approach used to compute costs. Section 3 presents the available wind resource in the region. Sections 4 and 5 describe the technology assumptions at the wind turbine and wind power plant level, respectively. Section 6 summarizes the port, grid, and supply chain requirements for floating wind in the O'ahu region and identifies the assumptions made in this study. Section 7 describes the cost modeling approach and methodology, and Section 8 presents the results. Finally, we include a summary of preliminary stakeholder outreach activities conducted as a part of this study Section 9. 


\section{Wind Resource}

NREL is in the process of updating and expanding its publicly available wind resource data sets. The Wind Integration National Dataset (WIND) Toolkit (Draxl et al. 2015), produced in 2013, has the been the foundation of wind energy cost analyses for many years. However, given significant R\&D advancements in the Weather Research and Forecasting numerical weather prediction model (WRF) model since 2013, an update to the WIND Toolkit was warranted. In producing these new data, NREL has prioritized the Hawai'i region as well as key U.S. offshore wind areas. Wind resource data for the full continental U.S. with the updated WIND Toolkit Long-term Ensamble Dataset (WTK-LED) are expected in 2022 (NREL 2021d).

The present study uses this updated, state-of-the-art offshore wind resource data set for the Hawai ' $i$ region to provide the best possible assessment of the AEP for floating wind power plants offshore $\mathrm{O}^{\prime}$ ahu. We refer to the new offshore wind resource data set for Hawai' $i$ as "HI20" because it covers the 20-yr modeling period (2000-2019). Optis et al. (2020) outlines the full modeling methodology in a study of the resource offshore California (CA20), which is the same as that used for HI20. The resulting 20 -yr mean wind speeds at $120 \mathrm{~m}$ are shown for the region around O'ahu in Figure 2. The figure includes boundaries marking the the analysis domain and Study Areas.

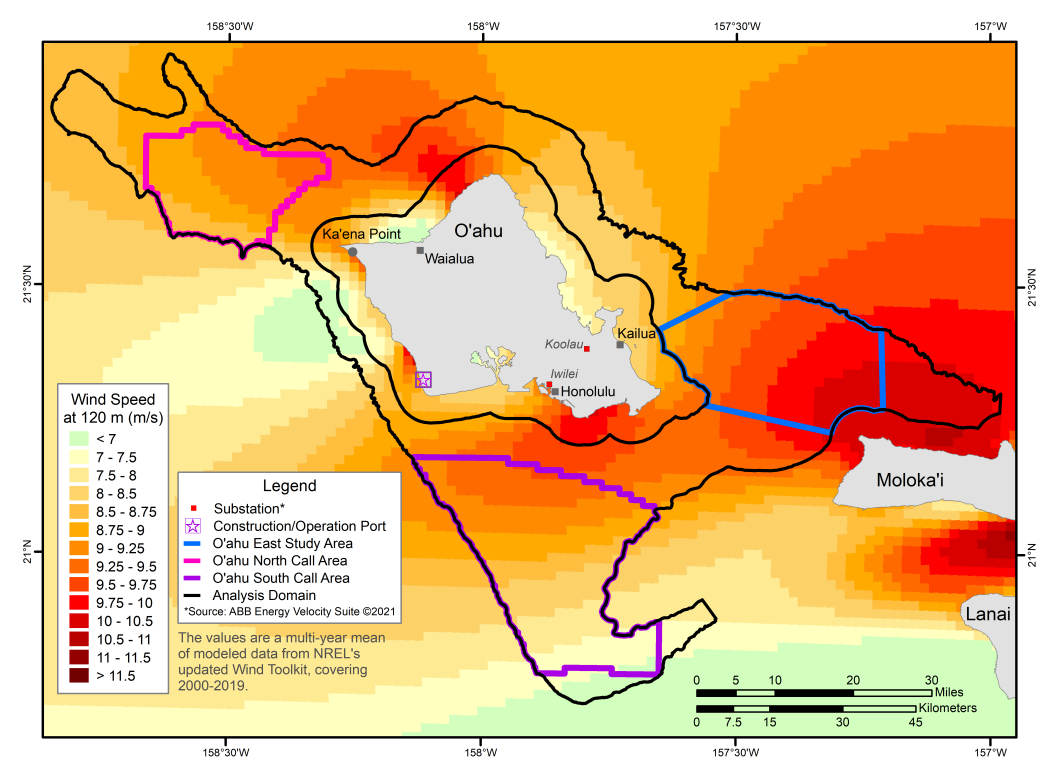

Figure 2. Map of 20-yr mean wind speeds at $120 \mathrm{~m}$ offshore O'ahu from HI20 data set.

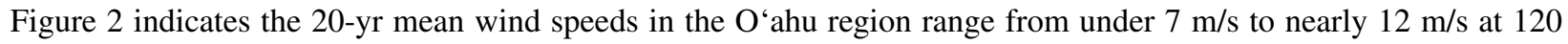
$\mathrm{m}$. The highest long-term mean wind speeds in the analysis domain are found in and around the O'ahu East Study Area. The area off the west coast of $\mathrm{O}^{\prime}$ ahu has the lowest mean wind speeds, due to the dominant east-northeasterly wind direction (see Figure 6) and the resulting "wind shadows" on the leeward (or westerly) side of the island. This blockage effect also explains why the East Study Area has the highest mean wind speeds because the winds here are not obstructed by any islands.

It is worthwhile to compare how this new HI20 data set compares to data used in previous analyses. The original WIND Toolkit did not originally include Hawai 'i. Rather, NREL contracted with AWS Truepower and 3Tier/Vaisala to produce an offshore wind resource data set for Hawai' $\mathrm{i}$ at $90 \mathrm{~m}$ (referred to as "2016 data set") (Musial et al. 2016). Figure 3 compares the HI20 and 2016 data sets at $90 \mathrm{~m}$, revealing magnitudes of mean wind speed difference as high as $4 \mathrm{~m} / \mathrm{s}$. For most of the region, the magnitudes of differences are nearly $2 \mathrm{~m} / \mathrm{s}$, which represents a substantial increase in the predicted wind resource. In general, the HI20 data set shows an increase in mean wind speeds relative to the 2016 data set. As wind turbines generate power proportional to the cube of the wind speed, this approximately $20 \%$ 
gain in the modeled wind speeds relative to previous data represents a significant increase in the available energy that can be produced by offshore wind power plants in the region.

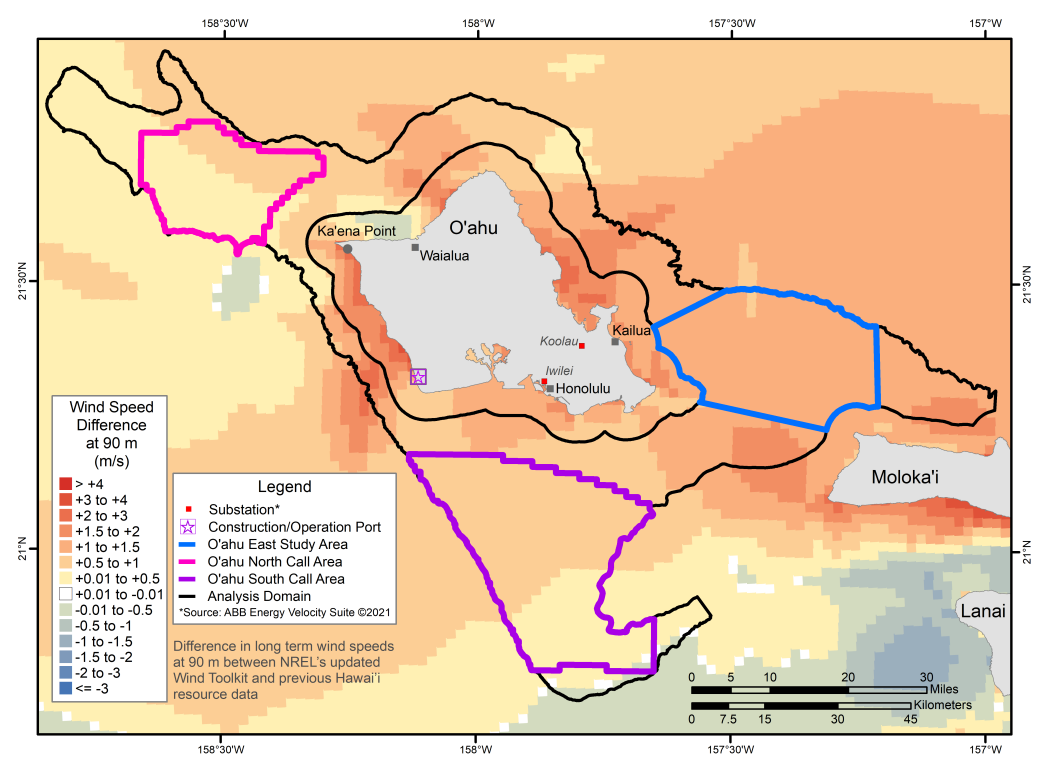

Figure 3. Map comparing HI2O and AWS Truepower data set mean wind speeds at $90 \mathrm{~m}$ offshore O'ahu.

NREL found a similar increase in the new data set for offshore California when compared to the WIND Toolkit (Optis et al. 2020; Rybchuk et al. 2021). Key drivers of the increased modeled wind resource include improvements in the parameterization of turbulence, the updated WRF version model, and the choice of the large scale atmospheric input data that drives the WRF simulation at the domain boundaries.

\subsection{Study Area Wind Resource Characteristics}

This section explores the wind resources at the centroids of the three Study Areas identified in Section 2. The 20-yr mean vertical wind shear profiles for the Study Areas are presented in Figure 4. Note that the dashed black lines in the figure indicate the assumed turbine hub heights associated with specific commercial operation dates (COD) used for analysis in this report.

From the vertical wind profiles in Figure 4, it is clear that the O'ahu East Study area has higher mean wind speeds than O'ahu North or O'ahu South at the Study Area centroids. Additionally, there appears to be slightly more vertical wind shear in O'ahu East, whereas the other Study Areas have flatter vertical profiles. Figure 5 compares the Study Area 20-yr wind speed distribution at $120 \mathrm{~m}$ in histograms. The dashed black lines in the figure indicate the cut-in, rated, and cut-out wind speeds of the turbines used for modeling in this report. Beiter et al. (2020) recently conducted a cost study evaluating floating offshore wind costs in California using the new 20-yr wind resource data from Optis et al. (2020). The long-term mean wind speeds at the O'ahu Study Areas fall in the middle of the range of the California Study Areas, and the vertical wind profiles are flatter, indicating less vertical wind shear.

Figure 5 reveals an atypical distribution of wind speeds (especially in the South Call Area), which deviates from the Weibull distribution often assumed in wind energy resource assessment. This additional concentration of wind speeds around the rated power of the wind turbines is advantageous for offshore wind power plants as it increases the time per year at which the wind turbines are producing their maximum power, while the distribution exhibits infrequent winds near cut-out, which can increase fatigue damage. The North and East Call Areas have higher frequencies of higher wind speeds than the South Call Area. Additionally, it is clear that the most frequent wind speeds occur near the turbine rated wind speed. Turbines operating at their rated wind speed exert the peak thrust force on the wind, leading to the strongest wakes. Fortunately for the Study Areas considered, the wind roses plotted in Figure 6 demonstrate a 


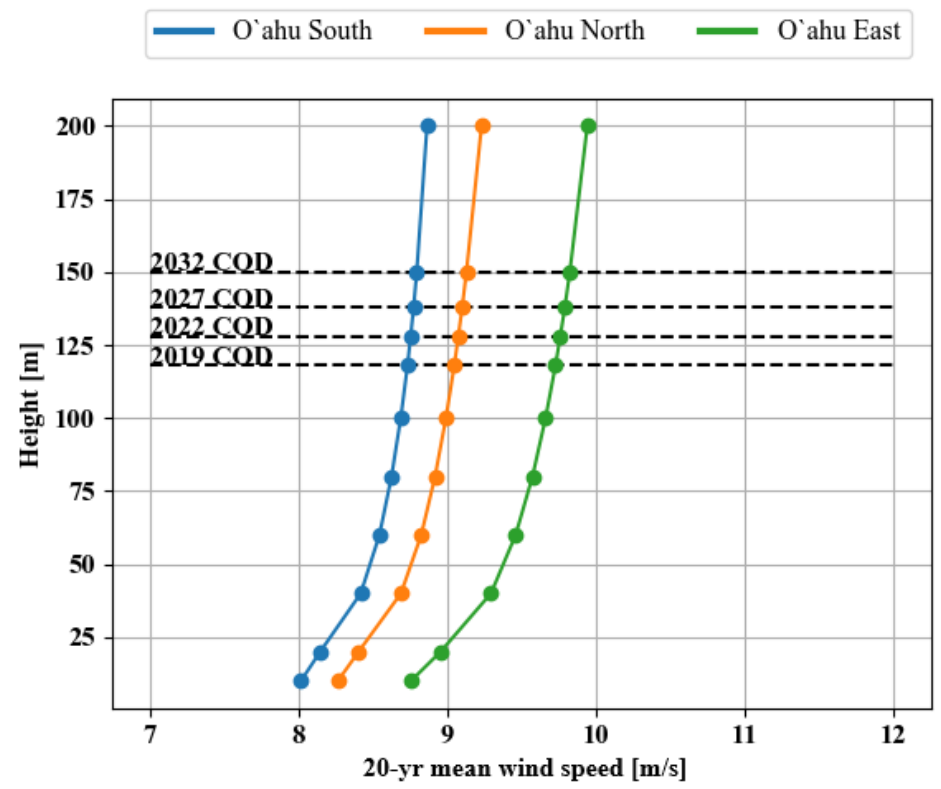

Figure 4. 20-yr mean vertical wind shear profiles at the O'ahu Study Area centroids.
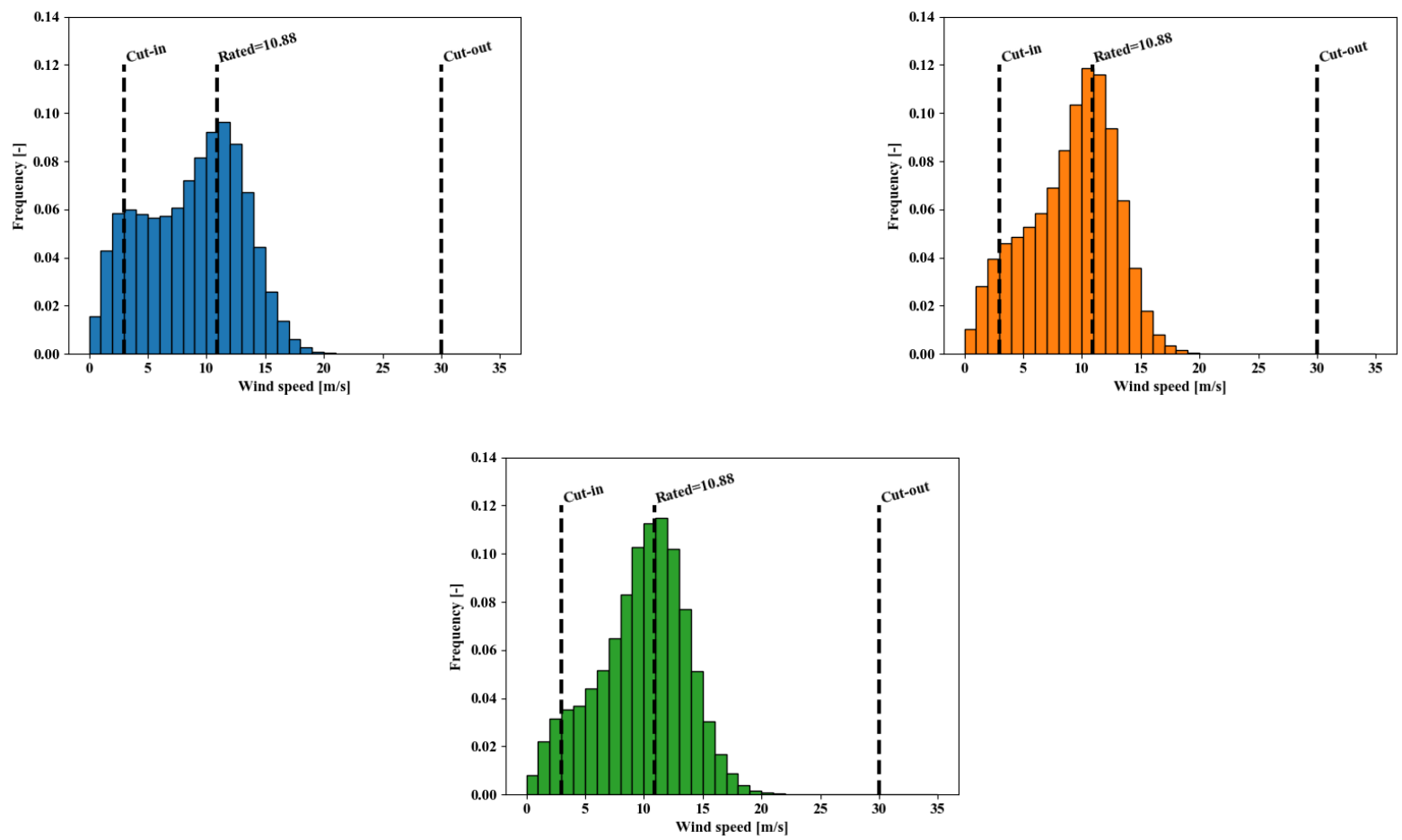

Figure 5. 20-yr wind speed distributions at $120 \mathrm{~m}$ at the centroids of $O$ 'ahu South (top left), O‘ahu North (top right), and O‘ahu East (bottom) Study Areas.

narrow band of winds consistently coming from the east-northeast direction. This persistent direction is caused by the Earth's general circulation, where winds will naturally flow easterly near the equator in the absence of significant land 
influences, as is the case for Hawai 'i. Fortunately, a clear dominant wind direction simplifies the wind farm layout and helps avoid wake losses through intentional wind plant layout design.
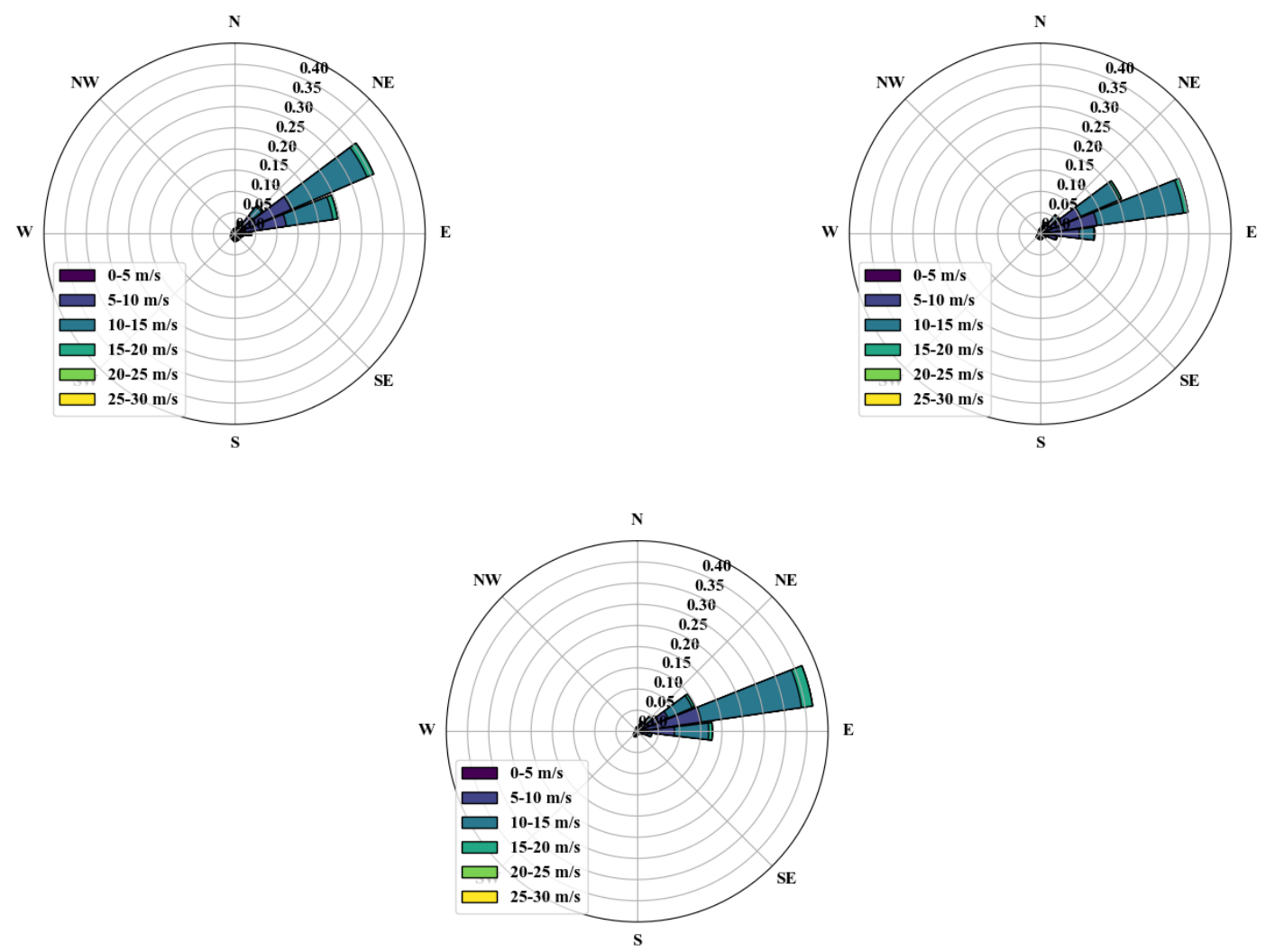

Figure 6. Wind roses at the centroids of O'ahu South (top left), O'ahu North (top right), and O'ahu East (bottom) Study Areas.

To better understand daily trends in the wind resource by season, diurnal profiles at the Study Area centroids are presented in Figure 7. We observe that the East Study area has the least wind speed variation throughout the day and the highest wind speeds of the Study Areas. The strongest daily variations come in the summer at the North Study Area. The North and South areas tend to follow a similar trend in wind speeds overnight and into the mid-morning, but diverge in the afternoon when the North Call Area sees higher wind speeds. Figure 7 also shows that the wind speeds vary seasonally around $\mathrm{O}^{\prime} \mathrm{ahu}$. The highest wind speeds occur in the summer, and the lowest wind speeds occur in the winter.

The new HI20 resource data set assumes that the meteorological conditions are static over time, which may not be the case with as the climate changes over time. These possible effects are beyond the scope of this study but should be considered in future assessments if resources allow.

Overall, the offshore wind resource surrounding $\mathrm{O}^{`} \mathrm{ahu}$ is favorable for electricity generation. This is especially true off of the east coast of the island and can be seen in Figure 2, which maps the strength of the wind. The wind speed distributions from Figure 5 show that wind speeds frequently fall in the power producing range for wind turbines. The wind roses in Figure 6 indicate that the wind predominantly comes from the east-northeast, which makes it easier to design a wind farm layout to reduce wake losses and generate higher amounts of power. 

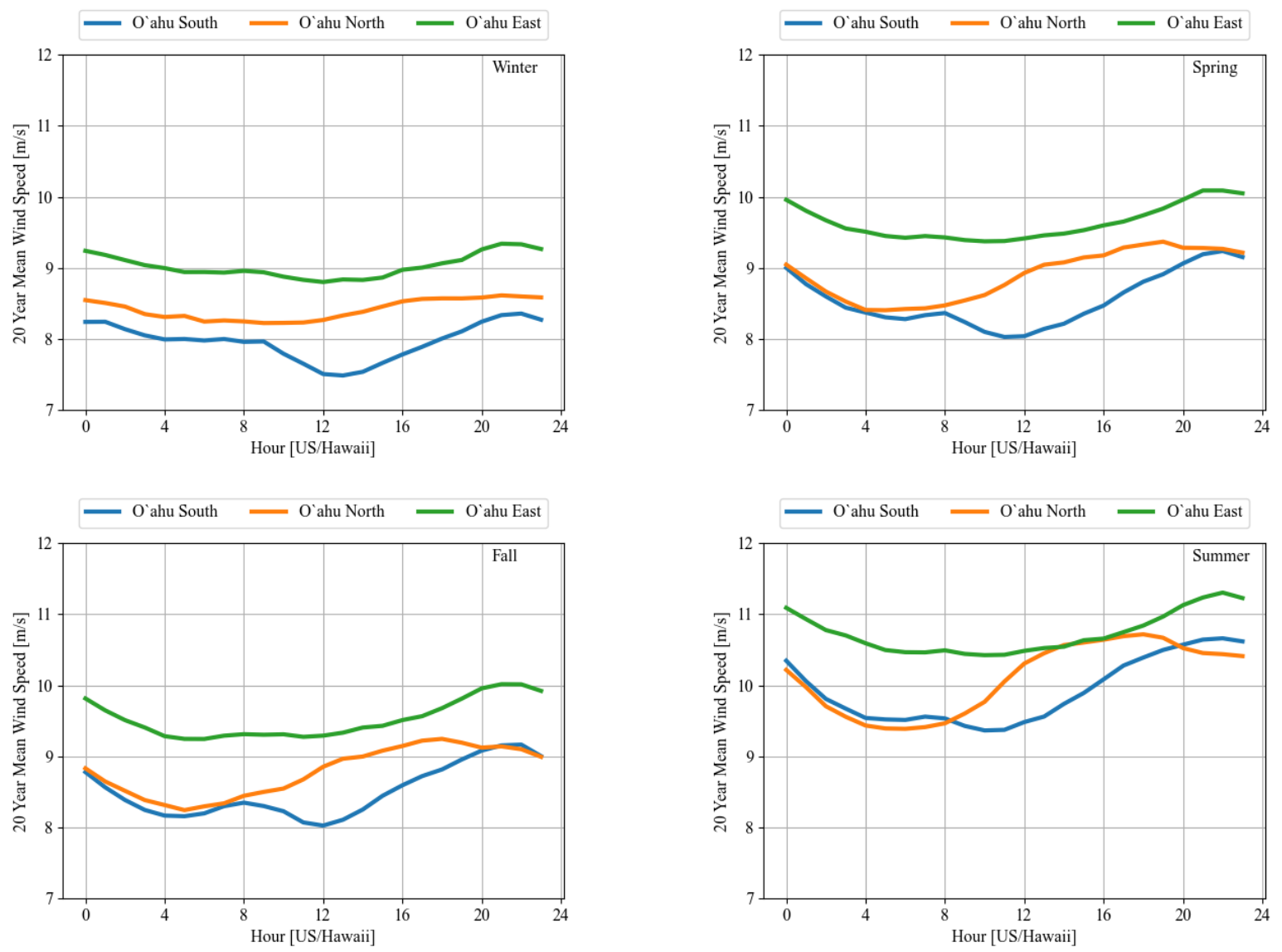

Figure 7. Seasonal diurnal profiles at $120 \mathrm{~m}$ for (clockwise from top left) winter, spring, summer, and fall seasons at the $O$ 'ahu Study Areas. 


\section{Technology Assumptions}

In this study, we consider the costs of floating wind in the $\mathrm{O}^{\prime}$ ahu region between 2019 and 2032. These Commercial Operation Date (COD) were selected to be consistent with a similar study conducted for the state of California (Beiter et al. 2020). Within this time horizon, we define specific technology assumptions at 4 reference COD years of 2019, 2022, 2027, and 2032 to generate the cost projections. These assumptions include the turbine rating, the support structure, the cost and performance impact of technological innovations, and the cumulative impact of progressing along the global learning curve for floating projects in future years. We define these technology trends to be reflective of ongoing market developments and supplement these empirical data with bottom-up analysis and designs that provide sufficient detail to incorporate these scenarios into our cost models. In this chapter, we characterize the turbine-level technology assumptions and provide some context to justify these choices. We describe the overall wind power plant in Section 5 and how these design choices are customized for the $\mathrm{O}^{\prime}$ ahu region and implemented in the NREL cost model in Section 7.

\subsection{Wind Turbines}

\subsubsection{Wind Turbine Technology Trends}

The wind turbine is the most important part of a wind power plant and comprises nearly $20 \%$ of the overall LCOE of a floating offshore wind project (Stehly, Beiter, and Duffy 2020). Wind turbines are designed to efficiently convert the kinetic energy of the wind to aerodynamic energy (which turns the blades), mechanical energy (which turns the generator), and ultimately electrical energy (which is delivered to the grid). Different design options are available with different turbines; for example, drivetrains may be direct-drive (which have higher upfront costs, reliability, and efficiency) or geared (which are smaller and cheaper, but less efficient and reliable). The offshore wind turbine market has consolidated around three-bladed, upwind, horizontal axis machines. A rendering of a conceptual 15-MW horizontal axis turbine on a floating platform is shown in Figure 8.

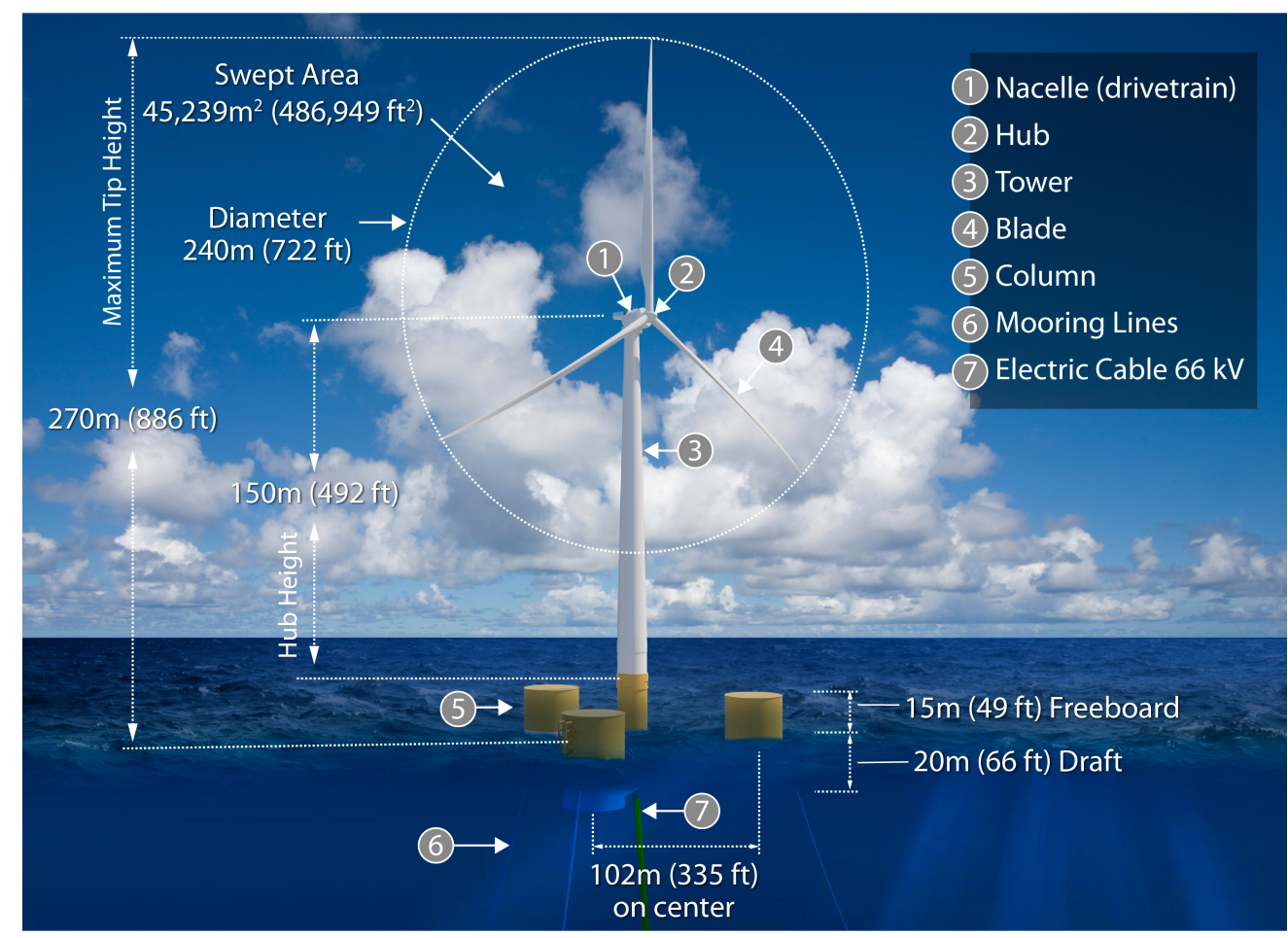

Figure 8. The International Energy Agency 15-MW reference offshore wind turbine (Gaertner et al. 2020) on a floating semisubmersible platform. Illustration by Josh Bauer, NREL. 
Although ongoing research into the viability of vertical axis or multi-turbine platforms is being conducted, it is unlikely that these designs will develop sufficiently robust supply chains to supplant the conventional single-rotor horizontal axis wind turbines, and therefore these are not considered in this study. Vertical axis designs have been considered for many decades, so they are not new, but none of the past designs have been developed beyond a 500-KW scale. This is because there are fundamental limitations that make them more difficult to scale to multi-megawatt power capacities, and they are less efficient than horizontal axis turbines. Also, there is no evidence that proof of concept development at this scale is underway. Finally, there have been no detailed studies that demonstrate that vertical axis wind turbines have a lower environmental impact than horizontal axis wind turbines. Multi-rotor platform designs have been proposed as well, but similarly, they will have difficulty competing with single-rotor designs because of technical complexities and upscaling, making them less attractive.

The most prevalent market trend of offshore wind turbines has been the rapid growth in turbine rating (or nameplate capacity) observed in recent years. The capacity-weighted average wind turbine rating installed globally has grown from around $4 \mathrm{MW}$ in 2015 to nearly $8 \mathrm{MW}$ in 2020 (Musial et al. 2021), and the major offshore wind turbine manufacturers have all announced that they will have 12-15-MW wind turbines ready for production by 2024 (Vestas 2021; Siemens Gamesa Renewable Energy 2019; General Electric 2019). Turbine upsizing allows fewer turbines to be used for a given plant capacity, which reduces balance-of-system costs (which include support structures, cables, electrical infrastructure, and installation), operation and maintenance costs, and wake losses, and leads to a significant reduction in LCOE (Shields et al. 2021). Industry experts consider this to be one of the most critical drivers for reducing the costs of offshore wind (Wiser et al. 2016; Wiser et al. 2021). As a result, project developers have a preference for selecting the largest commercially available turbine at the time of financial close (Musial et al. 2021).

In this study, we assume that the standard wind turbine installed for global projects with a COD of 2019 is 8 MW, and increases to 10,12, and $15 \mathrm{MW}$ for subsequent CODs of 2022, 2027, and 2032, respectively. Although this assumption may be conservative (as Vestas has already announced that their 15-MW wind turbine will be commercially available in 2024), historical trends have shown a lag of 5-10 years between prototype testing and significant market penetration (Musial et al. 2021). As a result, we select a more gradual implementation of larger wind turbines to account for any delays in developing the appropriate supply chains and any lags required to adapt fixed-bottom wind turbine technology (particularly control strategies) to the more nascent floating industry. Depending on supply chain development timelines, actual deployed turbine capacities may increase more rapidly than we illustrate.

\subsubsection{Wind Turbine Design Parameters}

The wind turbines used in this study are scaled versions of the open-source 15-MW offshore wind reference wind turbine developed by Gaertner et al. (2020), and are the same wind turbines used for an offshore wind cost and feasibility study for the state of California conducted by Beiter et al. (2020). This conceptual wind turbine was developed to provide a publicly available baseline design that does not expose any proprietary information from wind turbine developers. The power curve of the 15-MW reference wind turbine was scaled to create similar curves for the 8-, 10-, and 12-MW wind turbines by maintaining constant nondimensional power and thrust coefficient profiles over all wind speeds and scaling the rotor diameter to maintain a specific power of $332 \mathrm{~W} / \mathrm{m}^{2}$. In other words, the power rating and the rotor diameter of each reference wind turbine change relative to the 15-MW wind turbine but the ratio of the two remains constant. The hub height for each wind turbine was defined so that the blade tip maintains $30 \mathrm{~m}$ of clearance above the mean sea level at its lowest passage. By using similar reference wind turbines for each COD considered, the cost effects of wind turbine upsizing are captured without introducing additional cost sensitivities associated with switching between different wind turbine models. The resulting geometric features of the reference wind turbines are shown in Table 2.

The power curves calculated for each turbine are shown in Figure 9. The wind turbine begins producing power at the same cut-in wind speed of around $3 \mathrm{~m} / \mathrm{s}$, and the power production increases proportionally to the cube of the wind speed, up to the rated wind speed of $10.88 \mathrm{~m} / \mathrm{s}$. The variable speed, pitch actuated controller maintains constant power above the rated wind speed until the cut-out wind speed of $30 \mathrm{~m} / \mathrm{s}$. These wind turbines are the same ones used by Beiter et al. (2020). The power curves in Figure 9 represent the output electrical power produced by the turbine, meaning that they account for aerodynamic, mechanical, and electrical efficiencies in the power conversion process. A more complete discussion of the turbine losses can be found in Gaertner et al. (2020), and additional sources of 
Table 2. Technology assumptions for the O'ahu reference wind turbines.

\begin{tabular}{cccccc}
\hline & \multicolumn{5}{c}{ COD year } \\
& Units & 2019 & 2022 & 2027 & 2032 \\
\hline Turbine rated power & MW & 8 & 10 & 12 & 15 \\
Turbine rotor diameter & $\mathrm{m}$ & 175 & 196 & 215 & 240 \\
Turbine hub height & $\mathrm{m}$ & 118 & 128 & 138 & 150 \\
Cut-in wind speed & $\mathrm{m} / \mathrm{s}$ & \multicolumn{5}{c}{3} \\
Rated wind speed & $\mathrm{m} / \mathrm{s}$ & 10.88 \\
Cut-out wind speed & $\mathrm{m} / \mathrm{s}$ & \multicolumn{5}{c}{25} \\
Turbine specific power & $\mathrm{W} / \mathrm{m}^{2}$ & \multicolumn{5}{c}{332} \\
Waterline clearance & $\mathrm{m}$ & \multicolumn{5}{c}{30} \\
\hline
\end{tabular}

losses in the overall wind power plant are covered in Section 5. Note that the hard cut-out wind speed is idealized, and developers may customize turbine control strategies to avoid high wind speed hysteresis (see Section 7.3.9) after selecting a turbine model and plant layout.

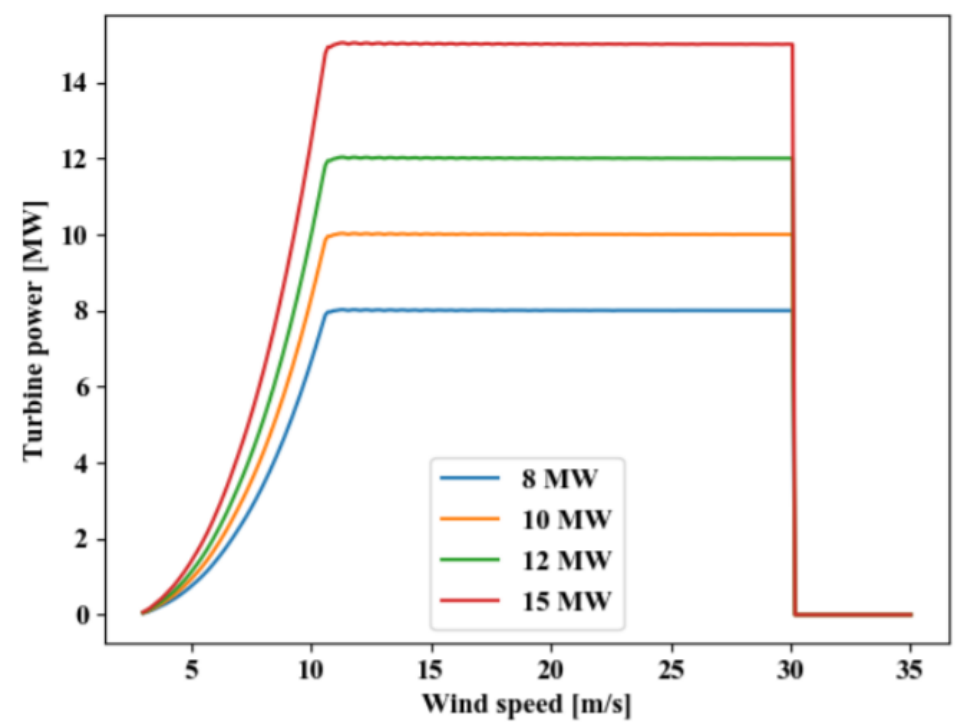

Figure 9. Power curves for the reference wind turbines used in this study (Beiter et al. 2020). The 8-MW, 10-MW, 12-MW, and 15-MW wind turbines correspond to CODs of 2019, 2022, 2027, and 2032, respectively.

\subsubsection{Designing for Hurricane Resiliency}

The Hawaiian Islands have experienced major hurricanes in recent decades, raising concerns that offshore wind turbines may not be able to withstand extreme winds in the region. Wind turbine manufacturers have obtained typhoonclass type certifications for ruggedized versions of their turbines, which demonstrate their machines can survive sustained wind speeds up to $57 \mathrm{~m} / \mathrm{s}$ and 3-s gusts up to $80 \mathrm{~m} / \mathrm{s}$ (Sirnivas et al. 2014). This additional reinforcement will lead to incrementally higher turbine costs. To evaluate the need for these turbines, it is necessary to consider the return period of these extreme events and the frequency with which they are expected to occur. It is important to note that an occurrence of a particular hurricane that exceeds these wind speed limits, such as Hurricane Iniki in 1992, does not necessarily require a typhoon-class turbine to satisfy design criteria. The anticipated frequency of these events is a critical factor in determining the risk of sustaining hurricane damage.

In a preliminary analysis we conducted using available data, we used a hazard curve derived for wind speeds in 
Hawai ${ }^{i}$,which shows the maximum 3-s gust as a function of return period, and scaled it to $150 \mathrm{~m}$ above sea level using estimated shear coefficients for hurricane boundary layers. As we do not have sufficient site-specific data to conduct a more robust analysis that considers the uncertainty around the calculations, we select the most conservative coefficients to estimate a worst case gust level for Hawai ${ }^{\prime} \mathrm{i}$. This analysis, which is described in detail in Appendix A, shows that the 500-year return period gust levels in the $\mathrm{O}^{\prime}$ ahu region fall just short of the International Electrotechnical Commission (IEC) requirements for a typhoon-class wind turbine, meaning that a standard IEC Class 1A wind turbine would likely be able to survive the most frequently occurring extreme loads in the region. As a result, we do not consider specific typhoon-class designs in this study, although we do include a $10 \%$ premium on the wind turbine costs to assume that a developer may desire additional redundancy systems such as battery control systems that could yaw the parked wind turbine in the direction of the storm if disconnected from the electricity grid.

The analysis provided in this report does not settle concerns about hurricane risk, however. A project developer would need to conduct a rigorous analysis of hurricane severity and the probability that a major hurricane would impact the project location. This study should take into account the latest guidance under development for floating wind turbines under the IEC TC-88 61400-3-2 committee and the ACP OCRP-2 working group. In addition, the possible impacts of climate change, which may result in increasing hurricane severity, should be assessed (IEC and DS 2019; ACP and ANSI 2021). After this additional information is obtained, the developer may indeed be required to select a typhoon-class wind turbine. This choice would raise the costs of the wind turbine incrementally, likely requiring stronger towers and blades as a minimum, but may be necessary for wind plant survival. A more detailed study is required to weigh the cost/benefit trade-offs of selecting a more robust turbine design.

\subsection{Floating Platform}

Floating support structures are typically more economically viable for offshore wind turbines located in water depths greater than $60 \mathrm{~m}$, which encompass $58 \%$ of the technical resource potential of offshore wind in the United States (Beiter et al. 2016; Musial et al. 2016). The deep water surrounding O'ahu means that the analysis domain falls within this category. Unlike the fixed-bottom offshore wind industry, which had installed over $32 \mathrm{GW}$ of deployment by the end of 2020 (Musial et al. 2021), floating wind remains a nascent industry with only 79 MW of demonstration and pre-commercial projects existing worldwide. Although some trends are emerging that are likely to define early deployment phases, floating offshore wind faces many uncertainties about the technology, supply chain, logistics, and environmental impacts surrounding the construction of commercial-scale projects. Gigawatt-scale projects are expected to be operational by 2025 (Musial et al. 2021), which will help the industry address these questions with empirical knowledge gained from the first installations. This section contains a brief summary of major technology choices for floating wind projects and identifies the selections made for the $\mathrm{O}$ 'ahu feasibility study.

A floating offshore wind system requires both a substructure to provide stabilization and buoyancy for the wind turbine and a mooring and anchoring system to provide station keeping capabilities. The most common substructure designs being considered for commercial deployment are the spar-buoy, the semisubmersible, and the tension leg platform. These designs are illustrated in Figure 10.

The key considerations in selecting a floating substructure include the cost, stability, and installation requirements of the structure. Environmental effects of the floating platform and mooring system, such as the seafloor disruption or effects on marine mammals, are also important but have not been extensively studied at this time. A spar-buoy contains ballast, which lowers the center of gravity of the overall assembly and provides stability against the motion of the wind turbine. The structures are relatively cheap to assemble, but the deep draft requires a sheltered deep-water area to assemble the turbine (such as the one used by Equinor to construct the 30-MW Hywind Scotland project in 2017), which may limit their commercial viability. Semisubmersibles provide static stability through their water plane area and distributed buoyancy in multiple columns, although the relatively complex design increases the cost of the platform. A semisubmersible and turbine system can be assembled at port and towed out to site, which limits costly and risky activities at sea. Tension-leg platforms are stabilized by taut, vertical mooring lines and are therefore unstable until this connection is made. As a result, they are unstable during tow-out and require auxiliary stabilization devices. Demonstration projects featuring the tension-leg platform are less prevalent than spar-buoy or semisubmersible prototypes.

In this study, we selected the semisubmersible platform as the most likely technology choice for offshore wind in 


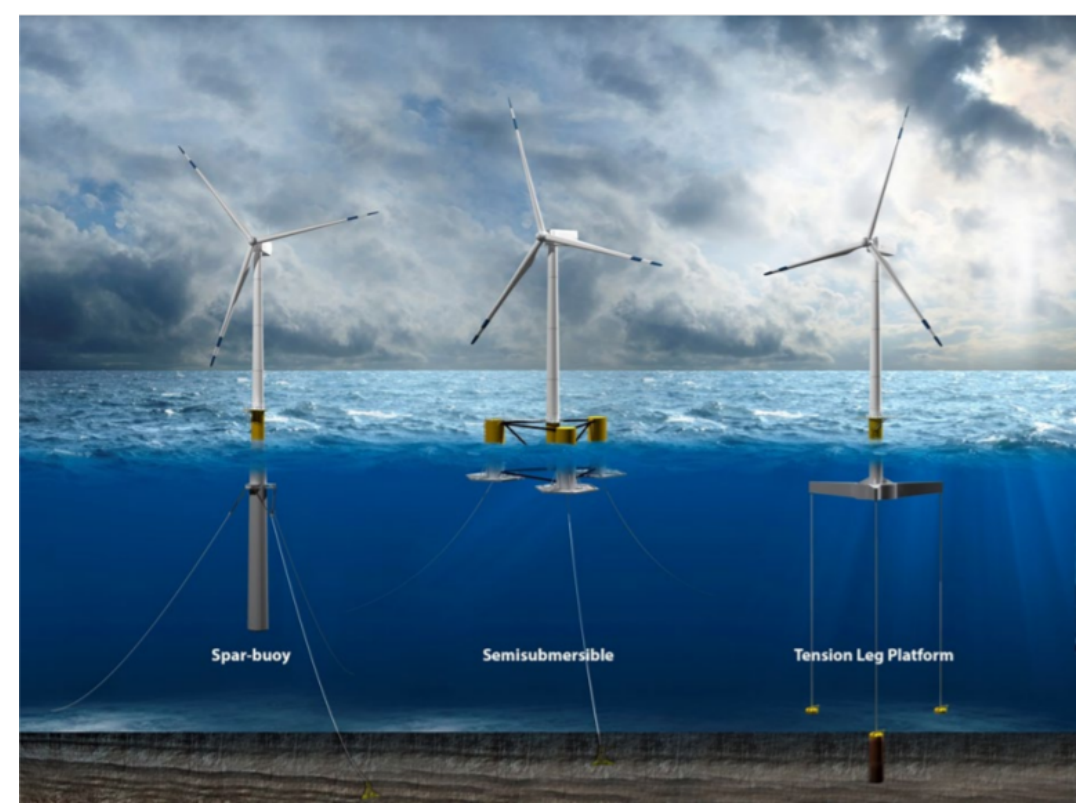

Figure 10. Substructure archetypes for floating offshore wind systems, including the sparbuoy, the semisubmersible, and the tension leg platform. Illustration by Josh Bauer, NREL.

the O'ahu region. Semisubmersibles account for around $75 \%$ of the anticipated global floating wind pipeline given their shallow draft and hydrodynamic stability, which permit most operations to be conducted at quayside (Musial et al. 2021). The ability to fabricate or assemble these structures at the construction port represents an opportunity to create local jobs, which is in line with the O'ahu port development plans (discussed in Section 6) while reducing cost and risk for the project. Realizing this opportunity would require a skilled workforce to conduct the fabrication, assembly, and operations phases of offshore wind projects, and it may be necessary to train this workforce on $\mathrm{O}^{\text {'ahu }}$ in order to create these local jobs instead of importing labor to conduct the work. As floating offshore wind is not yet a mature global industry, a robust supply chain does not exist for any of these substructure technologies. Our cost analysis assumes that a supply chain exists on the U.S. mainland that is able to produce these platforms, and then applies a cost premium to transport the components across the Pacific to a staging port on $\mathrm{O}^{`}$ ahu. This will be discussed in more detail in Section 7.

\subsection{Mooring, Anchoring, and Electrical Systems}

The floating platform is attached to the seafloor using 3 mooring lines, each with its own anchor. Mooring lines typically consist of relatively short sections of chain at the connection point to the floating platform and the anchor, with a longer section of lighter and cheaper synthetic rope in the middle. Additional components such as clump weights or damping mechanisms may be integrated into the mooring line to help control the dynamic response of the floating platform and the fatigue of the mooring line itself. In this study, we assume that the mooring line consists exclusively of chain and synthetic rope and extends to the seafloor in a catenary shape. This mooring system allows the turbine to move within a "watch circle" due to forces from the wind, waves, and current. The floating turbine is pushed away from the primary forcing direction, causing the upstream mooring lines to tighten and the downstream line to slacken. The direction of the net wind, wave, and current force may change at any given time. The size of the watch circle is approximately a quarter of the water depth, meaning that floating turbines located in the $\mathrm{O}^{\prime}$ ahu region would be able to move within a footprint with diameters between approximately $125 \mathrm{~m}$ and $250 \mathrm{~m}$. A depiction of the turbine motion within the watch circle is provided in Figure 11.

The footprint of a catenary mooring system increases with water depth; at the water depths within the analysis domain, the radius of the mooring line from the turbine would likely be double the water depth (although around a third of this footprint consists of the mooring line laying on the seafloor). A cross sectional view of mooring lines for 


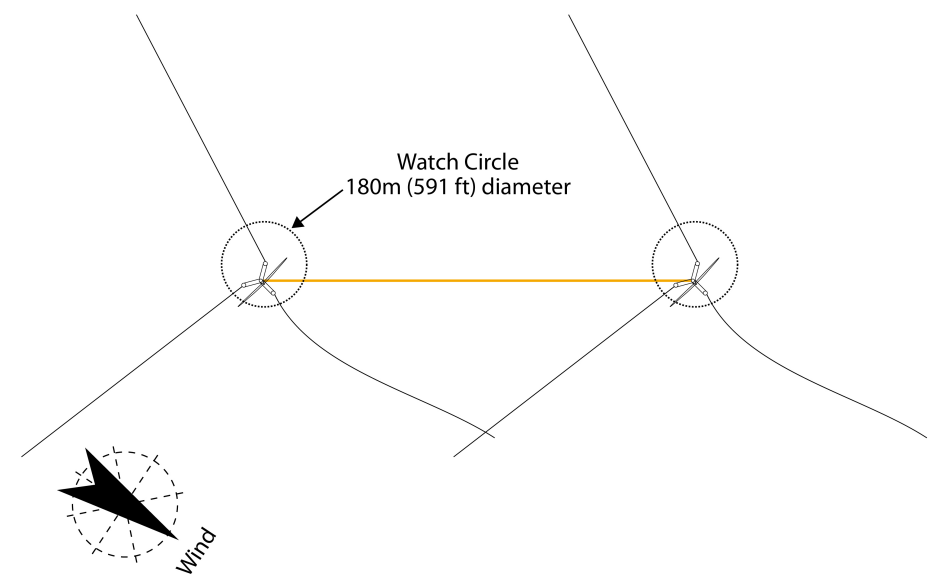

Figure 11. Turbine platform motion within the confines of a watch circle. Illustration by Josh Bauer, NREL.

adjacent turbines spaced 5 rotor diameters apart is shown in Figure 12 to provide a reference for the scale of such a system. It is likely that a real project would employ a semi-taut configuration (with lines extending to the seafloor at an approximately $45^{\circ}$ slope) instead of a full catenary configuration; however, we consider the more conservative approach to provide an upper limit on mooring line costs. Additional research into shared mooring and shared anchor systems, in which multiple platforms share mooring systems instead of each turbine having its own mooring lines and anchors, shows promise to reduce costs and complexity but is not considered in this preliminary study.

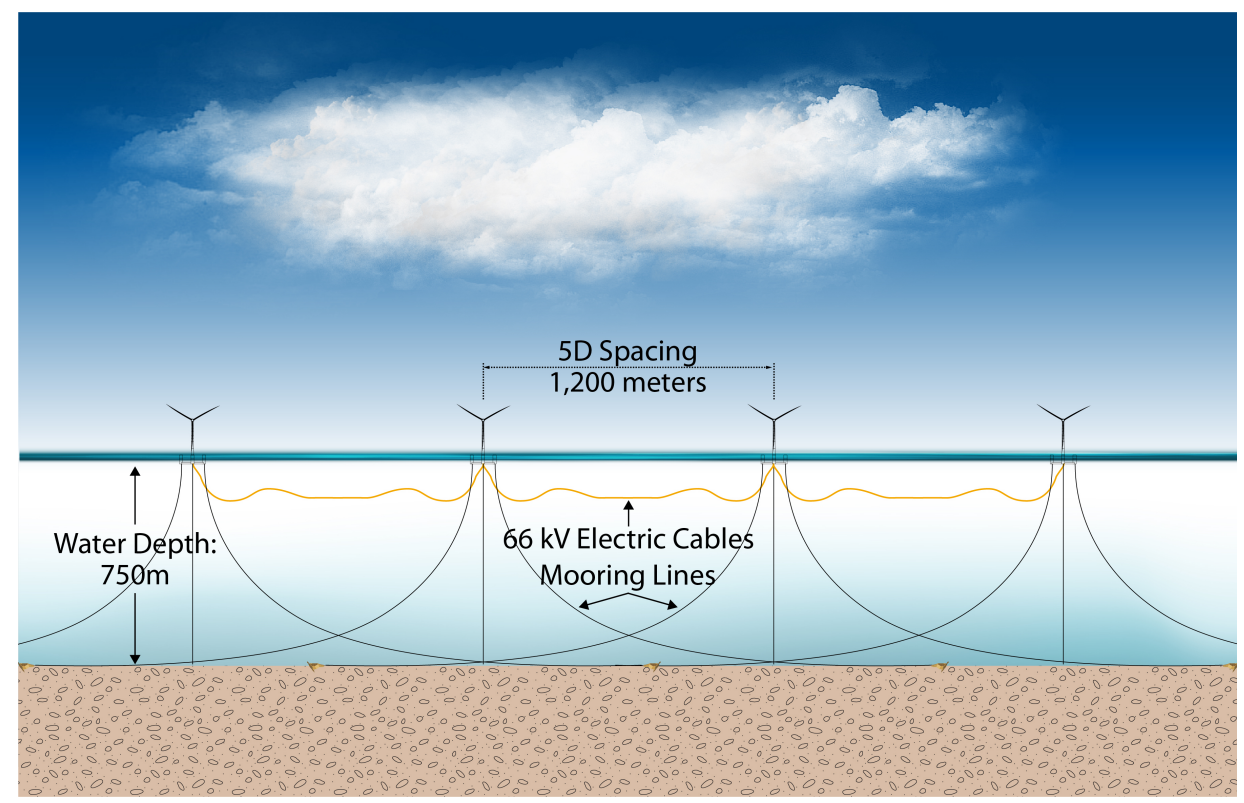

Figure 12. Cross sectional view of the water column with mooring lines and electrical cables for 4 turbines spaced 5 rotor diameters apart. The radius of the mooring line is approximately twice the water depth. Illustration by Josh Bauer, NREL.

Catenary mooring lines use drag embedment anchors (DEA) to attach to the seafloor. These devices are typically made from steel and are installed by a vessel that drags them horizontally, causing the anchor to drive itself approximately 
$10 \mathrm{~m}$ into the seafloor. These anchors cannot withstand vertical loads, requiring the final section of the catenary line to lie flat along the seafloor under its own weight regardless of the motion of the turbine. As a result, the contact length may be several hundred meters, and this section of the mooring line is made from a heavy chain. A rendering of a DEA with the length of mooring line near the seafloor is shown in Figure 13. Alternate anchor technologies, such as suction caissons, are pulled into the seafloor by creating a vacuum within the anchor cavity (such as those used at the Hywind Scotland pilot project (Equinor 2021)). These anchors depend on the seabed conditions and are more appropriate for mooring systems with vertical loads, such as for the tension-leg platform; however, as we employ the catenary mooring line in this study, only DEAs are considered. A more detailed investigation into the impacts of different mooring systems on project cost, the environment, and other ocean activities should be conducted prior to the development of any real wind project, and may lead to the selection of a different configuration than the one we use in this study.

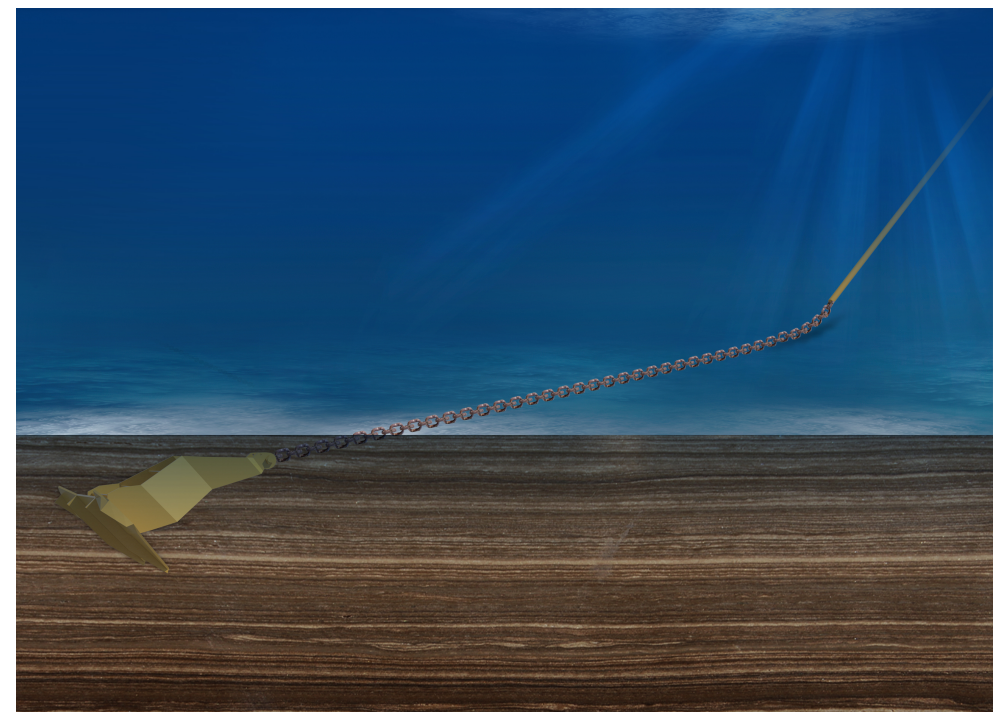

Figure 13. Drag embedment anchor and catenary mooring line. Illustration by Josh Bauer, NREL.

The final components of an offshore wind power plant located below the water surface are the array and export electrical cables. The array cables transmit power from individual turbines to an offshore substation, which collects the power and transmits it to the onshore grid. Modern array cables are rated at $66 \mathrm{kV}$, and export cables are typically rated at $220 \mathrm{kV}$. Unlike the cables used in fixed-bottom wind power plants, which are entirely buried under the seafloor, floating wind power plants require dynamic cables that are either entirely or partially exposed in the water column, depending on the water depth. The deep waters surrounding $\mathrm{O}^{\prime}$ ahu make it likely that the electrical cables of an offshore wind project would be suspended between the wind turbines at a specified distance below the water line. Part of the export cable would also be exposed as it stretches towards the seafloor. This subjects the cables to bending and twisting forces from the motion of the platform and the wave and tidal forces, which has the potential to create mechanical failures within the cable. As a result, floating wind projects will require dynamic cables with additional mechanical support and customized connectors to compensate for the imposed motion. Dynamic cables are therefore more expensive than the static cables used for fixed-bottom wind power plants, although this technology is still in an early stage of development.

An important feature of dynamic cable design is the water depth at which the cables are suspended. Lowering the cables further in the water column increases costs but may reduce impacts on vessels and fishing activities within the boundaries of the wind power plant. A standard cable depth has not been agreed upon by the floating wind industry, and will require further collaboration with relevant stakeholders to agree upon a common solution. To visualize what suspended array cables might look like and to provide context for these future discussions, array cables at a depth of $100 \mathrm{~m}$ are shown in Figure 12. There may be a need to locate the array cables deeper to avoid impacts on marine mammals or vessels. 


\section{Wind Power Plant Model}

The wind power plant model is made up of the wind turbine model, turbine layout, and the flow model. FLORIS is used to calculate the gross AEP and wake losses. ${ }^{4}$ These data are fed into NREL's Offshore Regional Cost Analyzer (ORCA) model to apply additional losses and compute the Net Capacity Factor (NCF) and LCOE. Integrating FLORIS with ORCA for the energy yield and wake loss analysis offers flexibility in the choices of plant and turbine models, wind resource data, and flow model parameters. The wind plant model setup for the present assessment in Hawai' $i$ is consistent with NREL's recent floating offshore wind cost study offshore California (Beiter et al. 2020).

\subsection{Turbine}

The turbine models used in this report are based on the 15-MW reference wind turbine (Gaertner et al. 2020). The key parameters for the energy production analysis are the turbine hub height, rotor diameters, and power coefficient and thrust coefficient curves. See Section 4 for the turbine specifications and curves.

\subsection{Plant Layout}

The plant layout considered in this report is intended to serve as a generic basis of comparison for offshore sites surrounding $\mathrm{O}^{\prime}$ ahu. Turbines were spaced 7 rotor diameters (7D) apart with a configuration as close to a square grid as possible. Because the number of turbines is not a perfect square in any of the COD years, a partial column is filled on the east side of the plant to reach the total plant capacity. The layout is not optimized to account for site-specific wind resource data, bathymetry, geohazards, array cable arrangements, or other cost drivers. The lack of optimization leads to conservative wake loss estimates. The reference power plant for this analysis has a total plant capacity of 600-MW, which is smaller than the 1,000-MW plants used in the California study (Beiter et al. 2020). This adjustment stems

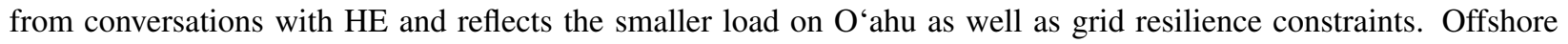
wind project costs tend to decrease with increasing plant capacity as economies of scale and bulk pricing are realized (Shields et al. 2021). It is possible that projects could be smaller than the 600-MW capacities used in this study as the load on O'ahu is relatively low (for example, the unsolicited projects proposed in 2016 were both 400-MW (BOEM 2021)), which would increase LCOE from the results we report. We provide a sensitivity study in Section 7.3.6 to demonstrate the potential impacts of changing plant capacity on overall costs.

This generic square turbine layout and 7D spacing is conservative in terms of wake losses. We showed that the wind roses presented in Figure 6 have a dominant and predictable prevailing wind direction from the east and northeast, which presents a significant opportunity to further lower wake losses with more optimum turbine and row spacing. Decreasing row spacing in the direction perpendicular to the dominant flow could potentially allow for a greater density of installed capacity within a given area. A rendering of this concept with $10 \mathrm{D}$ spacing parallel to the wind direction and only 5D spacing perpendicular to the wind direction is shown in Figure 14. The distances between rows and columns are based on the 240-m rotor diameter of the 15-MW wind turbine. This graphic places the wind power plant in the O'ahu East Study Area ( $\mathrm{O}^{\prime}$ ahu is visible in the background with a label for one of the most prominent geographic features, the Diamond Head volcano) and also shows a cutaway view of the underwater mooring lines and electric cables.

\subsection{Flow Model in FLORIS}

FLORIS includes a set of engineering tools for computationally inexpensive analysis of the steady-state wake characteristics in a wind farm (NREL 2021b). The steady-state wake conditions modeled by the type of engineering models available in FLORIS lack the fidelity of large-eddy simulations or direct numerical simulations, but FLORIS can be embedded into NREL's cost model without a substantial computational burden. Lower-fidelity engineering wake models were found to perform reasonably well for energy yield estimates compared to higher fidelity techniques (Nygaard 2015; Walker et al. 2016). The flow model in FLORIS consists of an engineering wake model to obtain the velocity deficit in a single wind turbine wake with a wake superposition method to account for wakes of multiple turbines. Turbulence and wake deflection models are also implemented in FLORIS. A Gaussian wake model and a sum of squares

${ }^{4}$ FLORIS (NREL 2021b) is NREL's publicly accessible set of wake modeling tools. See https://github.com/NREL/floris. 


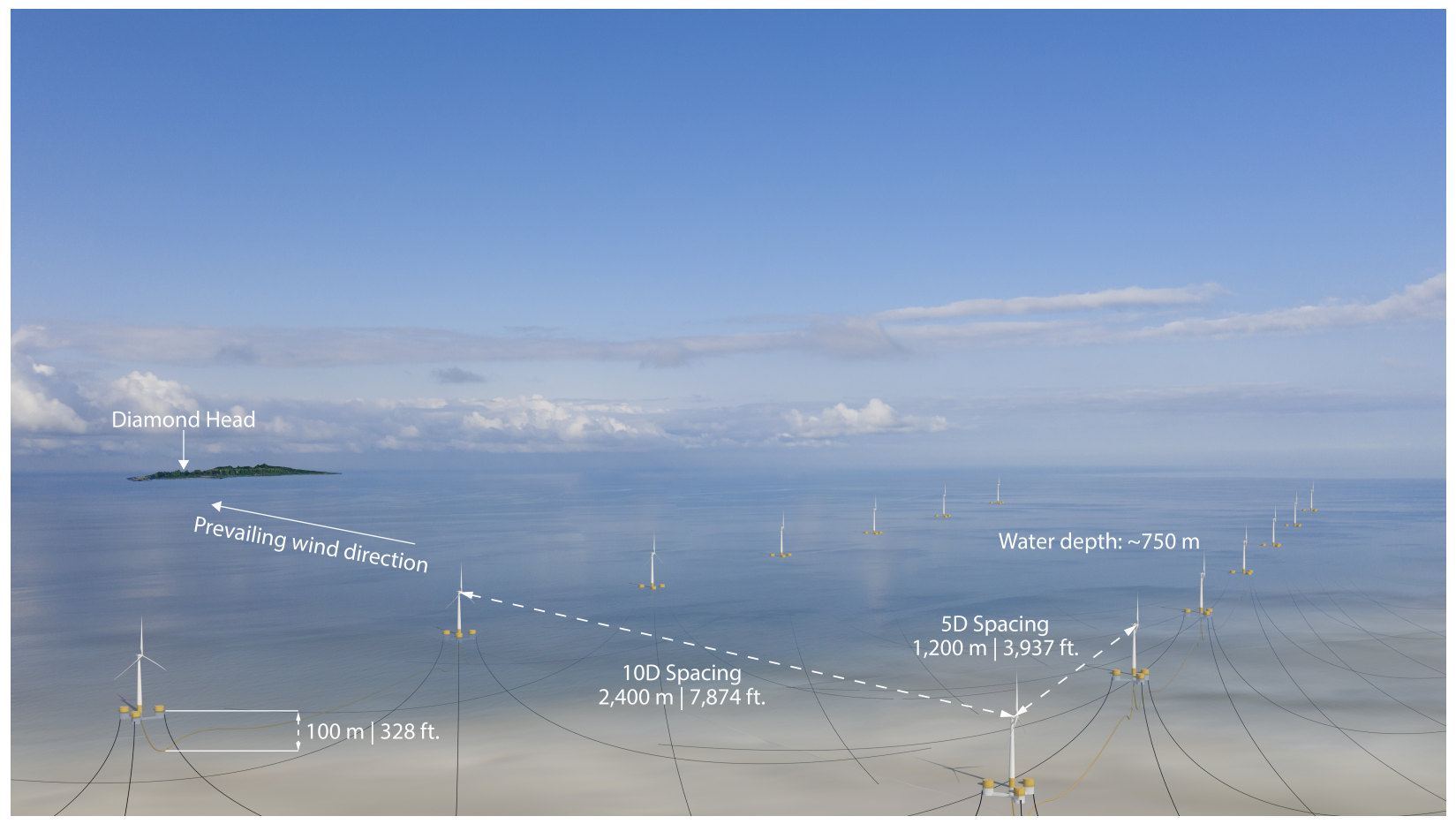

Figure 14. Conceptual rendering of a commercial-scale offshore wind plant using 15-MW wind turbines located within the O'ahu East Study Area. Illustration by Josh Bauer, NREL.

wake summation method are used (King et al. 2020). Tuning parameters are consistent with those used by Annoni et al. (2018) per the recommendations of the FLORIS development team at NREL. A free-stream turbulence intensity of $6 \%$ is prescribed to the inflow, as this is thought to be conservative for offshore wake recovery based on consultation with NREL experts. 


\section{Infrastructure and Logistics}

Floating offshore wind power plants are large-scale construction projects that require significant infrastructure resources. In this section, we describe the port, grid, and supply chain requirements for floating wind projects and identify potentially suitable resources on $\mathrm{O}^{\prime} \mathrm{ahu}$.

\subsection{Construction and Operations Port}

\subsubsection{Requirements for a Floating Wind Port}

The construction, assembly, and marshalling of major components takes place at local ports as the size of offshore wind turbines prevents transit via roads or rail. These activities could take place at a single port, often referred to as an "offshore wind hub," or multiple ports with specific functions dispersed throughout the region. The fixed-bottom offshore wind industry in Europe has developed offshore wind hubs in Bremerhaven (Germany), Rotterdam (the Netherlands), and Hull (United Kingdom), and a similar facility is under construction in New Jersey to support the Atlantic Coast buildout in the United States.

Floating wind projects have different port requirements than those used for fixed-bottom projects. The primary difference is that floating projects have the opportunity to assemble the turbine and platform at quayside and tow the completed structure out to the project site, whereas fixed-bottom projects dispatch large and expensive Wind Turbine Installation Vessels (WTIV) to assemble the turbine piece by piece at sea. The general approach would be to assemble the semisubmersible platform in a dry dock, assemble the turbine on top of the completed substructure, and then flood the dry dock and tow the unit out to sea using cheap and readily available tug boats. This different methodology for floating wind projects has the potential to reduce costs, delays, and risk to projects as the quayside assembly is conducted in a protected harbor. These benefits could also impact the operational stage of the project, as floating wind turbines can be disconnected from their mooring lines and electrical cables and towed back to port for major repairs (conversely, fixed-bottom projects require a WTIV to be mobilized to repair or replace blades, gearboxes, or generators, which may take several months). Minor repairs and maintenance of floating wind turbines would still take place at the project site. Achieving these benefits means that the port infrastructure required for floating wind projects must be designed or modified to accommodate the assembly of a floating wind turbine with hub heights that could reach $150 \mathrm{~m}$ above sea level (Figure 8). The lack of available ports with the capacity to support commercial-scale floating wind operations is a global challenge for the industry.

Porter and Philipps (2016) conducted a comprehensive study evaluating the readiness level of West Coast ports to support floating wind deployment. The authors evaluated existing ports in California, Oregon, Washington, and Hawai' $i$ based on a set of criteria to determine their suitability to act as construction or operations ports. Some of the major criteria that they considered were:

- Navigation channel width and depth

- Air draft (the presence of bridges or other obstructions that would prevent tow-out)

- Vessel type, operations, and availability

- Available laydown area to store components

- Crane capacity

- Quayside bearing capacity

- Dry dock or shipyard facilities

- Available fabrication and workforce resources.

We based our evaluation of $\mathrm{O}$ 'ahu ports on the study conducted by Porter and Philipps (2016) along with discussions with the Hawai'i Department of Transportation, Harbors Division (DOT-H). Further work will be required to investigate the port infrastructure upgrades that would be required to fabricate and install larger turbines as this is outside the scope of this study (Porter and Philipps (2016) considered 6- to 8-MW wind turbines). The 10- to 15-MW wind 
turbines used in this study would require larger cranes, greater quayside bearing capacities, and deeper channel depths for tow-out). The island of $\mathrm{O}$ 'ahu has two commercial ports, Honolulu Harbor and Kalaeloa/Barber's Point Harbor (KBPH). Although Honolulu is the larger of the two ports, it is less attractive as an offshore wind port because it has limited available space for the storage or assembly of offshore wind components and is more congested than KBPH. As a result, for this study we consider KBPH to be the sole construction and operations port for offshore wind projects in the O'ahu region.

\subsubsection{Description of the Kalealoa Barber's Point Harbor}

$\mathrm{KBPH}$ is a sheltered harbor located on the southwest corner of $\mathrm{O}^{\prime}$ ahu with moderate navigation channel widths and depths, access to large vessels, no air draft restrictions, and available upland storage areas (Porter and Philipps 2016). The harbor is located near the Kalealoa Airport, which may require permitting and coordination with the Federal Aviation Administration and the airport operators for offshore wind operations. The DOT-H is the regulating authority of both harbors, and in 2015 released a master plan for KBPH (Transportation Harbors Division 2015). This master plan provides long-term strategic guidance on comprehensive long-range strategies and land use concepts through 2040. The development plans for the port indicate an interest in expanding the facilities to accommodate new industries, and have the potential to be tailored to support the onsite assembly and tow-to-port maintenance strategies for floating wind.

KBPH is capable of handling dry-bulk (e.g., coal, cement, and sand) and liquid-bulk (e.g., petroleum products, ethanol, and asphalt), and provides space for ship maintenance and repair service; however, the berths have become increasingly congested as the port has gotten busier in recent years. The KBPH Master Plan therefore looks to expand harbor facilities. The cornerstone of this expansion is the construction of a dedicated Fuel Pier to separate dry-bulk and liquidbulk cargoes, with additional plans to expand the main cargo pier and conduct improvements to facilitate berthing for maritime support services, including a tenant floating dry-dock.

The specifications of KBPH are given in the Master Plan along with potential limitations. The KBPH entrance channel is narrower than the Honolulu Harbor, with the offshore channel entrance measuring about 1,000 m long, $140 \mathrm{~m}$ wide, and $12 \mathrm{~m}$ deep. The inshore channel measures about $300 \mathrm{~m}$ long, $140 \mathrm{~m}$ wide, and $12 \mathrm{~m}$ deep. The United States Army Corps of Engineers (USACE) studied modifications to the harbor entrance, and the results support the flaring and dredging of the harbor's entrance to increase the margin of safety for vessels transiting in and out of the harbor. The main harbor basin is 37 hectares and measures about 700 by $550 \mathrm{~m}$ with a depth of $12 \mathrm{~m}$. An expansion later added another 6 hectares, measuring approximately $180 \mathrm{~m}$ by $330 \mathrm{~m}$ and also $12 \mathrm{~m}$ deep. At minimum, these harbor basins and navigation channels would require additional dredging to support the deeper draft of upsized wind turbines, which may be at least 12-14 m for a 15-MW machine. These waterway improvements would be the responsibility of the federal government (DOT-H is responsible for the land side of the harbor) and would be conducted by the USACE. This would require significant effort to plan and permit the additional upgrades, which may not be within the financial abilities of the project developer. Port development on the East Coast has benefited from public-private partnerships in which state entities have taken the lead on harbor improvements but also collaborated with project developers to design and construct facilities that are appropriate for offshore wind project construction. This type of structure may be a template for the development of KBPH.

In addition to pier improvements, the Master Plan outlines current nearby land uses as well as predicted land-use requirements. The existing land utilized by KBPH sums up to roughly 120 hectares; however, nearly 70 hectares of this is unused or consists of coral stockpiles from original dredging. Because of this, the occupied land decreases by 23 hectares to 97 total hectares by 2040, even when taking expansions into consideration. This is primarily due to plans for the sale of coral stockpiles which, once removed, will open existing nearby land. This available space is attractive for laydown area for floating wind components. A proposed port configuration for 2040 from the Master Plan is shown in Figure 15.

It is unlikely that a full offshore wind supply chain would be developed on Hawai' $i$ to support the relatively few number of projects that would be built in the region. Instead, KBPH would likely be used as a marshalling port, which would receive finished components from a supply chain on the mainland U.S. or Southeast Asia and would stage components in a storage yard until they were ready for final assembly and transportation to a site. Following the construction phase of the project, some of the storage, crane, and workforce capabilities would be required to conduct 


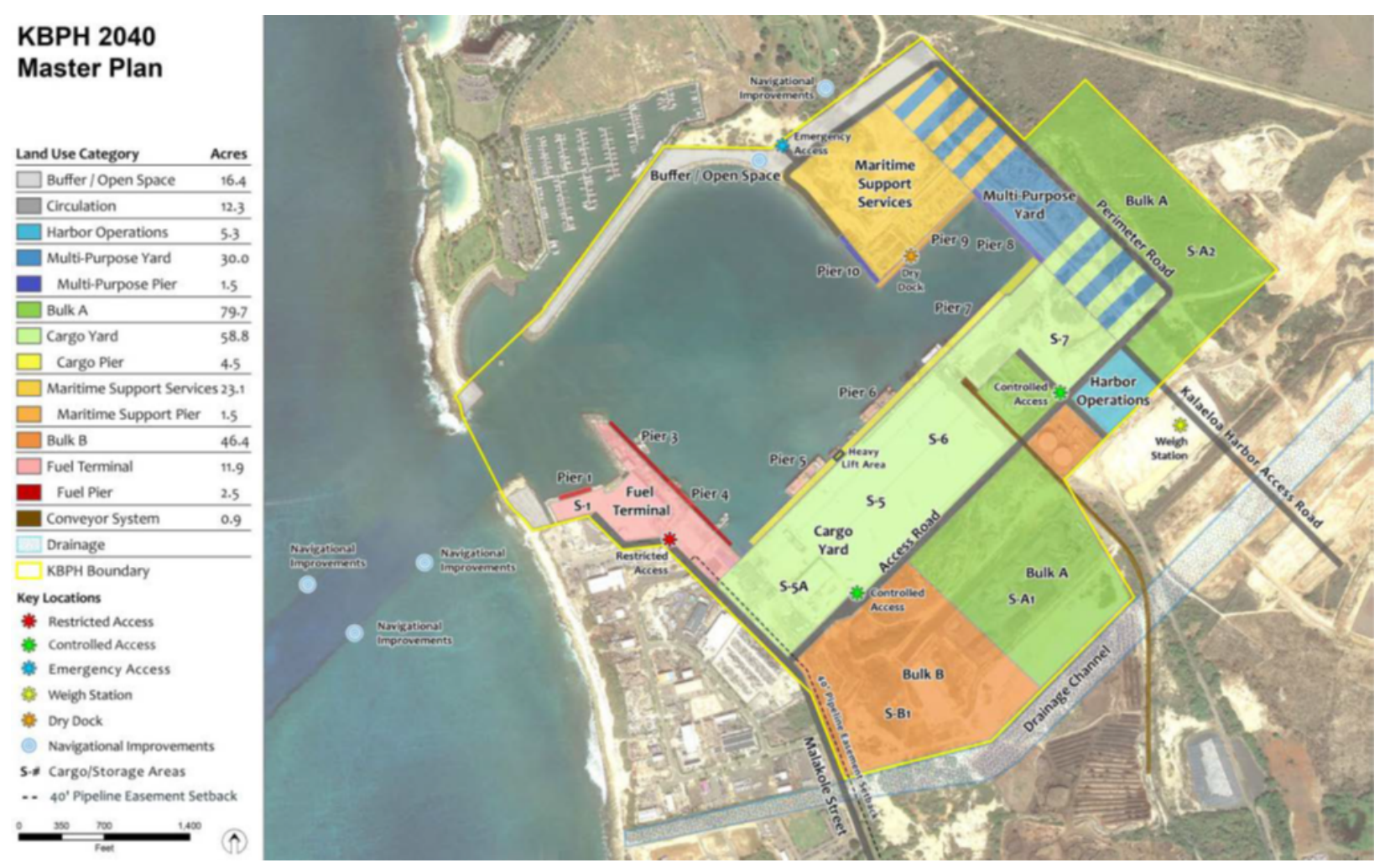

Figure 15. Proposed land use for the Kalealoa Barber's Point Harbor in 2040 (Transportation Harbors Division 2015).

operations and maintenance activities for the project. As such, offshore wind represents an opportunity to achieve economic and workforce benefits for the port, which can be realized if the long-term planning of the port is structured to accommodate the construction and maintenance of floating wind turbines.

\subsection{The Electricity Grid and Points of Interconnection}

Offshore wind projects connect to the bulk electricity grid and therefore require an understanding of how the grid operates in the region and where the potential interconnection points exit. $\mathrm{O}$ 'ahu has a daily peak load of around 1,200 MW and a daily minimum of around $600 \mathrm{MW}$ (Corbus et al. 2010). This load is primarily serviced by seven fossil fuel power plants ( 6 petroleum, 1 coal) with a firm generation capacity of around 1,800 MW and an additional sixteen wind or solar power plants with a total non-firm capacity of around $800 \mathrm{MW}$ (Hawaiian Electric 2020). There is also one recently retired petroleum plant that has been offline since 2014. Most these plants are consolidated on the southwest shore near Campbell Industrial Park; as a result, the power flow on the island primarily travels from west to east, as the highest concentration of electrical load is on the southeast shore in the vicinity of Honolulu. This adversely impacts the resiliency of the grid and means that communities on the west side of $\mathrm{O}$ 'ahu are disproportionately burdened by their proximity to power plants. The specifications for these plants can be found in Table 3. There is no utility-scale generation (fossil fuel or renewable) east of the Ko 'olau mountains, which represents a challenge for grid resiliency; if the transmission lines over this mountain range were impacted by a hurricane or other natural disaster, the east side of the island could be without power for a significant period of time.

Bulk system transmission is conducted through 138-kV lines, which are shown in Figure 16. There are no transmissionlevel lines north of Wahiawa (in the center of $\mathrm{O}^{`} \mathrm{ahu}$ ), and as a result, the North Shore is serviced by 46-kV lines that are at full capacity. Any new generation on the north side of the island would have to connect to the Wahiawa substation, incurring significant costs to build transmission over land. On the south side of the island, Hawaiian Electric identified two transmission-level substations, Ko'olau and Iwilei, as potential options for offshore wind points of inter- 
Table 3. Capacity of existing fossil fuel power plants on O'ahu with over 100 MW of generation capacity (Energy Information Agency).

\begin{tabular}{ccc}
\hline Power plant & Total nameplate capacity (MW) & Technology \\
\hline Kahe & 610 & Petroleum \\
Waiau & 475 & Petroleum \\
Kalealoa Cogen Plant & 299 & Petroleum \\
AES Hawai‘i & 203 & Conventional steam coal \\
Campbell Industrial Park & 113 & Petroleum \\
\hline
\end{tabular}

connection. Both substations have three transmission lines heading west, which could help to alleviate unidirectional power flows on the island. The Iwilei and Ko 'olau substations were used by Corbus et al. (2010) as viable interconnection points for subsea cables transmitting power from generation facilities on Lāna' $i$ and Moloka 'i. The Ko 'olau substation is also located east of the Ko'olau mountain range, meaning that connecting a generation source here could provide power to this side of the island if the transmission lines over the mountains were down. Ko "olau also has more available land surrounding the existing infrastructure, which could be used to build out the connection to an offshore wind project; these costs would be significant, and are not modeled in this study.

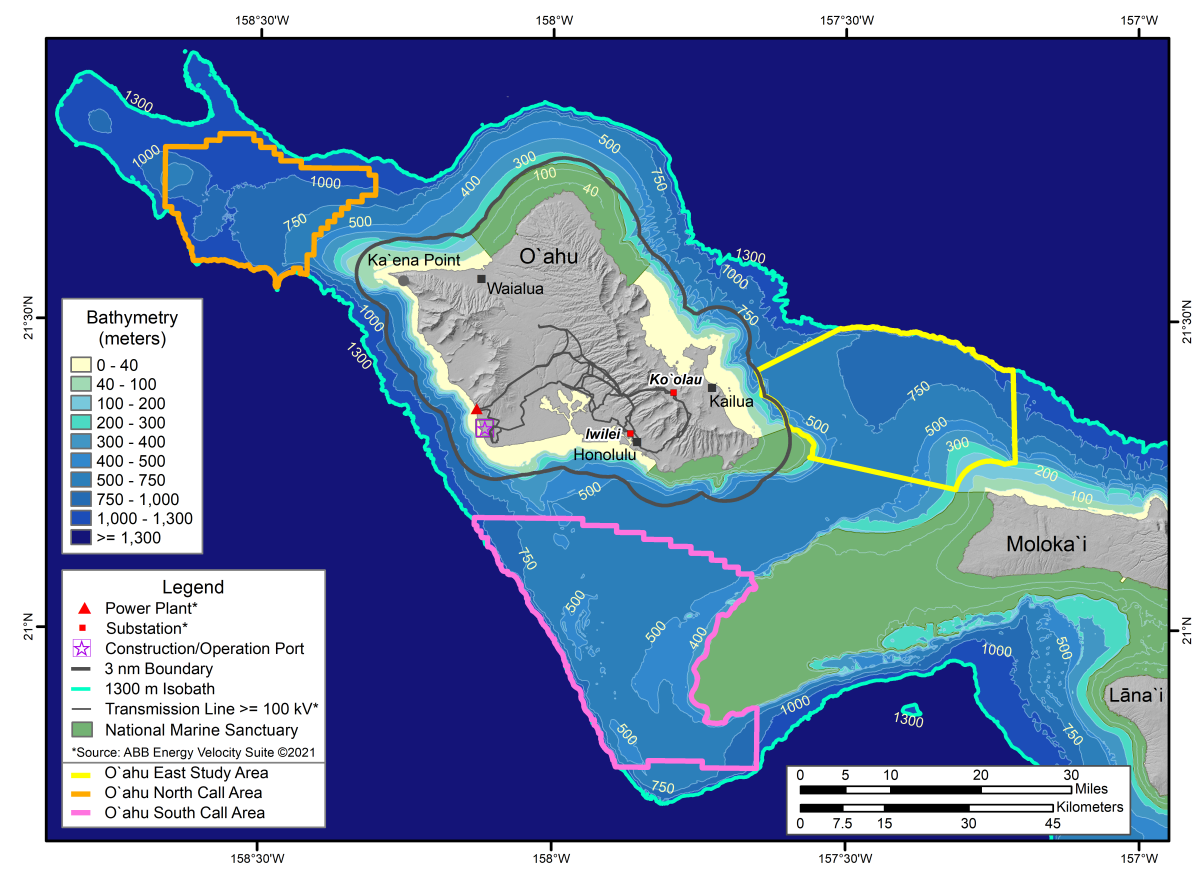

Figure 16. Topographic and bathymetric map of the island of $O$ 'ahu and surrounding region. Some sections of the transmission lines are underground cables, although these are not delineated on this map.

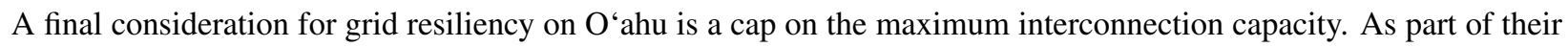
ongoing grid planning process, $\mathrm{HE}$ is constraining the largest interconnection to be $135 \mathrm{MW}$ to limit the required contingencies in the event of a loss of generation. For land-based solar or wind power plants, this may limit the overall size of the project; however, as we discuss in Section 7.3.6, in order to achieve economies of scale to reduce the costs of offshore wind, the project capacity would likely be over 400-MW (we consider 600-MW projects in this study). Typically, export cables are rated to transmit 300-400 MW of power (Shields et al. 2021); on O'ahu, smaller export cables would be used to limit the power to $135 \mathrm{MW}$ per cable. The use of smaller cables impacts the unit cost of the export cables as well as the total number of required cables. We summarize the net impact on cost in Section 7.3.4 and 
provide greater detail in Appendix B.

In this study, we assume that the Ko 'olau and Iwilei substations are the only two permissible interconnection points for offshore wind projects located throughout the $\mathrm{O}^{\prime}$ ahu analysis domain. These substations are advantageous for offshore wind development as they are the most straightforward to upgrade on the island, they will route electricity from east to west to improve power flows and grid resiliency, they will not place additional construction burden on communities on the west side of the island, and the Ko'olau substation is located on the eastern side of the Ko 'olau mountain range. Further work is required to understand the extent and cost of substation upgrades that would be required, the impacts on grid stability from injecting large capacities of offshore wind, and the potential environmental impacts of bringing subsea cables ashore in these areas.

In addition to the baseline scenario, we conduct a sensitivity analysis, which assumes that the Kahe power plant has retired and that its grid connection is available as an additional interconnection point. As the Hawai' $i$ RPS specifies $100 \%$ renewable generation, it is reasonable to assume that fossil fuel power plants will be retired and their existing grid connections will be available to offshore wind (or other renewable) power plants. An estimate of the project cost impact of such a retirement is obtained by permitting projects in the analysis domain to connect at Kahe; however, as the retirement scheduled for the conventional fuel power plants listed in Table 3 is not certain, it is possible that offshore wind could be built around $\mathrm{O}^{\prime}$ ahu before the existing facilities go offline.

\subsection{Supply Chain Assessment}

Previous NREL floating wind cost studies assumed a mainland U.S. manufacturing source for major project components and neglected to consider alternate supply chain scenarios (Beiter et al. 2020; Musial et al. 2019a). Hawai ' $\mathrm{i}$ presents a unique opportunity for alternate supply chain options due to its proximity to Asia. The relatively low electricity demand on Hawai ' $i$, coupled with a lack of an existing manufacturing industry and limited available land space, means that it would not be cost effective to build a complete local supply chain. Instead, project components will have to be manufactured elsewhere and towed to the island, and Asia has the potential to fulfill this supply chain need. A lower cost semisubmersible is of particular interest as it represents a significant portion of project CapEx (Stehly, Beiter, and Duffy 2020) and can be fabricated using existing shipyard capabilities such as steel work, welding, and painting. As a result, we conducted a preliminary assessment into the viability of sourcing semisubmersible platforms from Asia. This is not intended to be a comprehensive evaluation of the supply chains required to construct a floating wind project in the $\mathrm{O}$ 'ahu region; in reality, the sourcing of the other major components (e.g., turbines, mooring system, cables, offshore substation) would also need to be considered along with the quality and efficiency of the manufacturing facilities under consideration.

The four Asian countries with announced floating offshore wind projects include China, Japan, South Korea, and Taiwan (Musial et al. 2021). Of these four countries, South Korea is the most probable producer of commercialscale semisubmersible substructures that could be exported to the United States. This is due to the fact that multiple Memoranda of Understanding (MOU) have been signed by developers and the City of Ulsan for the production of at least $700 \mathrm{MW}$ of semisubmersible substructures (EDPR 2019). Ulsan seeks to become a manufacturing hub for floating offshore wind and, as of June 2020, had signed MOU with nineteen floating wind companies. The agreement ensures joint research and cooperation between businesses, developers, and the local government and ensures that a system will be put in place to develop a large floating wind complex for the city (Berthnal-Hooker 2020).

The primary source used to analyze possible supply chain cost differences between the United States and South Korea was a proprietary assessment conducted by NREL and industry partners in 2013, which included various fabrication costs of semisubmersibles. This assessment compared quotes from four different domestic and international semisubmersible manufacturers, which identified costs per unit for items such as fabrication, steel material, and final assembly. This analysis suggests that total installed platform cost is approximately $50 \%$ cheaper when a South Korean supply chain is used relative to U.S. manufacturers. It is important to note that this assessment was conducted to evaluate demonstration-scale projects (less than 5 wind turbines) and therefore did not consider fully mature supply chains customized for floating offshore wind; therefore, this cost differential may change if commercial-scale supply chains are available in both the United States and South Korea.

We conducted additional research on recent labor costs, steel costs, and steel tariffs to support the proprietary findings 
of the study from 2013. Hourly compensation costs in the manufacturing sector for the United States fall at $\$ 39.03$ per hour whereas for South Korea these costs fall at \$22.98 per hour (The Conference Board 2016). Compensation costs include direct pay as well as employer social insurance expenditures and labor related taxes, making this comparison data a more accurate representation of employer labor costs (The Conference Board 2018). This, therefore, is more appropriate for supply chain analyses as opposed to national data based solely on average earnings. When looking at this compensation cost comparison, it is clear how a supply chain with semisubmersible manufacturing occurring in South Korea could be more cost effective than a United States supply chain. This difference in labor rates is the primary driver of the lower costs of an imported semisubmersible platform. The accelerated development of the South Korean supply chain may also be enticing to a project developer, as the manufacturing facilities will gain efficiencies and expertise as more units are built, potentially reducing costs further relative to a U.S. manufacturer.

Steel prices, on the other hand, are of comparable value between the United States and South Korea. 2019 steel prices in the United States were $\$ 603.52$ per ton, while 2019 steel prices in South Korea were $\$ 658.75$ per ton (Focus Economics 2019; Jang 2020). This would have a relatively small, although nonzero, impact on a selecting a supply chain but does indicate that compensation costs for fabrication are the primary cost advantage offered by South Korean facilities. Tariffs were also ruled out as an impacting variable given that as of 2019 there are no tariffs for steel imported from South Korea. This could change with the new Biden administration, as section 232 of the Trade Expansion Act of 1962 authorizes the President to adjust the imports of an article, and under this the Trump administration imposed a 25\% tariff on steel articles. However, per the Korea-U.S. Free Trade Agreement implemented on January 1, 2019, South Korea is exempt from these tariffs, but has a 70\% quota on steel exports as an average of total exports by mass over the previous three years (Lester, Manak, and Kim 2019). Essentially, steel prices and tariffs are somewhat volatile and may impact the choice of domestic or international supply chains, although this likely depends on the specific project and the policy conditions at the time of financial close.

In summary, it is likely that there are some cost advantages to importing components for offshore wind projects; however, cost is not the only factor that impacts supply chain choices. Announced fixed-bottom offshore wind projects in the United States have made substantial local content commitments as part of their offtake agreements, and significant portions of the throughput in the developing Asian supply chains are allocated to local projects. As a result, offshore wind projects in the $\mathrm{O}^{\prime}$ ahu region could conceivably draw from a supply chains in the mainland U.S. or South Korea. These manufacturing activities would not contribute to local content requirements on $\mathrm{O}^{\text {' }}$ ahu as the fabrication of the major components would not take place on the island, although it is possible that final assembly could take place at $\mathrm{KBPH}$ to involve a local workforce. Without a more detailed analysis, there is not sufficient information available to assume an international supply chain, and so in this study we assume that major project components are manufactured domestically; however, we do add an additional cost to transport these components to Hawai 'i from the U.S. West Coast (as described in Section 7.3.5) and conduct a sensitivity study to demonstrate the potential benefits of reduced substructure cost on LCOE in Section 8.5.2. Finally, it is critical to note that the assumption of a suitable floating wind supply chain on the U.S. mainland would require significant investment in infrastructure (e.g., manufacturing facilities, ports, and transport vessels) and workforce development to compete with the existing capabilities of the Korean shipyards that are already fabricating components for Southeast Asian offshore wind projects. Such a supply chain would take several years to develop. If the domestic manufacturing capabilities do not progress substantially in the next decade, it would become increasingly likely that many of the major project components would be sourced from Asia. 


\section{Cost Modeling Approach}

We use NREL's Offshore Regional Cost Analyzer (ORCA) model to evaluate the costs of potential floating wind projects at each grid point within the analysis domain. ORCA is a deterministic model that incorporates technology, finance, operational, and energy production models to calculate LCOE (Beiter et al. 2016). Much of the methodology follows the approach taken in recent floating wind cost assessments for Oregon (Musial et al. 2019a) and California (Beiter et al. 2020). Musial et al. (2019a) defined Study Areas along the Oregon coast to provide a more detailed analysis of costs and infrastructure requirements for each site. The report also outlined the potential differences in costs between pilot-scale and commercial-scale projects, showing that the LCOE is around three times lower for a 600-MW project relative to a 24-MW project. In a study of offshore wind off the California coast, Beiter et al. (2020) refined the ORCA methodology to introduce a new wind resource data set, wind turbine models, CapEx projections, and data visualization techniques. In this study, we build upon the work conducted by Musial et al. (2019a) and Beiter et al. (2020) to use complementary NREL cost models to develop customized scaling factors to address the remote location and transmission constraints. Table 4 shows the modeling tools used to inform different cost components brought together with ORCA to compute LCOE. In this section we describe the model and the customized assumptions used to represent the $\mathrm{O}^{\prime}$ ahu analysis domain.

Table 4. Modeling tools informing cost analysis

\begin{tabular}{lll}
\hline Cost Component & Model & Source \\
\hline Wind Resource Data & Modeled with WRF & Optis et al. 2020 \\
Gross Capacity Factor, Wake Loss & FLORIS & NREL 2021b \\
Additional Transportation Costs & ORBIT & Nunemaker et al. 2020 \\
Export Cable Customization & ORBIT & Nunemaker et al. 2020 \\
CapEx, OpEx, LCOE & ORCA & Beiter et al. 2016 \\
\hline
\end{tabular}

\subsection{Global Floating Wind Costs}

Floating offshore wind remains a nascent industry, with only pre-commercial projects installed worldwide. As a result, no commercial-scale project cost data exist that can be used to understand the potential costs of offshore wind in $\mathrm{O}^{\prime}$ ahu. We incorporate several modeling techniques to estimate the costs of commercial-scale (600-MW) projects that become commercially operational between 2019 and 2032. This implicitly assumes that sufficiently mature supply chains, regulatory environments, and public acceptance exist throughout the time domain; although the industry has not yet achieved this level of readiness, this approach allows project costs to be compared on a like-for-like basis, which isolates the impact of technological advancement and progression along the learning curve on commercialscale projects. In reality, no commercial-scale offshore wind project could be built in the $\mathrm{O}$ 'ahu region in the early or mid 2020s as the BOEM permitting and site assessment activities can take nearly a decade from the time a lease area is awarded to a project developer (BOEM 2020). As no lease areas have yet been awarded in Hawai ' $\mathrm{i}$, it is likely that offshore wind would not be built until after 2030. If offshore wind is expected to meaningfully contribute to the HCEI goals, then it will be important to initiate the regulatory and development activities soon in order for these projects to be feasible by the early 2030 s.

We present LCOE beginning in 2019 to demonstrate the trajectory of floating offshore wind costs leading up to realistic installation dates for a project that could be built in the waters surrounding $\mathrm{O}^{\prime}$ ahu as technological innovations (such as larger turbines) and supply chain maturity are realized. We constrain the end of the time domain to 2032 as technology and deployment projections beyond these dates become increasingly uncertain. For context, a compilation of global analyst projections for floating wind costs is shown in Figure 17. These projections demonstrate a wide range of costs between $\$ 100-\$ 175 / \mathrm{MWh}$ for projects that could be installed today. These projections mostly converge to costs around $\$ 60 / \mathrm{MWh}-\$ 75 / \mathrm{MWh}$ in 2032. A comparison of offshore wind costs with other energy sources, including fossil fuels such as coal and natural gas, is available through NREL (2021a) or Lazard (2020), although care must be taken when comparing LCOE between different analyses as the underlying assumptions may not be treated consistently. 


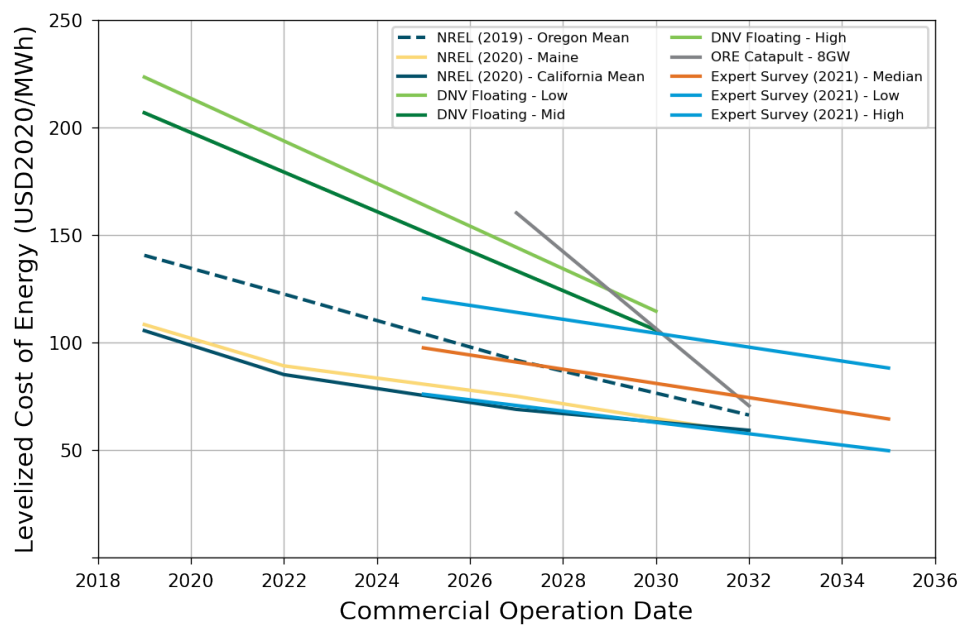

Figure 17. Global LCOE estimates of floating wind technology (Musial et al. 2021).

\subsection{Offshore Regional Cost Analyzer}

ORCA is a cost model that was developed by NREL for national and regional studies of offshore wind cost trends (Beiter et al. 2016; Beiter et al. 2020; Musial et al. 2019a; Musial, Beiter, and Nunemaker 2020). As a spatial analysis tool, it is designed to run quickly for a large number of sites. In order to do so, it is built on parametric cost curves for technological (e.g., turbine rating or substructure type), geospatial (e.g., wind speed and wave height), and financial parameters (e.g., debt-to-equity ratio and cost of capital). ORCA aggregates the results of these cost curves to calculate LCOE at each location within the analysis domain using Equation 7.1 from Short, Packey, and Holt (1995):

$$
\begin{aligned}
L C O E & =\frac{F C R \times C_{C a p E x}+C_{\mathrm{OpEx}}}{A E P_{\text {net }}}, \\
& =\frac{F C R\left(C_{\text {Turbine }}+C_{\mathrm{BOS}}\right)+C_{\mathrm{OpEx}}}{A E P_{\text {net }}},
\end{aligned}
$$

where $L C O E$ is the levelized cost of energy ( $\$ / \mathrm{MWh}), F C R$ is the fixed charge rate that must be collected annually (\%/year), $C_{\mathrm{CapEx}}$ are the total capital expenditures $(\$ / \mathrm{kW}), C_{\text {Turbine }}$ are the turbine capital expenditures $(\$ / \mathrm{kW}), C_{\mathrm{BOS}}$ are the balance of system capital expenditures $(\$ / \mathrm{kW}), C_{\mathrm{OpEx}}$ are the operational and maintenance expenditures $(\$ / \mathrm{kW}$ year), and $A E P_{n e t}$ is the net average annual energy production (MWh/year).

LCOE measures the lifecycle costs and energy production of an offshore wind project, including the costs required to design and develop the project; secure permitting; fabricate, procure, and install components; cover financing payments; and operate and maintain the project after commissioning. The total costs are scaled by the average annual energy production of the project, which account for the site-specific wind resource as well as technical, environmental, and availability losses. LCOE can be interpreted in a similar manner to net present value, in which future costs are discounted to a baseline year, although it encompasses energy production as well as capital and operational expenditures. LCOE does not consider the revenue streams available to a project, and we report the unsubsidized LCOE which does not account for tax credits available to project developers; as a result, LCOE can not be directly compared with electricity prices (Beiter et al. 2019). It is possible to use LCOE to compare different generation technologies (see, for example, Lazard (2020) or NREL (2021a)), but care must be taken to standardize the approach and assumptions.

Each of the terms in Equation 7.1 has multiple subcomponents; for example, the balance-of-system (BOS) costs include the procurement and installation costs for the floating platform, the mooring and anchoring system, and the electric cables. The underlying components of each term are modeled using a combination of spatially dependent, spatially independent, and cost multiplier approaches. Spatially dependent variables have costs that change from site to site; for example, installation and maintenance costs vary based on the distance from a project to the closest port and 
energy production varies with the local wind resource. Spatially independent variables are held constant throughout the analysis domain. These parameters include the procurement cost of the turbines, the auction fees required to obtain site control, and the financial assumptions for the projects. Finally, variables modeled using cost multipliers are assessed as a function of other project costs; for example, project management, construction insurance, contingency, and decommissioning costs are expressed as a percentage of overall project CapEx to reflect the impact of the scale and complexity of a specific project. These cost equations and assumptions were developed using a combination of bottom-up modeling tools, available empirical data for pre-commercial floating projects, and industry feedback and review. These equations are regularly updated to remain current with the state of the industry. A more detailed description of the underlying cost and performance equations used in ORCA is provided in Beiter et al. (2016), and a summary of the different types of equations is provided in Table 5. An input-output flow diagram for ORCA is provided in Figure 18.

Table 5. Summary of ORCA modeling approaches for different cost and performance terms.

\begin{tabular}{|c|c|c|c|}
\hline Item & Cost category & Modeling approach & Description \\
\hline Turbine & $C_{\text {CapEx }}$ & Spatially independent & Wind turbine \\
\hline Support structure & $C_{B O S}$ & Spatially dependent & $\begin{array}{l}\text { Floating platform, mooring lines, } \\
\text { anchors }\end{array}$ \\
\hline $\begin{array}{l}\text { Electrical infrastruc- } \\
\text { ture }\end{array}$ & $C_{B O S}$ & Spatially dependent & $\begin{array}{l}\text { Array and export cables, offshore } \\
\text { substation, onshore grid connec- } \\
\text { tion }\end{array}$ \\
\hline Installation & $C_{B O S}$ & Spatially dependent & Installation of all components \\
\hline Soft costs & $C_{B O S}$ & $\begin{array}{l}\text { Spatially independent } \\
\text { Cost multipliers }\end{array}$ & $\begin{array}{l}\text { Engineering, management, devel- } \\
\text { opment, insurance, decommission- } \\
\text { ing bond, contingencies }\end{array}$ \\
\hline Operations & $C_{O p E x}$ & Spatially independent & $\begin{array}{l}\text { Fixed annual costs (administration, } \\
\text { insurance, facility rental) }\end{array}$ \\
\hline Maintenance & $C_{O p E x}$ & Spatially dependent & $\begin{array}{l}\text { Variable annual costs (spare parts, } \\
\text { vessel charter fees) }\end{array}$ \\
\hline Gross capacity factor & $A E P_{\text {net }}$ & Spatially dependent & $\begin{array}{l}\text { Ratio of the actual wind power } \\
\text { plant energy production (no losses) } \\
\text { to the nameplate capacity }\end{array}$ \\
\hline Net capacity factor & $A E P_{\text {net }}$ & Spatially dependent & $\begin{array}{l}\text { Ratio of the actual wind power } \\
\text { plant energy production (including } \\
\text { wake, electrical, availability, and } \\
\text { other losses) to the nameplate } \\
\text { capacity }\end{array}$ \\
\hline $\begin{array}{l}\text { Weighted-average cost } \\
\text { of capital (WACC) }\end{array}$ & $F C R$ & Spatially independent & $\begin{array}{l}\text { The average after-tax return re- } \\
\text { quired by equity and debt investors }\end{array}$ \\
\hline Fixed-charge rate & $F C R$ & Spatially independent & $\begin{array}{l}\text { A factor that approximates the } \\
\text { average annual payment required } \\
\text { to cover the carrying charges on } \\
\text { investment and tax obligations. }\end{array}$ \\
\hline $\begin{array}{l}\text { Levelized cost of } \\
\text { energy }\end{array}$ & $L C O E$ & Spatially dependent & $\begin{array}{l}\text { The total project cost per } \\
\text { megawatt-hour of lifetime electric- } \\
\text { ity generation }\end{array}$ \\
\hline
\end{tabular}

We conduct the analysis throughout the entire $\mathrm{O}^{\prime}$ ahu analysis domain in order to provide comparative costs between the different parts of the region. We provide more detailed cost breakdowns for the three Study Areas to better indicate the geographic diversity of different cost components. Some of the cost categories outlined in Table 5 are modeled using the standard approaches within the ORCA model, whereas others are directly tailored to the conditions in O'ahu. 


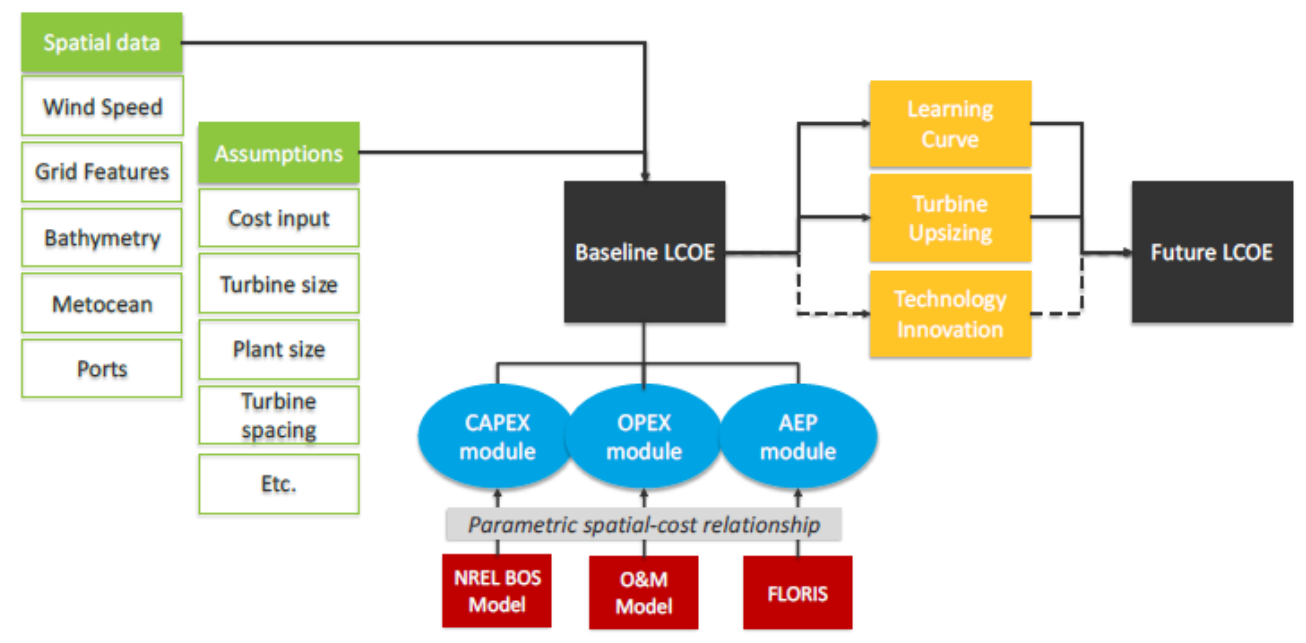

Figure 18. ORCA input-output flow diagram.

\subsection{Modeling Assumptions}

\subsubsection{Turbine Ratings and Costs}

As described in Section 4.1.1, offshore wind turbines have grown significantly in recent years. Higher nameplate capacities allow a developer to use fewer wind turbines to achieve a target wind power plant capacity, which results in in lower per-kilowatt cost of energy. Shields et al. (2021) conducted a detailed analysis into how favorable installation, operation, and component scaling relationships decrease LCOE as turbine size increases. ORCA models capital costs proportionally to the number of installed wind turbines, so as the rating is increased (and the number of required wind turbines for a 600-MW wind power plant decreases), cost savings are explicitly measured. We assume wind turbine ratings of $8 \mathrm{MW}, 10 \mathrm{MW}, 12 \mathrm{MW}$, and $15 \mathrm{MW}$ for projects with commercial operation dates in 2019, 2022, 2027, and 2032, respectively.

The procurement costs of offshore wind turbines have been reasonably constant over time on a per-kilowatt basis. ORCA assumes a standard rate of $\$ 1,300 / \mathrm{kW}$. For this study, we add a transportation cost premium to transport turbine components from the mainland United States, as well as a 10\% cost premium to account for additional backup systems due to stakeholder concerns about hurricane resiliency as described in Section 4.1.3. This increase the cost per wind turbine to $\$ 1,515 / \mathrm{kW}$, or a $\$ 2,150,000$ increase for a $10-\mathrm{MW}$ wind turbine relative to the standard cost.

\subsubsection{Lease Price}

We increased the assumed lease/site auction price in ORCA from $\$ 50$ million to $\$ 100$ million to match the default assumption in ORBIT (Nunemaker et al. 2020). The auction price is the amount paid by the developer through the federal leasing process to obtain site control, and the increase reflects higher prices paid in more recent auctions on the U.S. East Coast (Musial et al. 2019b). It is lower than the record-setting $\$ 135$ million paid for lease areas in Massachusetts, but there is uncertainty about whether floating offshore wind leases will initially command the same pricing as fixed-bottom offshore wind leases. The lease price is included in the soft costs within the balance-of-system $\left(C_{B O S}\right)$ in Equation 7.1.

\subsubsection{Floating Platform and Support Structure Costs}

The floating platform and support structure (mooring lines and anchors) cost equations in ORCA are based on parametric fits to bottom-up cost equations presented in Maness, Maples, and Smith (2017). The equations model the procurement costs of these components and are parameterized in terms of geospatial (water depth) and technology (wind turbine rating) conditions. As a result, these costs vary both spatially and temporally throughout the analysis. The ORCA cost equations are calibrated against cost data from floating wind developers and industry literature in 
order to provide reasonable estimates of component costs; however, it is important to recall that the nascent state of the floating wind industry introduces significant uncertainty into the costs of fully commercialized components. As the industry evolves, it will be important to update the cost estimates to obtain a more specific cost estimate for floating wind in the $\mathrm{O}^{\prime}$ ahu region. Floating platform and support structure costs are included in the balance-of-system $\left(C_{B O S}\right)$ in Equation 7.1.

\subsubsection{Electrical Infrastructure Costs}

Similar to the floating platform and support structure cost models in ORCA, electrical infrastructure (including the procurement and installation of the array cables, export cables, transformer equipment, ancillary systems, and offshore substation, along with construction costs required to connect to the onshore grid) are modeled as parametric curve fits based on bottom-up models from Maness, Maples, and Smith (2017). Unlike the floating platform and support structure, ORCA bundles the procurement and installation costs for electrical infrastructure into the same cost equations as these components are often contracted as an engineering, procurement, construction, and installation agreement with a single vendor for offshore wind projects. These cost equations primarily scale with water depth, distance to cable landfall, and plant capacity and are included in the balance-of-system $\left(C_{B O S}\right)$ in Equation 7.1. As floating offshore wind turbines are modeled, the export cable costs include an allowance for dynamic cables between the offshore substation and seabed. ORCA also models the costs to build onshore transmission to connect from the point of cable landfall to the substation as a function of the distance between the two points and the capacity of the offshore wind project. As this is an empirically-derived model, it does not fully capture the specifics of grid connection on $\mathrm{O}^{\prime}$ ahu. More detailed studies are required to understand the exact costs required to upgrade the substation to step down from 220 $\mathrm{kV}$ to the $\mathrm{O}^{\prime}$ ahu transmission voltage of $138 \mathrm{kV}$, the permitting and construction needed to run 5 upland circuits from cable landfall to the point of interconnection, tradeoffs between overhead and buried cables, and the best approach to horizontal directional drilling to bring the cables ashore. The complexities of the $\mathrm{O}$ 'ahu terrain and grid infrastructure may add additional costs to an offshore wind project that are not considered in this study (although it is worth noting that bulk transmission upgrades are typically not the responsibility of an offshore wind developer and are therefore not included as part of project LCOE).

The standard ORCA equations assume that the export cables are rated at $220 \mathrm{kV}$ for distances less than $115 \mathrm{~km}$ from shore (which covers the entire $\mathrm{O}^{\prime}$ ahu analysis domain). For the standard cable specifications, this corresponds to a power rating of around $300 \mathrm{MW}$ (Shields et al. 2021). Hawaiian Electric (HE) has mandated that no individual connections contribute more than $135 \mathrm{MW}$ in order to improve grid resiliency in the event of a natural disaster taking out one or more generation options. This would require an offshore wind project to use more export cables with smaller power ratings. We used NREL's Offshore Renewables Balance-of-system and Installation Tool (ORBIT) to determine how this would cause export system costs to scale (Nunemaker et al. 2020). The lower capacity export cables are cheaper than the 300-MW rated baseline; however, the 135-MW constraint requires 5 export cables for a 600-MW wind power plant instead of 2 higher capacity cables. Despite the lower unit costs, the increased number of

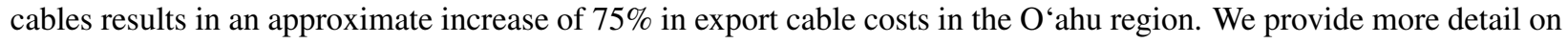
how this scaling factor was developed in Appendix B. Further investigation into the design of the floating substation would also be necessary, as the requirement for 5 export cables will increase the number of power transformers and will increase the size of the overall substation. As no floating offshore wind substations have currently been designed, we are not able to explicitly model these costs as part of this study, which may increase the overall LCOE.

As described in Section 6.2, we select the substations at Ko'olau and Iwilei as potential interconnection locations. For each point in the analysis domain, ORCA identifies the closest interconnection point and selects it for the specific project. The export cable connects to land at the point that minimizes the onshore distance to the interconnection point. As no interconnection points exist on the north side of the island, this results in higher export system costs, as these projects have to route a subsea cable around the island before coming ashore near Ko'olau or Iwilei. In addition to this baseline scenario, we conduct a sensitivity analysis in which the Kahe power plant on the west side of the island is retired, and offshore wind projects are able to connect to the grid here. 


\subsubsection{Transportation, Installation, Operations, and Maintenance Costs}

As we describe in Section 6, offshore wind projects in Hawai'i will likely rely on supply chains developed in the mainland United States or Asia, with major components or subcomponents being fabricated elsewhere and shipped to the construction port for assembly and installation. ORCA models these port, staging, logistics, and transport (PSLT) costs for each major component, as well as the specific installation costs for each component, using parametric cost equations that consider the water depth and distance to site that contribute to the balance-of-system $\left(C_{B O S}\right)$ in Equation 7.1. The model also applies a correction factor to account for weather downtime during installation. We do not consider differences in labor or fuel costs relative to the U.S. mainland as these parameters are not resolved in ORCA.

The underlying PSLT equations are unchanged from previous NREL analyses on the costs of floating wind in California and Oregon (Beiter et al. 2020; Musial et al. 2019a); however, offshore wind projects in Hawai' $i$ would require additional transportation costs to shuttle components from a supply chain on the U.S. West Coast across the Pacific. We again used ORBIT to estimate the cost impact of this additional transportation requirement. We specified a nominal barge type that could be used to transport turbines, substructure components, and carousels of cable from a port in California to the Kalealoa/Barber's Point Terminal on O'ahu. We also used ORBIT's component-specific representations to estimate the footprint that each major component would require when placed on the barge (barge parameters in Table 6). The parameters represent the largest barge for which we have reliable day rate information, though larger barges would likely be needed given that a barge with $6,000 \mathrm{~m}^{2}$ was used to install 8.4-MW turbines for the WindFloat Atlantic project (Boskalis 2019). This would likely add to the vessel day rate and increase the additional transportation costs, especially in future years as components sizes grow with the turbines.

Our simplified analysis identified that a barge could carry 5 wind turbines, 1 set of substructure components, or 3 cable carousels per 60-day round trip across the Pacific and back to California. The 60-day round trip includes an additional day each for loading and unloading the vessel, leading to a cost per round trip of approximately $\$ 1.8$ million before amortizing the vessel mobilization costs over the number of trips needed for each major component type (turbines, substructures, array cables, export cables, and offshore substations). We include this cost to transport the requisite number of wind turbines, semisubmersibles, and cable carousels to O'ahu for each modeled scenario. We apply this factor to the procurement costs of the specific components instead of the PSLT cost category in ORCA.

Table 6. Transportation barge specifications and required area per component.

\begin{tabular}{cc}
\hline \multicolumn{2}{c}{ Vessel parameters } \\
\hline Maximum cargo, $\mathrm{t}$ & 12,000 \\
Maximum deck space, $\mathrm{m}^{2}$ & 3,700 \\
Transit speed, $\mathrm{km} / \mathrm{hr}$ & 6 \\
Charter rate, $\$$ day & 30,000 \\
Mobilization cost, $\$$ & $5,000,000$ \\
\hline \multicolumn{2}{c}{ Component sizes } \\
\hline Substructure footprint, $\mathrm{m}^{2}$ & 3,500 \\
Turbine component footprint, $\mathrm{m}^{2}$ & 689 \\
Cable carousel mass, $\mathrm{t}$ & 4,000 \\
Cable carousel diameter, $\mathrm{m}$ & 30 \\
Cable carousel area, $\mathrm{m}^{2}$ & 707 \\
\hline
\end{tabular}

Note that this estimate assumes the availability of a Jones-Act-compliant barge on the U.S. West Coast. The Jones Act is a law that requires that merchandise and people transported between points in the United States be carried by U.S. built, flagged, and owned vessels. Transporting offshore wind components between the U.S. Mainland and the island of $\mathrm{O}^{\prime}$ ahu would require Jones-Act-compliant vessels. The number of Jones-Act-compliant barges capable of transporting large offshore wind components is an outstanding question, and the lack of vessel availability would present a significant bottleneck to offshore wind logistics.

Finally, ORCA models the OpEx required to maintain an operational wind power plant after commissioning. This 
includes the costs for both regular and unscheduled maintenance. In reality, maintenance costs are likely to increase later in a project's life after wear and tear on equipment. In ORCA, OpEx are amortized over the lifetime of a project such that there is a constant OpEx cost each year in terms of $\$ / \mathrm{kW}$-year. In ORCA, operations costs are constant for a given project size, while maintenance costs are parameterized as a function of distance to the service port and average significant wave height.

\subsubsection{Wind Power Plant Size and Economies of Scale}

We assume a 600-MW wind power plant capacity as described in Section 5.2. This is a balance between the size of the average fixed-bottom wind power plant installed in 2019 (400 MW) and the larger projects that have currently been proposed in the United States (Shields et al. 2021; Musial et al. 2021). Larger projects are expected to reduce costs as they benefit from economies of scale, which distribute fixed costs (such as port infrastructure, export systems, and project management) over a larger number of assets (Shields et al. 2021). Although the results in this study have only considered a 600-MW wind power plant, we provided additional scaling factors to HE to understand how capital costs may scale for larger or smaller projects to facilitate capacity expansion modeling for variable sized projects. The scaling factors for individual cost categories (including procurement and installation costs) and the total project CapEx are shown in Figure 19. We generated these scaling factors using ORBIT to model wind power plant capacities between $200 \mathrm{MW}$ and $800 \mathrm{MW}$ and following the approach taken by Shields et al. (2021). The results show that a 200-MW project would be approximately $15 \%$ more expensive than the baseline 600-MW project, and that the cost reductions exhibit diminishing returns as project capacity increases to $800 \mathrm{MW}$. These results are likely conservative as ORBIT does not explicitly consider additional benefits due to bulk pricing for larger component orders, more efficient supply chains for larger projects, or the specific distribution of management costs.
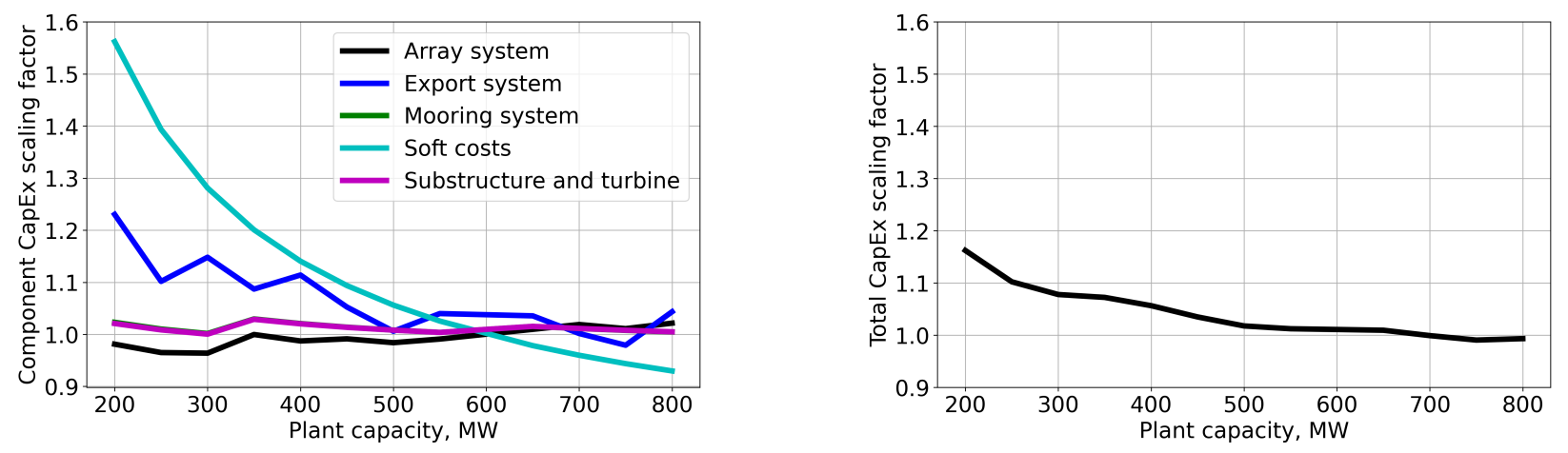

Figure 19. Expected economies of scale for individual cost categories (left) and overall CapEx (right) for increasing wind power plant capacities.

\subsubsection{Annual Energy Production}

Annual Energy Production (AEP) is a primary driver in determining LCOE. First, the gross AEP is determined from the wind resource data over the analysis domain and the wind turbine power curves for each COD year. This represents the theoretical energy production without losses. Then, a series of energy loss calculations are made to determine the net AEP, or the energy delivered to the grid from the modeled wind farm. The gross and net energy production values are expressed in terms of Gross Capacity Factor (GCF) and Net Capacity Factor (NCF). These parameters can be viewed as the percentage of annual energy that the wind power plant actually generates relative to a scenario in which it operates at full capacity for the entire year (without and with losses, respectively). We used FLORIS to estimate both GCF and wake losses in floating wind farms offshore O'ahu (NREL 2021b). Other plant losses computed with ORCA (Beiter et al. 2016) are combined with the wake losses and deducted from the GCF to yield the NCF, which can be used to scale the nameplate capacity of the plant to calculate net AEP.

While a detailed uncertainty analysis is outside the scope of this study, it should be noted that capacity factor estimates are uncertain. This is true of both estimating the wind resource and modeling the wind power plant (Murcia 2017). 
Developers typically conduct pre-construction wind resource measurement campaigns, and the industry is actively working to reduce this uncertainty as it directly impacts financial risk of wind energy projects (Lee and Fields 2021).

\subsubsection{Gross Capacity Factor}

We calculate GCF with FLORIS across the analysis domain for each COD year using the power curves presented in Section 4 and the hub height wind resource data discussed in Section 3. Costs are calculated on a grid with a resolution of $1.1 \mathrm{~km}$, but the wind resource is modeled on a $2-\mathrm{km}$ grid. Wind data is therefore interpolated linearly between grid points at a given height. The GCF allows for a comparison of wind resource between different wind energy sites and plant sizes. The GCF and NCF results for this study are presented together in Section 8.

\subsubsection{Energy Losses}

The net AEP represents the predicted AEP delivered to the land-based grid. The losses described in the following subsections are deducted from the gross AEP to yield the net AEP and contribute to the $A E P_{\text {net }}$ category in Equation 7.1. Note that ORCA combines the loss categories like efficiencies of different stages in a series of processes, computed as:

$$
L_{\text {total }}=1-\left[\left(1-L_{1}\right) \times\left(1-L_{2}\right) \ldots \times\left(1-L_{n}\right)\right],
$$

where $L_{\text {total }}$ represents the total loss, and $L_{1}, L_{2}$, and $L_{n}$ are the percent losses attributed to each loss source. This differs from direct linear summation of the loss categories. Similarly, the total losses represent the percentage of the GCF that is lost before delivery to the grid, whereas the GCF and NCF are expressed relative to the energy if the power plant was always operating at full capacity. Each loss category is explained in greater detail below.

\section{Wake Losses}

A wake forms behind a turbine as it extracts momentum from the wind. Wind turbine wakes are regions of reduced wind speed and increased turbulence. For a turbine operating in the wake of another, this means lower power production and increased fatigue loads. As the wake propagates downstream, the kinetic energy of the wake is replenished by turbulent mixing with the free-stream layers outside the wake boundaries (and above a wind plant). Eventually at some distance downstream, the wind speed recovers to the point where it is no longer distinguishable from the free-stream wind speed. Wake losses represent the energy lost as a result of the decreased wind speeds in the turbine wakes interacting with downstream turbines. The wake loss $L_{\text {wake }}$ is computed as:

$$
L_{\text {wake }}=\frac{A E P_{\text {gross }}-A E P_{\text {wakes }}}{A E P_{\text {gross }}},
$$

where $A E P_{\text {gross }}$ represents the gross $\mathrm{AEP}$, and $A E P_{\text {wakes }}$ represents the $\mathrm{AEP}$ after wake losses are considered. Both are computed with FLORIS. The magnitude of the wake loss depends primarily on the turbine thrust curve, the wind speed and direction distributions, and the plant layout. Although they may be significant, wake effects from other wind plants or future wind energy development are not considered, and neither are deep-array effects or wind plant blockage effects, such as those discussed in Bleeg et al. 2018. A public engineering wake model that couples wakes and wind farm blockage effects is under development, but is still in the initial validation stage (Nygaard et al. 2020). These topics serve as possible points of future improvements in the cost modeling methodology.

\section{Environmental Losses}

The environmental losses include a standard value of $1 \%$ for energy lost as a result of icing or blade soiling. In Hawai $i$, ice accumulations on blades would be rare-to-nonexistent, but soiling or blade degradation could reduce aerodynamic performance. These default environmental losses also include $0.5 \%$ for low-/high-temperature shutdowns and $0.1 \%$ for lightning losses. Effects from building development or tree growth are ignored offshore. These assumptions for generic environmental losses should be reassessed if actual energy yield assessments are being made but are considered conservative for offshore sites in Hawai' $i$ where icing, soiling, and lightning conditions may be more benign. These losses are the same values as those used in Beiter et al. (2020). 


\section{Technical Losses}

A $1 \%$ loss is assumed because of hysteresis, $0.1 \%$ for onboard equipment (parasitic load), and $0.1 \%$ for rotor misalignment loss across all turbines. Hysteresis losses in a wind turbine arise to reduce loads on the turbine when the mean wind speed (often a 10-minute moving average) is fluctuating around the cut-out wind speed. To prevent the turbine from rapidly starting and stopping in this high-wind situation (and the induced loads), the control strategy may shut down when the mean wind speed exceeds the cut-out speed. It will then wait until the mean wind speed falls below a lower threshold than the cut-out speed to resume production. The lost energy from the time when the turbine has shut down but has not resumed operation is the hysteresis loss. While a rotor misalignment loss is included, the magnitude of this loss for a floating offshore wind turbine will depend on the full system dynamics and controls strategy for the selected turbine.

\section{Electrical Losses}

Electrical losses are computed in ORCA for the export system as a function of the distance from the site to the cable landfall and the water depth (Beiter et al. 2016). These losses do not consider the electrical losses in the array cables or power electronics, which provides an opportunity for future model improvement. Inclusion of the collection system electrical losses would likely increase the total losses and decrease the NCF slightly, leading to a small increase in LCOE.

\section{Availability Losses}

The availability losses use an assumption of $95 \%$ availability, which is held constant over time. This is a conservative choice that is used to maintain consistency with the analysis of offshore wind in California conducted by Beiter et al. (2020). In reality, the more benign metocean conditions (manifested by lower significant wave heights as displayed in Table 1) would likely lead to higher availability in the $\mathrm{O}$ 'ahu region. The availability losses $\left(L_{\text {avail }}\right)$ are calculated from Equation 7.4:

$$
L_{\text {avail }}=1-\text { availability }
$$

and represent a blanket loss of 5\% resulting from turbine, plant system, and grid downtime. Note that in practice, the availability has a strong dependency on the meteorological ocean (metocean) conditions, which vary across the analysis domain. In winter there is a greater frequency of high wind speeds and large significant wave heights, impacting the ability of maintenance vessels to access the turbines for repairs and leading to lost energy production. Better accounting for the impact of the spatially varying metocean conditions on availability represents a potential future improvement to the ORCA loss module.

Availability is also impacted by the supply of spare parts and vessels required to conduct repairs. The $95 \%$ availability taken from Beiter et al. (2020) is predicated on the assumption that sufficient resources exist in California to minimize downtime for major repairs. Using this same value for $\mathrm{O}^{\text {‘ }} \mathrm{ahu}$ assumes that sufficient local infrastructure can be developed to support OpEx activities without relying on importing components or vessels from the U.S. mainland. This represents an opportunity for decision makers on $\mathrm{O}^{`}$ ahu to invest in appropriate port facilities, operations vessels, and workforce training to localize operations activities and reduce costs of offshore wind projects. Without these upfront investments, availability may be lower, and OpEx costs may be higher than the ones we report here.

\section{Performance Improvements Over Time}

To account for likely improvements in wind turbine technology that reduce losses over time, a total loss reduction is applied based on the COD year. The total magnitude of these loss reductions by COD 2032 is $2.74 \%$ - the same as those applied in the cost analysis for California (Beiter et al. 2020). Similarly, a GCF increase of 5.03\% is applied over time to account for increases in yield as a result of innovations improving the ability of the wind turbine to extract energy from the wind. The magnitudes of the loss reduction and GCF increase were both derived from (Hundleby et al. 2017). 


\subsubsection{Financial Parameters}

We followed the approach taken by Beiter et al. (2020) to determine finance terms that are consistent with the current financial structures of commercial-scale, fixed-bottom offshore wind projects. We use a nominal Weighted-average cost of capital (WACC) of 5.4\% and a subsequent nominal fixed change rate (FCR) of 7.2\% derived from literature and validated by industry reviewers (Guillet 2018). We assume that these values do not change between 2019 and 2032. Floating wind projects have the potential to achieve the same financing terms as the more mature fixed-bottom industry provided that they exhibit (Weber 2020):

- Experienced project sponsors and a developed supply chain

- Low country sovereign risk

- Technological solutions validated through prototypes and due diligence

- Minimal revenue risk

- Strong insurance coverage and contingency budgets

- Strong contract management and reduced interface risk.

While financing terms may evolve with maturity of floating offshore wind, using a constant value of FCR reflects both our choice to model a commercial-scale floating project as well as uncertainty about future interest rates. We include FCR as a parameter in the input sensitivity in Figure 29 to illustrate the impact of changes in FCR on LCOE. The financing assumptions in ORCA are listed in Table 7; a more detailed description of each term is provided in Beiter et al. (2016). We do not consider any benefits from the Investment Tax Credit as part of this study.

Table 7. Commercial-scale floating offshore wind financing assumptions.

\begin{tabular}{cc}
\hline Parameter & Value \\
\hline Nominal after-tax FCR, \% & 7.2 \\
Real after-tax FCR, \% & 5.3 \\
Nominal after-tax WACC, \% & 5.4 \\
Real after-tax WACC, \% & 2.9 \\
Capital recovery period, years & 30 \\
Share of debt, \% & 75 \\
Nominal debt rate, \% & 4.4 \\
Nominal return on equity, \% & 12.0 \\
Tax rate, \% & 26 \\
Inflation, \% & 2.5 \\
Nominal after-tax capital recovery factor, \% & 6.8 \\
Real after-tax capital recovery factor, \% & 6.0 \\
Project finance factor, $\%$ & 105 \\
Depreciation basis, \% & 100 \\
Depreciation schedule & 5-year MACRS \\
Present value of depreciation, $\%$ & 86 \\
\hline
\end{tabular}

\subsubsection{Cost Projections and Floating Wind Learning Curves}

We anticipate that the floating wind industry will achieve significant cost reductions from three major sources as it matures over the next decade. The first source is from experiential learning within the industry, as practitioners develop improved methods and supply chains for constructing floating wind projects. Second, larger turbine models will enable cost reductions through economies of size; the approach taken to model these impacts in ORCA is outlined in Section 7.3.1. Finally, the continual introduction of technological innovations will achieve component level cost reductions and performance improvements that will positively impact LCOE. These cost reductions do not account for the advancement from pre-commercial demonstration projects to full commercial-scale projects as we only consider 
commercial-scale projects in this study; in other words, we assume that the substantial cost reductions between precommercial and commercial levels of development are already in place for projects with COD in 2019.

We assess the impact of experiential learning and supply chain maturity using a learning rate approach outlined in Beiter et al. (2020). We derive an experience curve from reported fixed-bottom offshore wind project CapEx data between 2015 and 2020 (Musial et al. 2021) using multivariate linear regression. This regression fit models the impact of global deployment on capital costs-specifically, the decrease in costs as a function of an increasing amount of installed project capacity. By controlling for variables such as turbine rating, project capacity, water depth, and installation country, we separate these effects from the relationship between project CapEx and deployed capacity. This method yields a learning rate of $7.5 \%$, which we attribute to learning by doing, learning by researching, improved supply chain and manufacturing efficiencies, and investment (Louwen and Subtil Lacerda 2019). As no empirical data exists for floating offshore project costs, we apply the fixed-bottom learning rate to floating projects as well. A more detailed description of the methodology is available in Beiter et al. (2020).

In order to apply the learning rate to the costs modeled in ORCA, we assume a global floating wind deployment trajectory that reaches 8,000 MW by 2030 (4C Offshore 2020). For every doubling in total installed capacity, a 7.5\% decrease in overall project CapEx is applied in ORCA. This results in progressively cheaper offshore wind projects relative to the baseline COD in 2019. The nature of the learning curve means that any additional deployment beyond the 8,000 MW level would result in additional cost reductions, although with diminishing returns as deployment continues to grow. An additional cost reduction due to turbine upsizing is also modeled explicitly in ORCA as the cost equations for individual units (such as wind turbines and substructures) are scaled by the total number of wind turbines in the wind power plant. As the multivariate regression used to derive the learning curve is controlled for wind turbine rating, the impacts of increased wind turbine size are not captured within the learning curve and so no double-counting of cost reduction potential takes place.

We apply an additional layer of cost reductions to individual components based on expert elicitations conducted by Valpy and English (2014) and Hundleby et al. (2017). These cost reductions formed the complete basis for previous NREL cost studies (Musial et al. 2019a), although the learning curve methodology has now superseded the component level CapEx reductions from Valpy and English (2014) and Hundleby et al. (2017). This is because these individual cost reductions are implicitly linked with the effects of supply chain growth and turbine upsizing, and are therefore eliminated from the cost projections to avoid double-counting. The expert-derived cost projections are still applied to OpEx and AEP parameters. The projected variation in CapEx, OpEx, and AEP from these multi-model approaches is provided in Figure 20, which shows a reduction in CapEx and OpEx costs coupled with an increase in AEP over time.

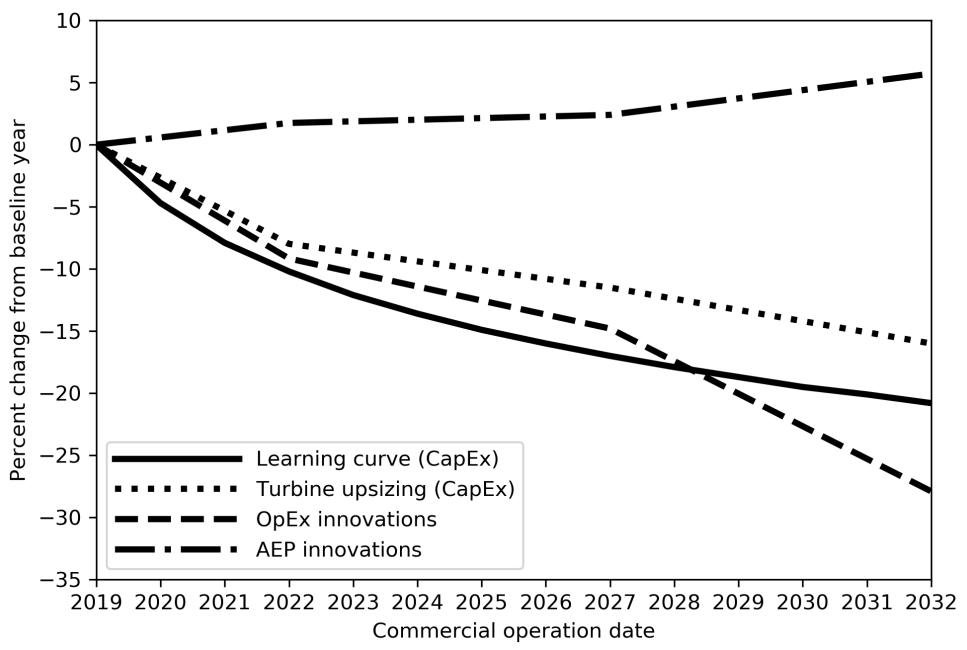

Figure 20. Modeled CapEx, OpEx, and AEP cost reductions from the baseline year. Changes in CapEx are the sum of learning curve and turbine upsizing effects, and changes in OpEx and AEP are derived from Valpy et al. (2017). 


\subsection{Analysis Sites}

We discretized the analysis domain shown in Figure 1 into a grid with a resolution of $1.1 \mathrm{~km} \times 1.1 \mathrm{~km}$ and ran ORCA at each grid intersection point, resulting in 5,057 total analysis sites within the domain. This is the highest resolution available in ORCA and a higher resolution than previous cost studies (e.g., Beiter et al. (2020)) as the $\mathrm{O}$ 'ahu analysis domain is relatively small, and the tighter grid spacing provides smoother cost distributions within the region. ORCA takes the geospatial conditions at each point and computes the LCOE of a 600-MW offshore wind power plant centered on that location, meaning that the actual spatial boundaries of a project built at each analysis site would overlap; however, as ORCA evaluates each site independently, this does not impact the cost calculations.

\subsection{Methodology}

We conduct the following procedure to evaluate floating wind costs in the $\mathrm{O}$ 'ahu region using ORCA:

1. Develop key technology and financial assumptions about current and future floating technology, including:

- Wind turbine rating, power curve, and geometry

- Plant size and turbine spacing

- Substructure type

- Cable voltage

- Financing parameters.

2. Identify appropriate construction and operation ports and grid interconnection points.

3. Collect relevant geospatial data, including:

- Wind speeds at hub height

- Metocean conditions

- Distance from each analysis site to port and grid features

- Bathymetry.

4. Calculate net energy production accounting for losses due to wake, electrical, environmental, and availability effects at each analysis site.

5. Run ORCA to estimate the baseline LCOE for a COD of 2019.

6. Generate a floating wind learning curve based on projected future global floating wind deployment levels.

7. Calculate future values of LCOE by applying learning curve effects, economies of size from wind turbine upsizing, and impacts of technological innovations to the 2019 baseline.

8. Generate heat maps showing the spatial variation in LCOE, CapEx, OpeX, and NCF throughout the analysis domain. 


\section{Results}

This section covers the cost results generated with the ORCA cost model using the assumptions and methodology described in previous sections. All costs are for 600-MW power plants and are presented in $\$ 2019$, unless otherwise indicated. We present cost and performance results as heat maps showing the spatial variation throughout the domain along with more detailed line plots and tables demonstrating the geographic differences between the three Study Areas and how these values change for different CODs. Heat maps for CapEx, OpEx, and NCF are presented for the baseline year, while the LCOE heat maps are presented for 2019 and 2032 to show the impact of the cost reduction trajectories

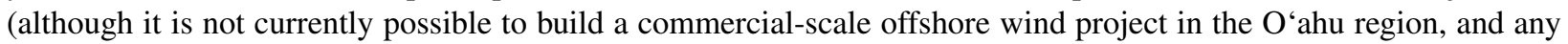
development would likely not take place until after 2030). A full page image of each map is available in Appendix C. We present several key sensitivities of the LCOE calculation to understand the impact of uncertainty or alternative assumptions on the results. Finally, we show a preliminary visualization of land-use tradeoffs between offshore wind and land-based solar projects. These final visualizations also depict the potential size of a 600-MW offshore wind project, which would occupy a relatively small portion of the Study Areas.

\subsection{Capital Expenditures}

Figure 21 shows how CapEx varies throughout the analysis domain. The costs increase with distance to shore due to to increased installation costs and longer export cables. This is particularly evident in the North Study Area, which has to interconnect at the Ko 'olau substation on the southeast corner of the island, requiring a subsea export cable to be buried around the north side of the island. The lowest capital costs in the region occur just south of Honolulu on the boundary of the South Study Area; although these locations may represent an opportunity for less capital-intensive projects, the proximity to the busy ports of Honolulu and Pearl Harbor, along with the coastal population, make it unlikely that an offshore wind project would be sited here. We project that average CapEx value in the domain decreases by approximately 34\% between 2019 and 2032, from 5,264 to 3,456 \$/kW.

The average costs over time for each of the Study Areas is shown in Figure 22. The proximity of the northern boundary of the $\mathrm{O}^{\prime}$ ahu South Study Area to the construction port and grid interconnection results in a lower average CapEx relative to the North or East Study Areas. As the same cost reduction drivers are applied to each Study Area, the trajectories are similar. The trends show significant cost reductions in the first half of the decade followed by slightly diminishing returns as the COD extends past 2030. This is consistent with the learning curve approach used to project costs. As little floating wind deployment has taken place globally at the time of this study, the industry is expected to learn and mature quickly as more commercial-scale projects are installed. After the easiest improvements to the supply chain, construction methodologies, and permitting requirements have been achieved, cost reductions become more incremental. This trend still results in a 34\% reduction in capital costs for offshore wind between 2019 and 2032.

A more detailed breakdown of the CapEx values computed in ORCA for each of the Study Areas is presented in Table 8. Several of the cost categories are the same between the different locations; for example, the wind turbine procurement costs are held constant throughout the analysis domain, and the substructure costs are parameterized in terms of turbine rating and are therefore also constant. Installation costs vary slightly between Study Areas as a function of distance to port, with the South Study Area achieving the lowest costs. The most significant difference between the locations is in the electrical infrastructure, which is driven by the export cable costs. The long distance to the available substations at Iwilei and Ko'olau penalizes the North Study Area and is the primary reason that it has the highest CapEx. Finally, the soft costs are either constant through the domain or are estimated using cost multipliers of project CapEx, leading to small variations between locations.

\subsection{Operational Expenditures}

The range of OpEx costs in the baseline year throughout the analysis domain is shown in Figure 23. These values span approximately $\$ 65 / \mathrm{kW}$-yr to $\$ 85 / \mathrm{kW}$-yr and show relatively little variance throughout the region, with slightly lower costs occurring for locations closer to the KBPH operations port. It is worth noting that the OpEx costs in the O'ahu region are significantly lower than those reported for California, which ranged from $\$ 71 / \mathrm{kW}$-yr to $\$ 140 / \mathrm{kW}$-yr for COD in 2019 Beiter et al. (2020). This is because all sites within the analysis domain are closer to the operations port than the more dispersed California coastline, and the metocean conditions are more benign in $\mathrm{O}^{`}$ ahu, with average 
Table 8. Spatially averaged 2019 CapEx line item values across the Study Areas, $\$ / k W$. Note: Values are rounded to the nearest $\$ / k W$.

\begin{tabular}{|l|l|l|l|}
\hline Line Item [values in \$/kW] & $\mathbf{O}^{`}$ 'ahu South & O'ahu North & O'ahu East \\
\hline Tower & 185 & 185 & 185 \\
\hline Rotor nacelle assembly & 1,138 & 1,138 & 1,138 \\
\hline Additional transport \& hurricane upgrade cost (turbine) & 191 & 191 & 191 \\
\hline Turbine supply & $\mathbf{1 , 5 1 5}$ & $\mathbf{1 , 5 1 5}$ & $\mathbf{1 , 5 1 5}$ \\
\hline Substructure & 1,260 & 1,260 & 1,260 \\
\hline Additional transport cost (substructure) & 234 & 234 & 234 \\
\hline Support structure & $\mathbf{1 , 4 9 4}$ & $\mathbf{1 , 4 9 4}$ & $\mathbf{1 , 4 9 4}$ \\
\hline Port, staging, logistics, and fixed costs & 45 & 45 & 45 \\
\hline Turbine installation & 80 & 88 & 87 \\
\hline Substructure installation & 39 & 48 & 42 \\
\hline Total installation & $\mathbf{1 6 4}$ & $\mathbf{1 8 1}$ & $\mathbf{1 7 4}$ \\
\hline Array cabling & 268 & 300 & 275 \\
\hline Export cable & 587 & 1,040 & 671 \\
\hline Onshore spur line & 1 & 4 & 30 \\
\hline Total electric system & $\mathbf{8 5 6}$ & $\mathbf{1 , 3 4 4}$ & $\mathbf{9 7 6}$ \\
\hline Development & 155 & 175 & 160 \\
\hline Lease price & 180 & 180 & 180 \\
\hline Project management & 81 & 91 & 83 \\
\hline Balance of system & $\mathbf{2 , 9 3 0}$ & $\mathbf{3 , 4 6 5}$ & $\mathbf{3 , 0 6 8}$ \\
\hline Insurance during construction & 51 & 57 & 53 \\
\hline Project completion & 51 & 57 & 53 \\
\hline Decommissioning & 21 & 23 & 22 \\
\hline Procurement contingency & 249 & 278 & 256 \\
\hline Installation contingency & 41 & 47 & 45 \\
\hline Construction financing & 209 & 234 & 215 \\
\hline Total soft CapEx & $\mathbf{6 2 1}$ & $\mathbf{6 9 7}$ & $\mathbf{6 4 4}$ \\
\hline Total CapEx & $\mathbf{5 , 0 6 6}$ & $\mathbf{5 , 6 7 7}$ & $\mathbf{5 , 2 2 7}$ \\
\hline & & & \\
\hline
\end{tabular}




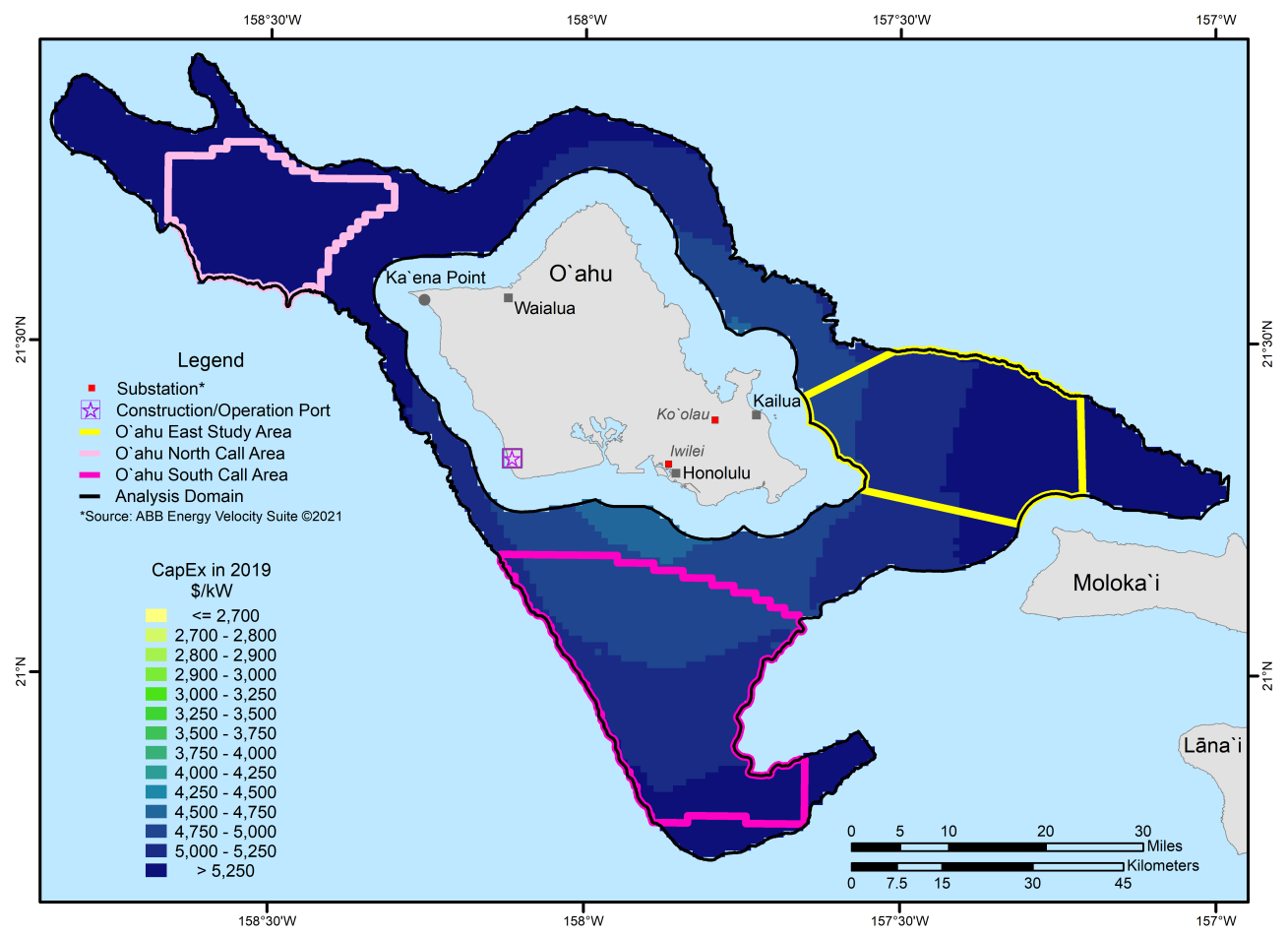

Figure 21. CapEx estimates in the O'ahu analysis domain for the baseline study year (COD 2019).

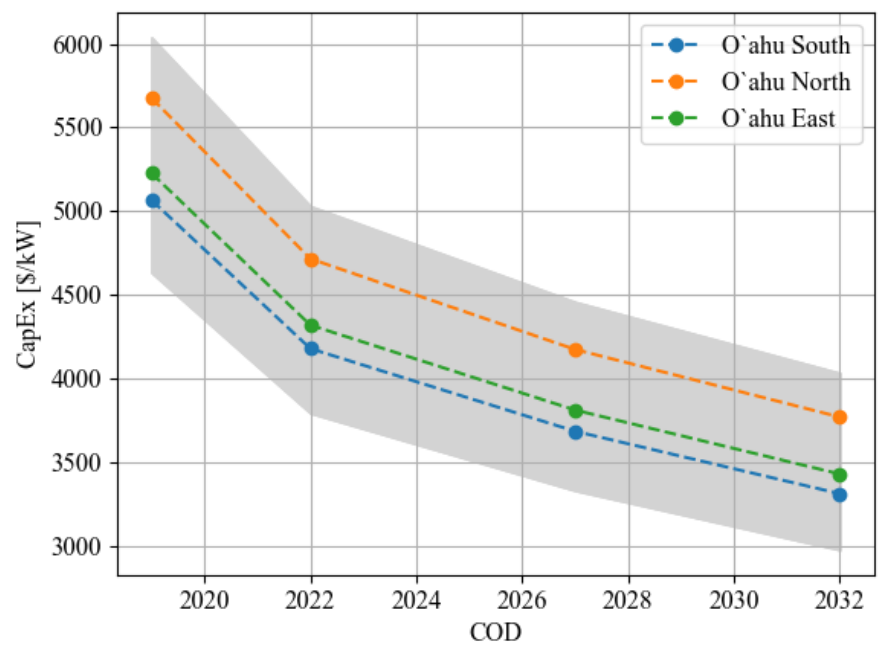

Figure 22. CapEx projections for CODs between 2019 and 2032 for the three Study Areas. Gray shading indicates range between minimum and maximum values over the analysis domain.

significant wave heights on the order of $1.5 \mathrm{~m}$ instead of $2.5 \mathrm{~m}$ in California (NREL 2021c). This makes it easier and cheaper to travel to the project site and service the turbines, and decreases the downtime in the event of major failures. The improved accessibility and availability of these projects represents a significant advantage to developing offshore 
wind in the region; however, it is important to note that these cost savings are attributed to the lower significant wave heights and if a site-specific survey conducted by a project developer identified more adverse metocean conditions, OpEx costs would likely increase.

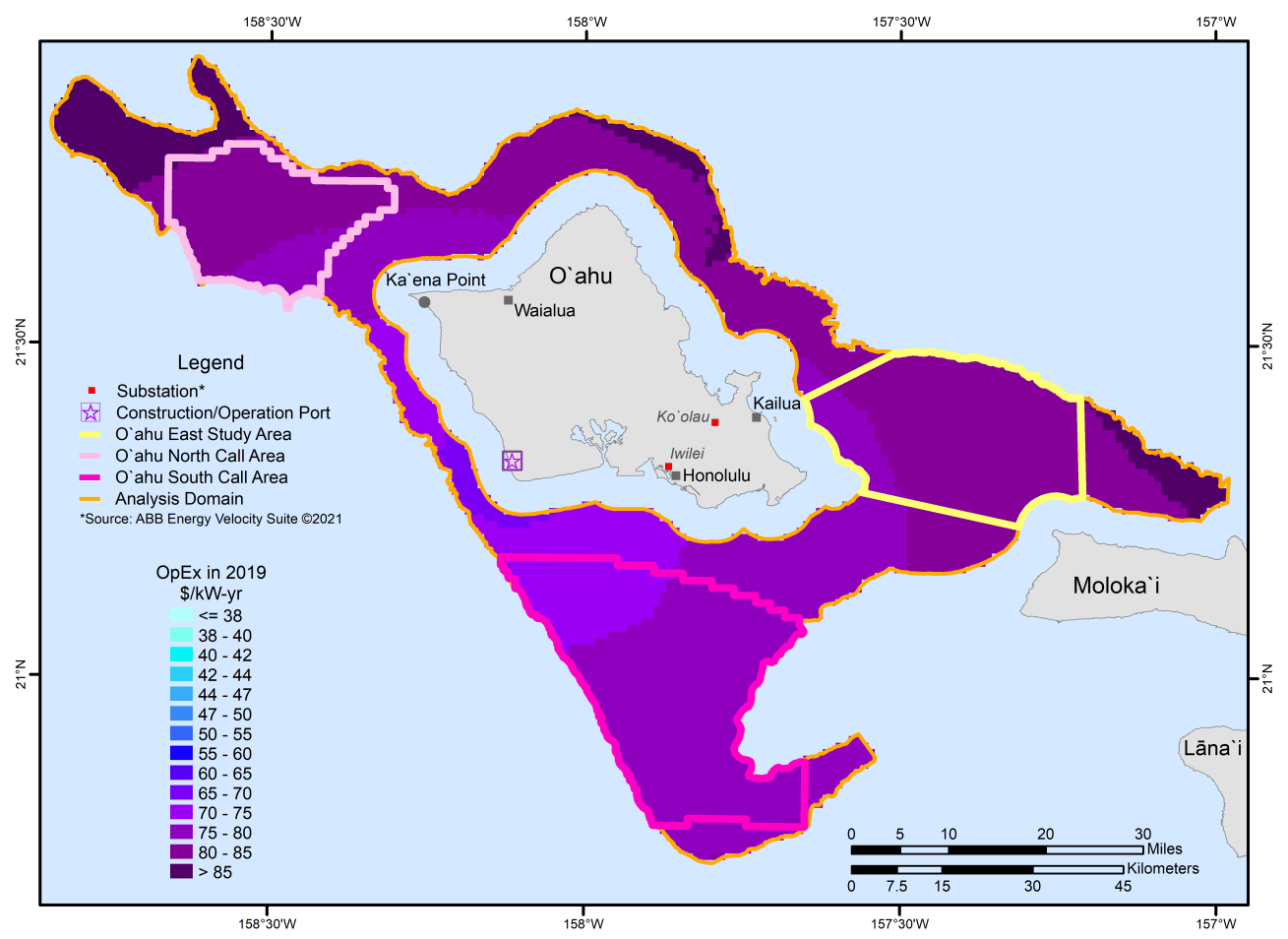

Figure 23. OpEx estimates in the O'ahu analysis domain for the baseline study year (COD 2019).

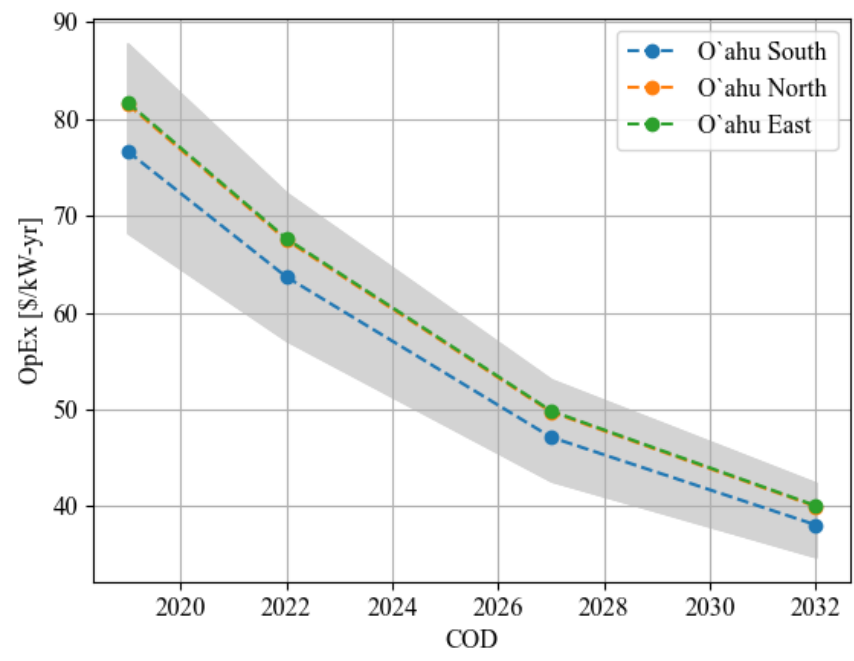

Figure 24. OpEx projections for CODs between 2019 and 2032 for the three Study Areas. Gray shading indicates the range between minimum and maximum values over the analysis domain. 
Table 9. Spatially averaged 2019 OpEx line item values across the Study Areas, $\$ / k W-y r$.

\begin{tabular}{|c|c|c|c|}
\hline Line Item [values in $\$ / \mathrm{kW}-\mathrm{yr}$ ] & O'ahu South & O'ahu North & O'ahu East \\
\hline Operations & 30 & 30 & 30 \\
\hline Maintenance & 47 & 52 & 52 \\
\hline Total OpEx & 77 & 82 & 82 \\
\hline
\end{tabular}

The OpEx of the three Study Areas is shown in Figure 24. The O'ahu North and O'ahu East Study Areas show nearly identical results; although the East Area is further away from the operations port, it also has a lower significant wave height (Table 1). These characteristics provide canceling effects and lead to similar OpEx costs. The O'ahu South Study Area has the lowest significant wave height and shortest distance to port, and therefore realizes the lowest OpEx. Unlike the CapEx cost reductions plotted in Figure 22, which relied on an empirically-derived learning curve, the trajectory of the OpEx costs is based on the cumulative impact of technological innovations derived from Hundleby et al. (2017). These effects result in an approximately 50\% drop in operational costs for projects commissioned between 2019 and 2032.

\subsection{Capacity Factors and Energy Production}

The net capacity factor over the analysis domain is shown in Figure 25. The spatial distribution of NCF reflects the variation in the average wind speed depicted in Figure 2 given that the wind speed distribution is the dominant factor in determining NCF. The region with the highest NCF is to the east of $\mathrm{O}^{\prime}$ ahu and north of Moloka'i. The lowest NCF values are found immediately west of $\mathrm{O}^{\prime} \mathrm{ahu}$ on the leeward side of the island. Note that the three Study Areas are indicated on the heat maps, and it is clear that the East Study Area has the highest NCF values, followed by the North then East Study Areas. It is noteworthy that the entire analysis domain demonstrates excellent NCFs with values commonly above 50\%; as discussed in Section 5, this value includes the impact of losses relative to the GCF. The high values of NCF are attributed to the strong and consistent wind resource. As NCF dictates the net annual energy production of a wind power plant, it is the most impactful component in the LCOE equation (Shields, Beiter, and Kleiber 2021). As a result, these high capacity factors will significantly contribute to low values of LCOE.

From the wind resource data presented in Section 3 and the NCF heat maps in Figure 25, we noted that the East Study Area had the strongest wind resource and highest NCF. Figure 26 confirms this by showing the trajectory over time of the average GCF and NCF values within each Study Area. Since the turbine model is constant across the analysis domain, the driving factor in GCF differences across the Study Areas is the wind speed distribution. NCF results from accounting for losses. Table 10 summarizes the average magnitudes of the loss categories and total losses in each Study Area for COD 2019. Differences in the total losses between the Study Areas come from the wake losses and electrical losses.

Table 10. Losses for O‘ahu Study Areas for COD 2019.

\begin{tabular}{|l|l|l|l|}
\hline Loss Category [values in \%] & O'ahu South $^{\text {' }}$ & O'ahu North $^{\text {'a }}$ & Ohu East \\
\hline Wake losses & 6.4 & 7.8 & 7.5 \\
\hline Environmental losses & 1.6 & 1.6 & 1.6 \\
\hline Technical losses & 1.2 & 1.2 & 1.2 \\
\hline Electrical losses & 3.6 & 4.4 & 3.8 \\
\hline Availability losses & 5 & 5 & 5 \\
\hline Total losses & 16.7 & 18.6 & 17.9 \\
\hline
\end{tabular}

Wake loss differences come from the wind speed and direction distributions because the turbine model and plant layout remain constant across the analysis domain. In Figure 5 we observed that the wind speed distribution peaked near the rated wind speed (and peak thrust force). This peak thrust force is associated with stronger wakes and higher wake losses. The average wake loss across the analysis domain in COD 2019 was $7.9 \%$, higher than the $6.7 \%$ calculated in California (Beiter et al. 2020) despite the smaller total plant capacity (fewer turbines) in Hawai 'i. Electrical losses are computed as a function of water depth and export cable length, and values are presented in Table 1. The $\mathrm{O}$ 'ahu North 


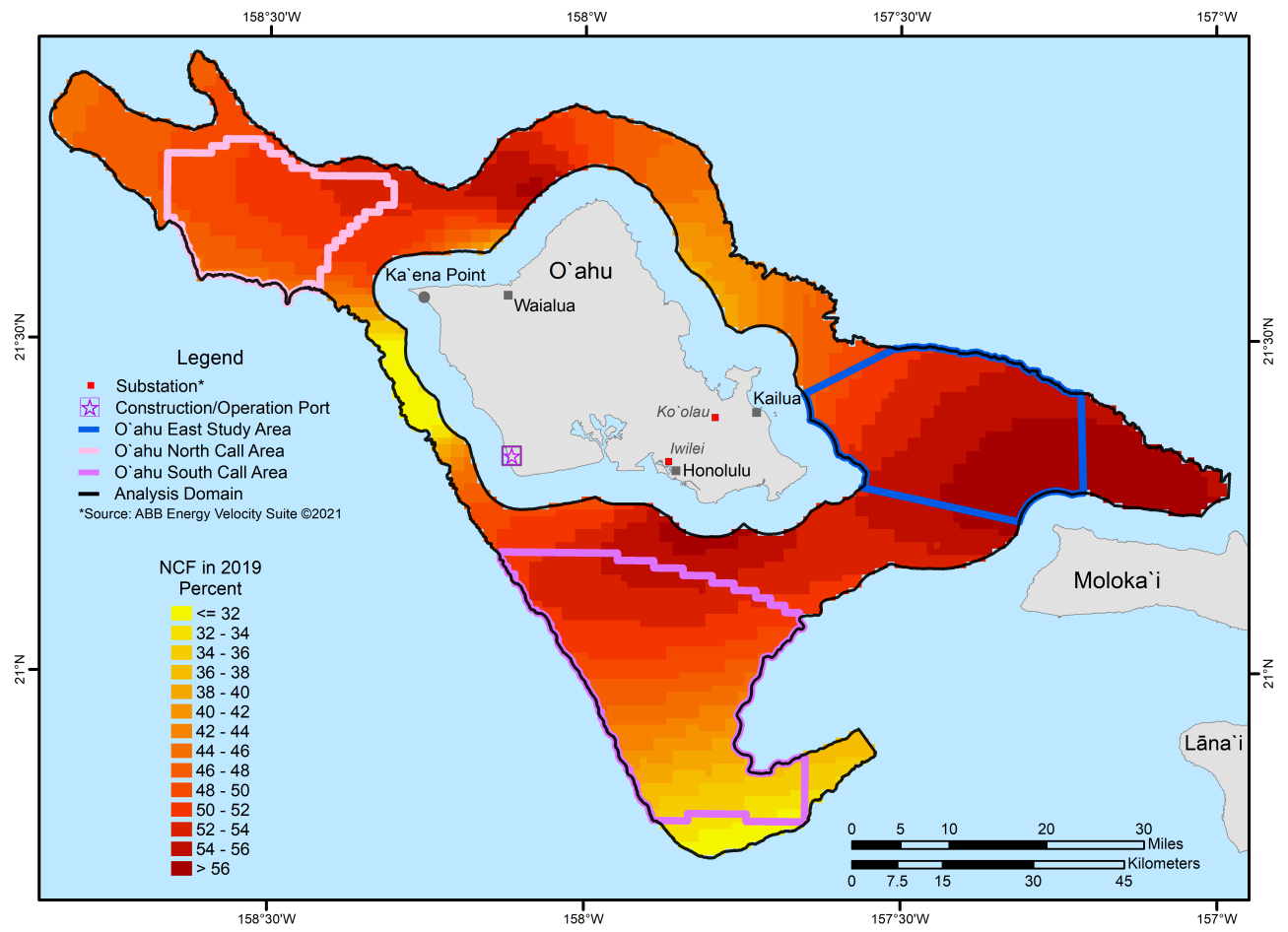

Figure 25. NCF estimates in the O'ahu region for the baseline study year (COD 2019).
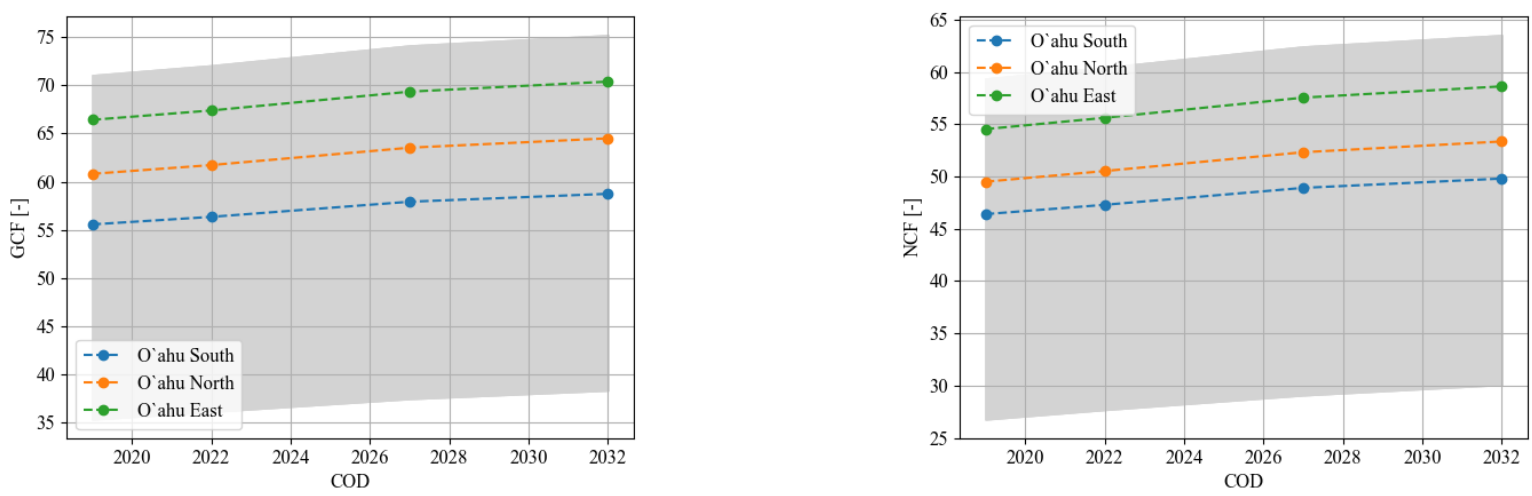

Figure 26. Line plots showing spatially averaged gross (left) and net (right) capacity factors in time across each Study Area. Gray shading indicates the range between minimum and maximum values over the analysis domain.

Study Area has the largest water depth and export cable length, leading to the greatest electrical losses. The $\mathrm{O}^{\text {‘ahu }}$ South Study Area has the shallowest water depth and shortest export cable and lowest electrical losses. Numerical values of GCF and NCF are tabulated along with total losses in Table 11.

\subsection{Levelized Cost of Energy}

The CapEx, OpEx, and NCF results, along with the financial assumptions from Table 7, are aggregated together using Equation 7.1 to compute LCOE throughout the analysis domain. The resulting heat maps are shown in Figure 27 for projects with COD in 2019 and 2032 to demonstrate the net impact of cost reductions and performance improvements 
Table 11. Gross and net capacity factors with losses over time for each Study Area.

\begin{tabular}{|l|l|l|l|}
\hline Item & O'ahu South & O'ahu North & '`ahu East \\
\hline 2019 COD & 55.5 & 60.8 & 66.5 \\
\hline GCF [\%] & 16.7 & 18.6 & 17.9 \\
\hline Total losses [\% of gross production] & 46.3 & 49.5 & 54.6 \\
\hline NCF [\%] & 56.3 & 61.7 & 67.4 \\
\hline 2022 COD & 18.2 & 17.5 \\
\hline GCF [\%] & 16.2 & 50.5 \\
\hline Total losses [\% of gross production] & 47.2 & 53.7 \\
\hline NCF [\%] & 63.5 & 69.4 \\
\hline COD 2027 & 57.9 & 17.6 & 17.0 \\
\hline GCF [\%] & 52.3 & 57.6 \\
\hline Total losses [\% of gross production] & 15.7 & \\
\hline NCF [\%] & 48.8 & 70.4 \\
\hline COD 2032 & 58.7 & 64.5 & 16.7 \\
\hline GCF [\%] & 17.3 & 58.7 \\
\hline Total losses [\% of gross production] & 15.4 & 53.3 \\
\hline NCF [\%] & 49.7 &
\end{tabular}

in CapEx, OpEx, and AEP. Naturally, the areas of lowest LCOE are correlated with the lowest costs and highest energy production. The lowest values of LCOE occur in the O'ahu South Study Area, but in the area closest to shore, which is unlikely to be developed. The South Study Area also shows the highest range of values, with low costs on the northern edge and the highest costs in the analysis domain at the southern edge. By contrast, the $\mathrm{O}$ 'ahu North and $\mathrm{O}$ 'ahu East Study Areas are more uniform (although over a smaller footprint). Across the analysis domain offshore O'ahu, the values of LCOE range between around \$83/MWh-\$194/MWh for a COD in 2019 and decrease to around \$48/MWh-\$109/MWh by 2032.

We present the LCOE trajectories of the three Study Areas in Figure 28. Although the O'ahu South Study Area has the lowest values of CapEx and OpEx, the higher capacity factors in the O'ahu East Study Area produce the lowest overall LCOE in this region. Although O'ahu North has a better capacity factor than O'ahu South, the costs associated with connecting to the grid on the south side of the island result in the highest LCOE between the three Study Areas. It is important to note that the CapEx, OpEx, NCF, and LCOE results reported for the three Study Areas are averages over these regions and the costs of a specific project within the boundaries of a Study Area would be based on its particular site conditions. The shape of the cost trajectories are heavily influenced by the significant CapEx reductions attributed to the increasing maturity of the supply chain during the 2020s. The average LCOE within the three Study Areas range from \$96/MWh-\$113/MWh for a COD in 2019 to \$56/MWh-\$66/MWh for a COD in 2032. These results rely on the simplifying assumptions implemented throughout the analysis. Additional project costs could be incurred for upgrading the onshore substation, importing resources for OpEx activities, relying on immature or remote supply chains, decreasing the project capacity, differences in the learning rate used to project future costs, ${ }^{5}$ or selecting alternate technologies to address cultural or environmental impacts. We conduct a simple sensitivity analysis in Section 8.5.1 to demonstrate how deviations in capital, operational, and financing costs or net capacity factor can impact LCOE. A critical theme with these major sources of uncertainty is that realizing low values of LCOE requires the supporting infrastructure (including grid, supply chain, ports, and workforce) to be sufficiently capable to efficiently deploy and service offshore wind projects. Early investment in these sectors (both on O'ahu and as part of the global development of the floating wind industry) presents an opportunity to develop low-cost projects while creating local jobs and economic benefits. If the supporting infrastructure is sufficiently mature, the costs of floating offshore wind in the $\mathrm{O}^{\prime}$ ahu region have the potential to be on the lower end of the projected global range of LCOE shown in Figure 17. Despite accounting for the logistical complexities and cost additions associated with

\footnotetext{
${ }^{5}$ Beiter et al. (2020) provide a discussion on the uncertainty bounds of the derived learning curve and the potential impacts on the CapEx projections.
} 

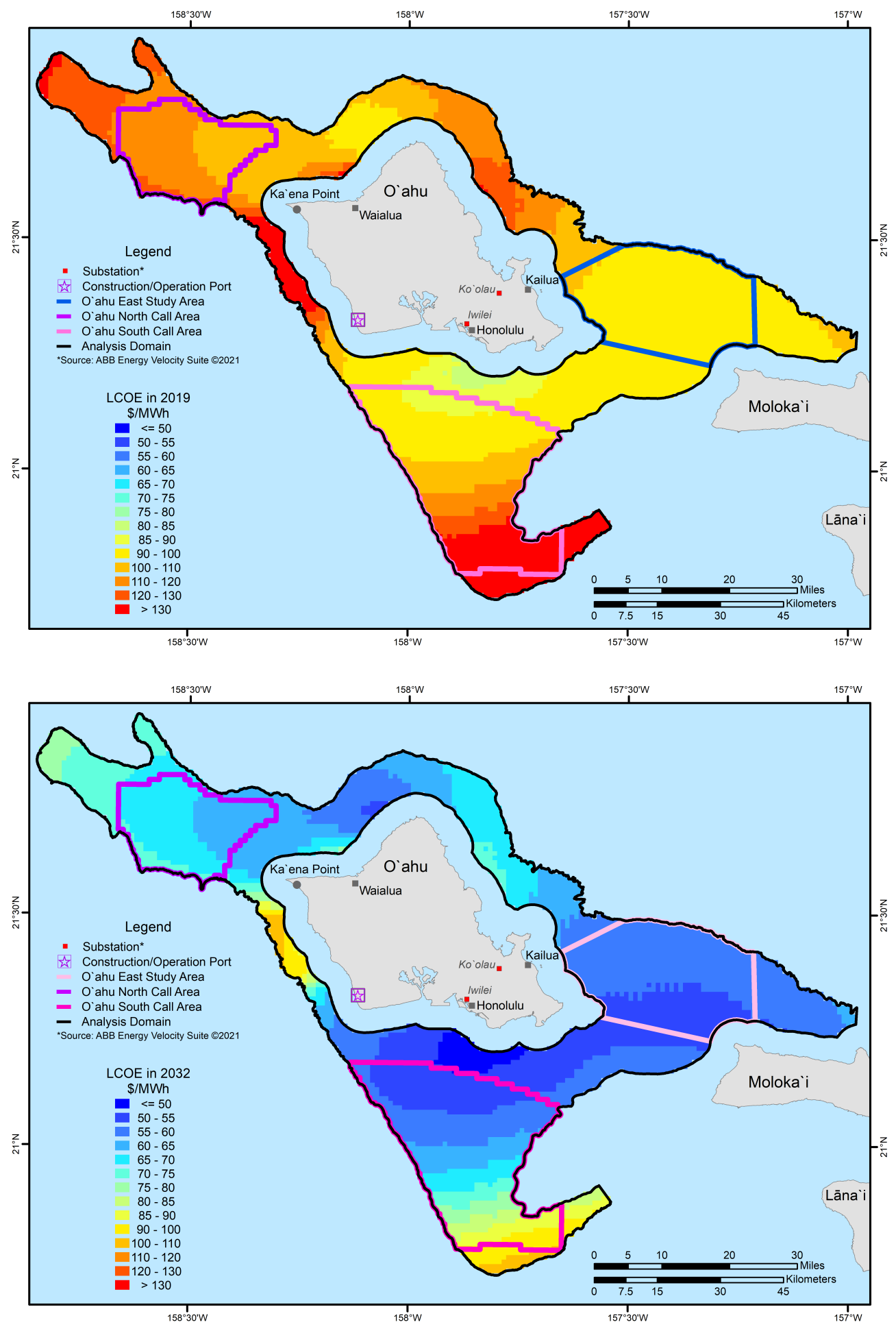

Figure 27. Heat maps of LCOE in the O'ahu region for CODs in 2019 (top) and 2032 (bottom). 
developing offshore wind far from supply chains, the conditions in the region are ideal and could compensate for the additional costs.

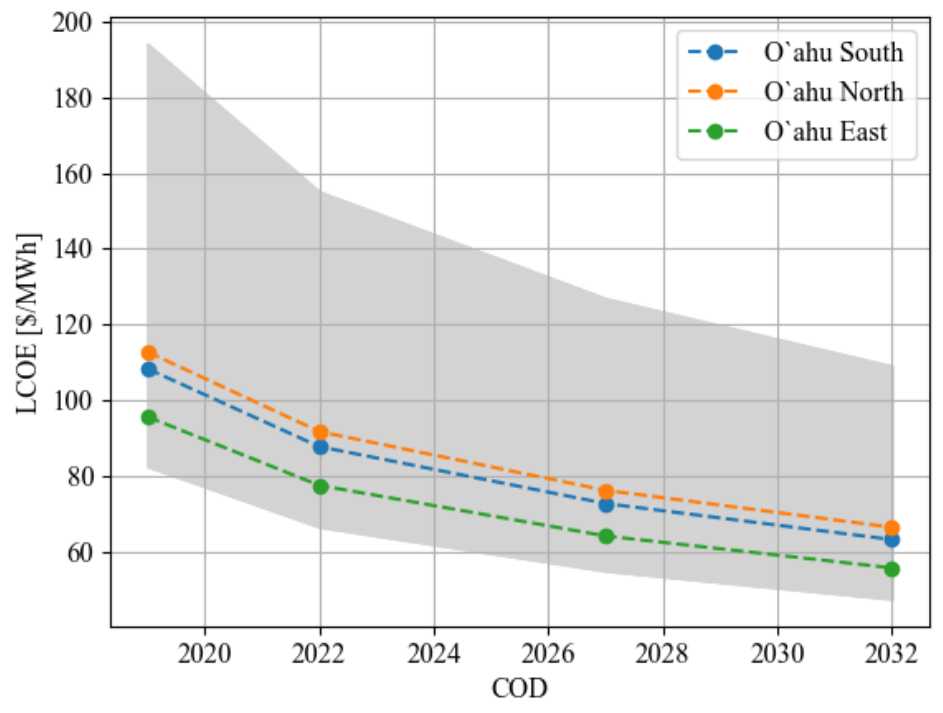

Figure 28. LCOE projections for CODs between 2019 and 2032 for the three Study Areas (spatial average of all analysis nodes within Study Area boundaries). Gray shading indicates the range between minimum and maximum values over the analysis domain.

\subsection{Sensitivity Analyses}

In this section, we demonstrate the sensitivity of the LCOE computation to different input parameters and assumptions made within the study. We first consider a simple one-at-a-time sensitivity analysis of key model variables, and then estimate the impact of different supply chains and points of interconnection on LCOE.

\subsubsection{Uncertainty in Input Costs}

To gauge the sensitivity of LCOE to the major input variables, we vary them by $+/-10 \%$ from their reference value and compute the impact on LCOE using the average values across the analysis domain in 2019. The analysis domain average values in 2019 are taken as the reference values and represent the baseline case (see Table 12). The resulting LCOE using Equation 7.1 is \$106/MWh. The resulting LCOE ranges are shown in Figure 29 along with the values of the varied parameters.

Table 12. 2019 analysis domain average cost parameters

\begin{tabular}{ccc}
\hline Parameter & Reference value & Variation \\
\hline CapEx, $\$ / \mathrm{kW}$ & 5264 & $-/+10 \%$ \\
OpEx, $\$ / \mathrm{kW}-\mathrm{yr}$ & 80 & $-/+10 \%$ \\
NCF, $\%$ & 49.2 & $+/-10 \%$ \\
FCR, $\%$ & 7.18 & $-/+10 \%$ \\
Semisubmersible CapEx, $\$ / \mathrm{kW}$ & 1494 & $-/+50 \%$ \\
\hline Computed LCOE, $\$$ /MWh & 106 & Calculate \\
\hline
\end{tabular}

It is clear that of the major components of LCOE, the NCF has the largest impact for our reference case, as a 10\% change yields LCOE changes of approximately -9 to $+11 \$ / M W h$. In addition, we include a sensitivity to the semisubmersible CapEx, described in greater detail below. 


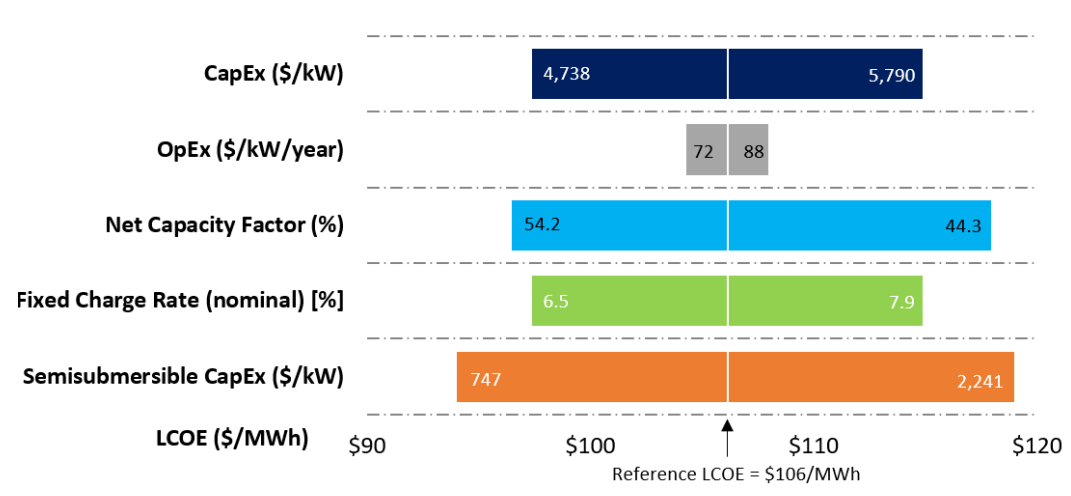

Figure 29. LCOE sensitivity to main cost variables.

\subsubsection{Alternate Supply Chain}

As we discuss in Section 6, offshore wind in $\mathrm{O}^{\text {‘ }}$ ahu has the potential to use supply chains from Southeast Asia to obtain cheaper substructures and reduce LCOE; however, the exact cost differential between U.S. and alternate supply chains is not easily established. To better understand how sourcing semisubmersibles from an alternate supply chain in Asia impacts LCOE, we vary the substructure CapEx from 50\% to $100 \%$ of its 2019 value $(\$ 1,494 / \mathrm{kW})$ and propagate the effect through to LCOE using Equation 7.1. For this exercise, we take the analysis domain average 2019 values for CapEx, OpEx, and NCF to represent the baseline case (see Table 12). The results are presented in Figure 30. Because the semisubmersible procurement costs are a significant portion of the Total CapEx, the impact of reducing (or increasing) semisubmersible costs on LCOE is appreciable. A 50\% change in semisubmersible costs yields an $11.7 \%$ change in LCOE.

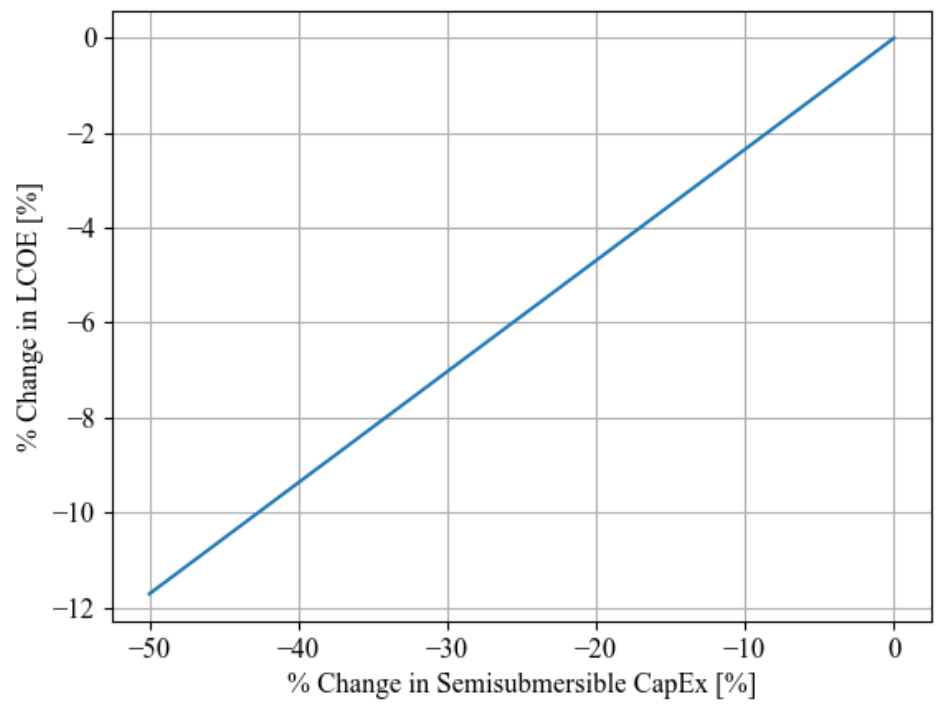

Figure 30. LCOE sensitivity to semisubmersible CapEx.

\subsubsection{Additional Point of Interconnection}

Because only two Point(s) of Interconnection (POI) on the southern half of the island were considered in the main cost analysis, we investigate the impact on export cable CapEx and LCOE of adding an additional POI at the 610-MW Kahe generation plant on the western side of the island. This scenario assumes that this petroleum-fired power plant 
will be retired as part of the process of achieving the HCEI targets. In the ORCA cost model, the export cable costs are based on the distance from the site to the point of landfall. Onshore spur line costs are computed as a function of the distance from the export cable landfall point to the nearest POI for the site. Adding another POI in the north changes the nearest cable landfall points and thus the cost calculus.

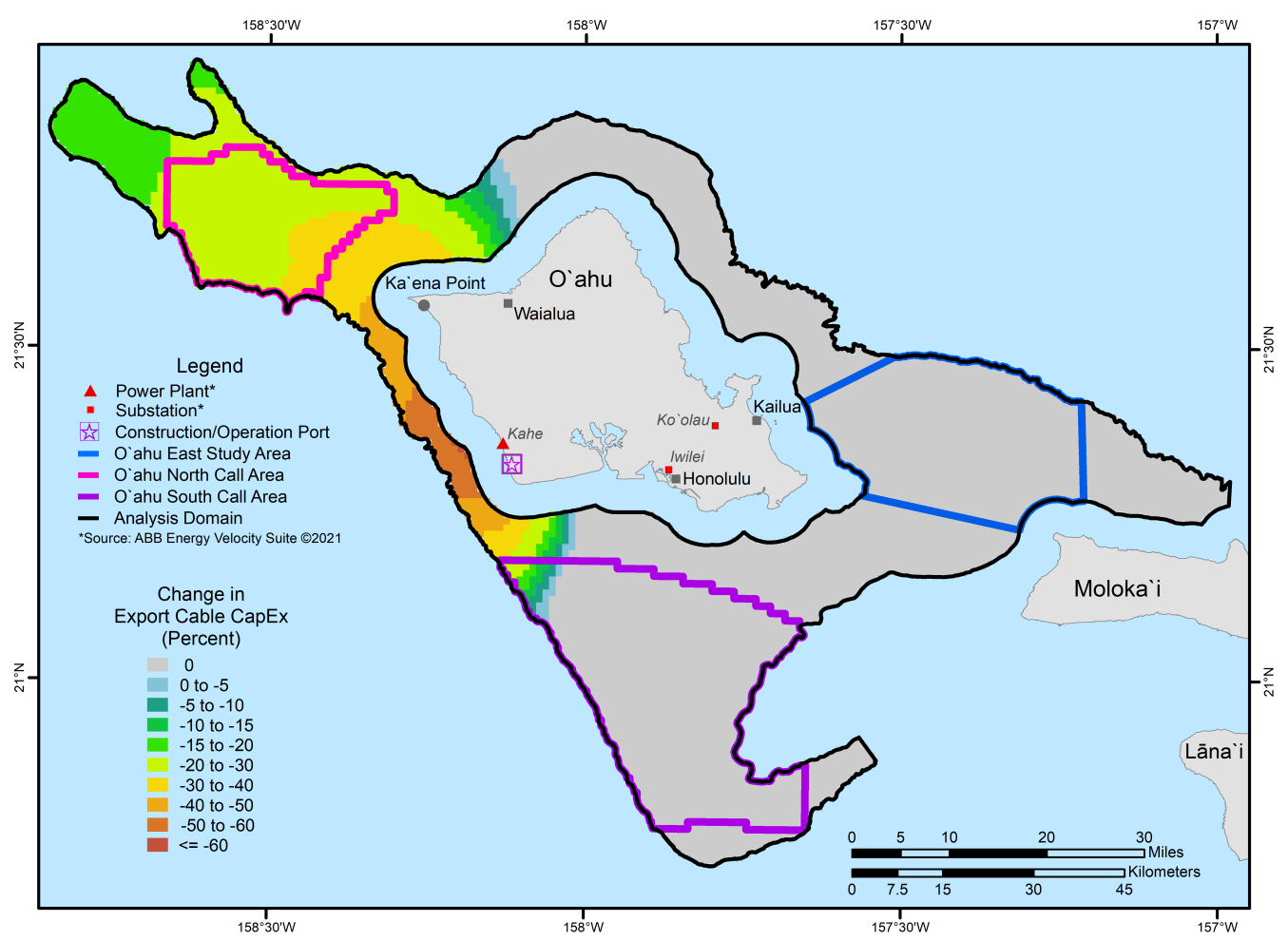

Figure 31. Percent change in export cable costs if the Kahe power plant is available as an interconnection point.

We see from Figure 31 that this additional POI at Kahe only impacts costs for sites in the west and northwest portion of the analysis domain. Export cable CapEx decreases in these sites as much as 60\% relative to the baseline case that excludes the Kahe POI, which corresponds to an $8 \%$ decrease in LCOE. The cost reduction impacts decrease with increasing distance from the Kahe POI.

\subsection{Visualization of Land-Use Tradeoffs}

Solar photovoltaic (PV) generation is a promising option for meeting the Hawai ' 1 Renewable Portfolio Standard (RPS) of $100 \%$ net electricity sales generated by renewable sources by 2045 given the strong solar resource (Grue et al. 2020). Previous NREL studies have investigated the impacts of high penetration solar and land-based wind scenarios on grid stability on $\mathrm{O}^{\prime}$ ahu and found that the island would require over $700 \mathrm{MW}$ of solar and $100 \mathrm{MW}$ of onshore wind to support $20 \%$ of the electricity demand (Eber and Corbus 2012). This study focused on the performance of the electricity grid under various renewable penetration scenarios and did not consider the amount of land that commercialscale solar would require on $\mathrm{O}^{\prime} \mathrm{ahu}$. Siting large solar projects presents additional complexities as they would need to compete with existing residential, agricultural, or cultural land use. Offshore wind provides an alternate pathway to a clean energy future that would preserve more land availability by shifting power generation out to sea.

We conducted a preliminary capacity expansion modeling exercise to demonstrate the potential reduction in landuse requirements enabled through offshore wind penetration. We used NREL's Engage Energy Modeling Tool, a publicly available capacity expansion modeling tool that allows users to consider and visualize tradeoffs between different electricity generation and transmission scenarios (NREL 2018). Engage was developed in collaboration 
with HSEO. The model assumes future electricity demand and optimizes generation and transmission assets to meet the load requirements. We allowed Engage to build out land-based PV and wind resources to meet the electricity demand through 2045 under three offshore wind penetration scenarios corresponding to 0,1 , or 2 offshore wind power plants with a nameplate capacity of $600 \mathrm{MW}$ each. The anticipated electricity demand was provided by HE from their Integrated Grid Planning projections. We assume each offshore wind project has a power density of $3 \mathrm{MW} / \mathrm{km}^{2}$, corresponding to a footprint of $200 \mathrm{~km}^{2}$ (Musial et al. 2021). We do not constrain the model to provide any setbacks or exclusions to residential, agricultural, cultural, or other competing-use areas; instead, the projects are simply located at the points of lowest LCOE. Maps showing the subsequent footprints of solar and offshore wind are provided in Figure 32; although land-based wind and rooftop solar were also available within the Engage model, a negligible amount of capacity was deployed as utility-scale solar was comprehensively cheaper on $\mathrm{O}$ 'ahu. The offshore wind project footprints also show the approximate location of $4015-\mathrm{MW}$ wind turbines that would be required for a $600-\mathrm{MW}$ offshore wind power plant. They are sited in 4 rows of 10 wind turbines consistent with the conceptual plant graphic shown in Figure 14. It is worth noting that these 600-MW projects occupy a relatively small portion of the overall Study Areas.

These results indicate that $\mathrm{O}^{\prime}$ ahu would require over 2,300 MW of solar PV to meet the anticipated electricity demand in 2045 with no contribution from offshore wind. This would require $82 \mathrm{~km}^{2}$ of land to be allocated to utility-scale solar development. Introducing offshore wind into the generation portfolio reduces the requirements for solar PV to support the load on $\mathrm{O}^{\prime}$ ahu. The required generation capacity of solar PV reduces to 1,136 MW and $595 \mathrm{MW}$ for a buildout of 600 and 1,200 MW of offshore wind, respectively. This displacement corresponds to a $75 \%$ reduction in the amount of solar generation and land usage.

Table 13. Offshore wind and solar PV buildout scenarios in 2045. The offshore wind buildout is prescribed, and the required amount of solar PV is calculated by the Engage model.

\begin{tabular}{lllll}
\hline $\begin{array}{l}\text { Number of } \\
\text { offshore wind } \\
\text { power plants }\end{array}$ & $\begin{array}{l}\text { Offshore wind capacity } \\
(\mathrm{MW})\end{array}$ & $\begin{array}{l}\text { Ocean footprint } \\
\left(\mathrm{km}^{2}\right)\end{array}$ & $\begin{array}{l}\text { Solar PV capacity } \\
(\mathrm{MW})\end{array}$ & $\begin{array}{l}\text { Land footprint } \\
\left(\mathrm{km}^{2}\right)\end{array}$ \\
\hline 0 & 0 & 0 & 2,335 & 82 \\
1 & 600 & 200 & 1,136 & 40 \\
2 & 1,200 & 400 & 595 & 21 \\
\hline
\end{tabular}

These results are intended to provide a simple demonstration of the tradeoffs between the amount of land-based solar generation and offshore wind generation required to support the power demand on $\mathrm{O}^{\prime}$ ahu. The specific locations of solar and offshore generation on the maps are not necessarily representative of where actual projects would be sited. More sophisticated and detailed planning exercises that consider the relative costs, spatial exclusions, environmental impacts, and cultural sensitivities of both solar PV and offshore wind are required to understand exactly where these projects should be built, which may impact their footprint. 


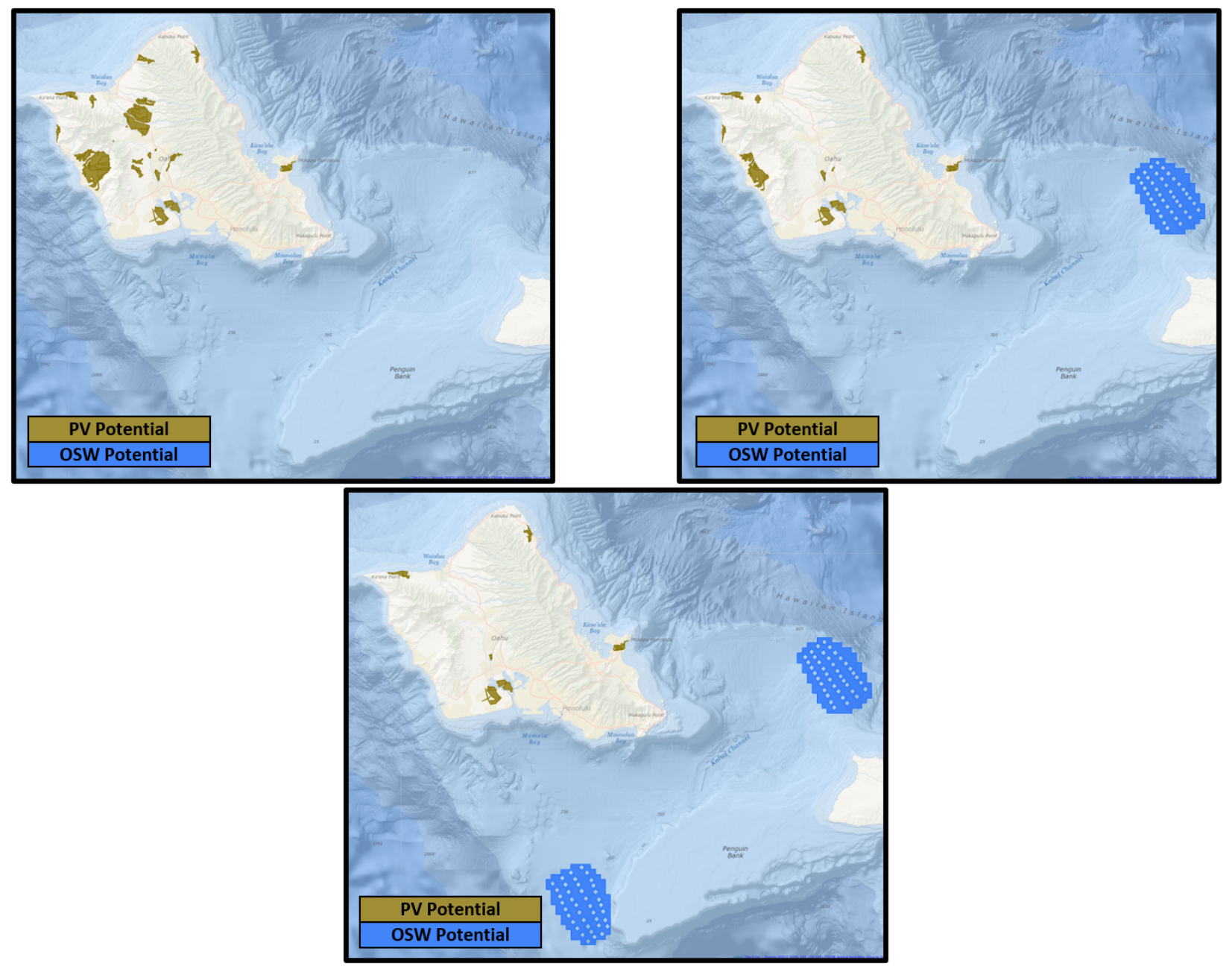

Figure 32. Land and ocean footprints for $100 \%$ renewable generation scenarios in 2045 corresponding to no offshore wind buildout (top left), $600 \mathrm{MW}$ of offshore wind buildout (top right), and 1,200 MW of offshore wind buildout (bottom).

This report is available at no cost from the National Renewable Energy Laboratory at www.nrel.gov/publications. 


\section{Summary of Stakeholder Feedback}

Although NREL has not previously conducted stakeholder outreach as a part of floating wind cost and feasibility studies (Musial et al. 2019a; Beiter et al. 2020), it was clear during the early stages of the project that any offshore wind development in the waters surrounding Hawai' $i$ must understand the cultural and environmental considerations that are vital to local communities. The scope of this study did not explicitly include outreach activities; however, we took several steps to conduct a high-level analysis to categorize and quantify stakeholder concerns with potential offshore wind development off the coast of O'ahu. Similar to the cost and technology results presented in this report, we present some of the key findings as areas that will require significant further investigation to understand the viability of offshore wind in the region. We do not attempt to identify solutions or mitigation strategies in this report as the questions raised by stakeholders are complex and deserve a complete investigation.

The first step in our stakeholder outreach activities was to review transcripts and submitted comments from community engagement activities conducted by BOEM in 2016 when they released a call for information and nominations along with a notice of intent to prepare an environmental assessment for offshore wind in the O'ahu region (BOEM 2021). This announcement was followed by a public comment period and 3 public meetings. We compiled the comments submitted by community members and categorized them into common themes.

Following the initial literature survey, we shared information with stakeholders as part of a webinar hosted by the Hawaiian Electric Company Solution Evaluation and Optimization working group on January 22, 2021. We presented the intended scope of the $\mathrm{O}^{\prime}$ ahu cost and feasibility study and solicited comments from the audience both in real time and during a 2-week email submission period. The audience of the webinar included a broad group of interested parties, including community members, local media, government officials, and project developers. A documented summary of the webinar was publicly posted on Hawaiian Electric's website (IGP Solution Evaluation and Optimization Working Group 2021), and a request for public comments was posted by the Hawai 'i State Energy Office as well as a participating stakeholder (Curtis 2021; Hawai'i State Energy Office 2021). We received comments from more than 35 individuals with a range of supportive and concerned perspectives. We tallied the comments from stakeholders with concerns about offshore wind and included them with the comments from the BOEM outreach conducted in 2016. We did not explicitly track the positive comments, as the intent of this section is to identify areas of concern that will require further investigation, although there were a number of respondents that were supportive of offshore wind to achieve the Hawai' $i$ clean energy targets. The complied list of categorized comments is provided in Table 14.

The final analysis consists of 29 separate categories, some of which are broader than others and encompass more items. The top 5 categories identified include ecosystem/ wildlife, fishing, viewshed, the cultural significance of Ka 'ena Point, and hurricanes/ waste contamination. These 5 categories consist of $60 \%$ of the total concerns when quantified by individual mention. The most common concern identified was categorized as impacts to the local ecosystem/wildlife. This category is rather broad and consists of concerns regarding birds (albatross in particular), bats, whales, migratory fish, coral, and other species. Fishing was also of high importance and includes both disruption of migratory fish and lack of access for fishers. This coincides with the concern that the wind turbines will act as Fish Aggregation Devices attracting fish, but fishers will not be allowed near the turbines for safety/security reasons. Viewshed is a commonly cited concern with wind developments around the country, both onshore and offshore. Stakeholders have concerns with both seeing the turbines from the shore during the day and seeing blinking red lights (as required by the Federal Aviation Administration) at night. The cultural significance of Ka'ena point is a more regional concern. Stakeholders in the northwest region of $\mathrm{O}^{\prime} \mathrm{ahu}$ are concerned that a project will be built within sight of this sacred location and therefore oppose any development in this area. The final top category, hurricanes/waste contamination, is the primary concern identified that is assessed elsewhere in the study and will impact the cost model. Stakeholders are concerned that the increasing frequency and severity of hurricanes surrounding $\mathrm{O}^{\prime}$ ahu will potentially put any wind farm at risk and may lead to disastrous impacts if a hurricane causes wind turbines to break loose from moorings and wash ashore. This concern contributed to our decision to further analyze the need for a hurricane resilient turbine in the $\mathrm{O}$ 'ahu region, which is expanded upon in Section 4.

The final stakeholder activity we conducted was to present the scope of the $\mathrm{O}^{\prime}$ ahu cost and feasibility study at a meeting of the Hawaiian Islands National Humpback Whales Marine Sanctuary Advisory Council ("the SAC") on 
Table 14. Categories of stakeholder concerns regarding offshore wind in the O'ahu region.

\begin{tabular}{cc}
\hline Key concerns & Total number of comments \\
\hline Ecosystem/wildlife & 54 \\
Fishing & 30 \\
Viewshed & 29 \\
Cultural significance of Ka'ena Point & 28 \\
Waste contamination/hurricanes & 22 \\
Surf disruption & 16 \\
Community acceptance & 12 \\
Technology is untested & 12 \\
Tourism & 12 \\
Cultural/spiritual significance of oceans & 11 \\
Transmission/grid development & 9 \\
Lack of local participation & 9 \\
Limited community benefit & 9 \\
EIS needs to be expansive & 9 \\
Ownership issues with federal government & 8 \\
Hard to stop once project gets going & 8 \\
Ocean access & 8 \\
Decommissioning & 7 \\
Military radar/operations & 6 \\
Outside ownership & 5 \\
Turbines should be near load area & 3 \\
Subsidies & 3 \\
Property value & 3 \\
Harbor limitations & 2 \\
Lack of awareness/education & 2 \\
Highest bidder conflict & 1 \\
Back-up reserves (non-spinning) & 1 \\
Sound may impact health & 1 \\
Meetings will not be ocurring on the other islands & 1 \\
\hline
\end{tabular}


May 11, 2021. The SAC is a volunteer group that represents the islands of Moloka' $i$, Lāna' $i$, Kaua ‘i, Hawai ‘ $i$, Maui, and $\mathrm{O}$ 'ahu; native Hawaiian cultural advisors; fishing, business, conservation, science, education, and community representatives; and government officials. Although we were not able to conduct a public comment period for this meeting as the analysis portion of the study was nearing completion, the comments from the SAC provided further insight into the critical considerations of potential offshore wind development in Hawai' $i$ (some of which overlap with the results of Table 14). The major comments from the meeting were:

- If offshore wind development takes place in Hawai ' $i$, it will have to accommodate the opinions and perspectives of Native Hawaiians. The best way to do this is by involving Hawaiians in integral project roles from the outset of a project and by incorporating these views into a truly holistic view of the benefits and drawbacks of offshore wind.

- Further investigation into the impacts on endangered birds and marine life is necessary, and offshore wind developers should consider non-conventional technologies, such as vertical axis wind turbines, if they reduce the impact on wildlife.

- The risk of tsunamis and earthquakes is perceived as a threat to the viability and safety of offshore wind projects and needs to be studied in detail.

- Offshore wind development should engage stakeholders from historically marginalized communities and consider justice, equity, and inclusion as key project metrics.

- The NREL cost and feasibility study should include appropriate reviewers from Hawai ' $\mathrm{i}$. 


\section{Summary and Conclusions}

This report describes a cost and feasibility study conducted by NREL to determine how the LCOE of offshore wind varies spatially and temporally in the O'ahu region. The concept of the project was developed by HSEO and BOEM and was funded by BOEM, and both organizations remained actively involved throughout the course of the analysis. The goal of the project was not to conduct a marine spatial planning exercise or to advance the development of a specific project, but to report on likely cost, technology, and infrastructure trends that could be adopted by offshore wind in the region. These results are intended to provide information to government and community decision makers on $\mathrm{O}^{\prime}$ ahu as they evaluate the viability of using offshore wind to support the Hawai' $\mathrm{i}$ RPS. We have also provided the costs results from this study to Hawaiian Electric to facilitate the ongoing Integrated Grid Planning effort to design the generation mix required to reach this standard.

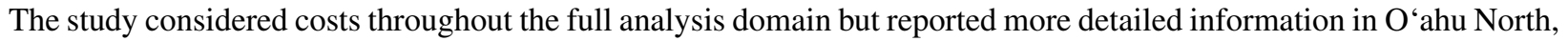
East, and South Study Areas as a way to present how costs vary geographically throughout the region. The key results from the study are:

- The estimated average LCOE for a 600-MW plant in the three Study Areas ranges from $\$ 96 / \mathrm{MWh}-\$ 113 / \mathrm{MWh}$ for a COD in 2019 to $\$ 56 / \mathrm{MWh}-\$ 66 / \mathrm{MWh}$ for a COD in 2032, with the lowest costs occurring in the East Study Area.

- Despite accounting for regionally-specific logistics costs, such as the cost to transport components from the mainland to $\mathrm{O}^{\prime}$ ahu and the cost to restrict export cable capacity to $135 \mathrm{MW}$, the range of LCOEs are at or slightly below the levels reported by Beiter et al. (2020) for offshore wind in California. These cost additions are offset by a strong wind resource, benign metocean environment, and close proximity to ports and grid connections.

- The decrease in offshore wind costs over time are attributed to benefits from turbine upsizing, advanced maturity of the supply chain, improved experiential learning within the industry, and technological innovations that improve operations and performance.

- The spatial variability of costs is due to the site-specific water depth, distance from port, distance to the grid interconnection point, and wind resource. The East Study Area has the lowest average LCOE, as it has the strongest wind resource and is located close to the interconnection points on the southeast side of the island (although it is further from the construction port than the South Study Area). The North Study Area is the most expensive as it has the longest export cable distance to reach the interconnection points.

Throughout the report we have also identified a number of follow-on studies and activities that would be helpful for Hawaiian decision makers:

- Comprehensive environmental impact studies to determine potential effects of offshore wind turbines, floating substructures and mooring systems, dynamic cables, and onshore grid or port upgrades on local wildlife and ecosystems.

- A more rigorous investigation into the potential impacts of hurricanes on a floating offshore wind project in the $\mathrm{O} `$ ahu region, including wind turbine design and OpEx strategies.

- An assessment of the effects of climate change on the wind resource, along with the frequency and magnitude of hurricanes in the region.

- A detailed transmission planning analysis that considers the technical requirements and costs to upgrade substations, connect export cables overland, and possibly upgrade the grid to accommodate offshore wind on $\mathrm{O}^{\prime}$ ahu.

- A coordinated planning effort between Hawai'i Department of Transportation, Harbors Division (DOT-H) and offshore wind technology providers or project developers to understand the needs to construct and operate commercial-scale floating wind out of the Kalaeloa/Barber's Point Harbor (KBPH). 
- A detailed supply chain analysis that considers the most likely suppliers for all major components and identifies potential opportunities to develop manufacturing, assembly, operations, or workforce capabilities on $\mathrm{O}^{`}$ ahu.

- An evaluation of site-specific energy losses in the $\mathrm{O}^{\prime}$ ahu region, including the impacts of deep-array effects and environmental effects.

- A detailed analysis of optimal OpEx strategies to minimize the risk and cost due to the remote location of Hawai' $i$ relative to mature floating wind supply chains. This study should incorporate site-specific metocean condition measurements to better inform the maintenance strategies.

- A comparison of the lifecycle costs, projected wholesale prices and spatial requirements of offshore wind with different generation technologies (including solar PV and battery storage) to determine the most valuable renewable energy solutions for $\mathrm{O}^{`}$ ahu.

Finally, although we did not conduct a detailed study of the environmental or cultural impacts of offshore wind for O'ahu, the preliminary stakeholder outreach we did conduct identified the importance of involving Native Hawaiian perspectives at early stages of the planning process of offshore wind projects. Understanding the potential benefits and consequences of siting and building an offshore wind project, along with the associated port construction, grid interconnection, regulatory policies, workforce development, community impact, and environmental or wildlife effects, will be critical to developing renewable energy solutions that can help Hawai' $i$ achieve its goal of sequestering more atmospheric carbon and greenhouse gases than it produces as quickly as practicable, and no later than 2045. 


\section{Bibliography}

4C Offshore. 2020. 4C Offhshore Monthly Reports (Accessed through Subscription Services). Visited on 2020. https: //www.4coffshore.com/.

ABB. XLPE Submarine Cable Systems. https://new.abb.com/docs/default-source/ewea-doc/xlpe-submarine-cablesystems-2gm5007.pdf.

ACP and ANSI. 2021. ACP Offshore Compliance Recommended Practices (OCRP)-2 working group. Standard. Washington D.C.: American Clean Power (ACP) and American National Standards Institute (ANSI).

Annoni, J., P. Fleming, A. Scholbrock, J. Roadman, S. Dana, C. Adcock, F. Porte-Angel, F. Haizmann, and D. Schlipf. 2018. "Analysis of control-oriented wake modeling tools using lidar field results". Wind Energy Science. doi:https: //doi.org/10.5194/wes-3-819-2018.

API. 2019. API RP 2A-LRFD 2nd Ed Recommended Practice for Planning, Designing, and Constructing Fixed Offshore Platforms- Load and Resistance Factor Design 2nd Ed. Standard. Washington D.C.: American Petroleum Institute (API). Visited on 10/01/2021. https://www.apiwebstore.org/publications/item.cgi?ee123d17-f1ca-4c8f9832-054e1f6656e3.

Beiter, P., W. Musial, A. Smith, L. Kilcher, R. Damiani, M. Maness, et al. 2016. A Spatial-Economic Cost Reduction Pathway Analysis for U.S. Offshore Wind Energy Development from 2015-2030. Tech. rep. https://www.nrel.gov/ docs/fy16osti/66579.pdf: National Renewable Energy Laboratory.

Beiter, P., P. Spitsen, W. Musial, and E. Lantz. 2019. The Vineyard Wind Power Purchase Agreement: Insights for Estimating Costs of U.S. Offshore Wind Projects. Tech. rep. https ://www. nrel.gov/docs/fy19osti/72981 . pdf: National Renewable Energy Laboratory.

Beiter, P., W. Musial, P. Duffy, A. Cooperman, M. Shields, D. Heimiller, and M. Optis. 2020. The Cost of Floating Offshore Wind Energy in California Between 2019 and 2032. Tech. rep. NREL/TP-5000-77384. Visited on 12/28/2020. doi:10.2172/1710181. https://www.osti.gov/servlets/purl/1710181/.

Berthnal-Hooker, J. 2020. MOUs herald Ulsan's floating wind future. Visited on 03/03/2021. https://www.4coffshore. com/news/mous-herald-ulsan92s-floating-wind-future-nid17585.html.

Bleeg, J., M. Purcell, R. Ruisi, and E. Traiger. 2018. "Wind Farm Blockage and the Consequences of Neglecting Its Impact on Energy Production”. 11. ISSN: 1996-1073. doi:10.3390/en11061609. https://www.mdpi.com/19961073/11/6/1609.

BOEM. 2020. The Renewable Energy Process - Leasing to Operations. Visited on 06/12/2020. https://www.boem. gov/sites/default/files/documents/renewable-energy/Leasing-Process_0.pdf.

- . 2021. Hawai 'i Activities - Bureau of Ocean Energy Management. Visited on 06/17/2021. https://www.boem.gov/ renewable-energy/state-activities/hawaii-activities.

Boskalis. 2019. Fjord Semi-Submersible Barge Equipment Sheet. Visited on 10/04/2021. https : //boskalis . com/ download-center/download/eyJmaWxlVWlkIjoxNzIyMiwicmVmZXJlbmNlVWlkIjoxMjE2NH0\%3D/2020cb70c9a3e86692cdee21t html.

Corbus, D., M. Schuerger, L. Roose, J. Strickler, T. Surles, D. Manz, D. Burlingame, and D. Woodford. 2010. O ‘ahu Wind Integration and Transmission Study: Summary Report. Tech. rep. Published: NREL/TP-5500-48632. NREL. https://www.nrel.gov/docs/fy11osti/48632.pdf.

Curtis, H. 2021. Community Comments Sought for O'ahu Offshore Wind Study. Visited on 01/27/2021. http://www. ililani.media/2021/01/community-comments-sought-for-oahu.html?q=offshore+wind.

Draxl, C., A. Clifton, B.-M. Hodge, and J. McCaa. 2015. “The Wind Integration National Dataset (WIND) Toolkit". Applied Energy 151:355-366. doi:https://doi.org/10.1016/j.apenergy.2015.03.121.

Eber, K., and D. Corbus. 2012. HAWAII SOLAR INTEGRATION STUDY: Executive Summary. Tech. rep. https:// energy.hawaii.gov/wp-content/uploads/2011/10/NREL_HawaiiSolarIntegrationStudyPub.pdf: NREL.

EDPR. 2019. EDPR and Aker Solutions to Develop Floating Wind Farm in Ulsan, South Korea. Visited on 03/03/2021. https://www.edpr.com/en/news/2019/10/18/edpr-and-aker-solutions-develop-floating-wind-farm-ulsan-southkorea.

Energy Information Agency. Form EIA-860 detailed data with previous form data (EIA-860A/860B). Visited on 02/23/2021. https://www.eia.gov/electricity/data/eia860/. 
- .2021. Hawai ${ }^{\prime}$ S State Profile and Energy Estimates. Visited on 02/23/2021. https://www.eia.gov/state/?sid=HI\#tabs4.

Equinor. 2021. Hywind Scotland. Visited on 08/15/2021. https ://www. equinor. com/en/what - we - do/floating wind/hywind-scotland.html.

Focus Economics. 2019. Steel (USA) Price Outlook. Visited on 03/11/2021. https://www. focus- economics . com/ commodities/base-metals/steel-usa.

Gaertner, E., et al. 2020. Definition of the IEA 15 MW Offshore Reference Wind Turbine. Tech. rep. Published: NREL/TP-75698. International Energy Agency. https://www.nrel.gov/docs/fy20osti/75698.pdf.

General Electric. 2019. Haliade-X 12 MW offshore wind turbine platform. Visited on 06/29/2020. https://www.ge. $\mathrm{com} /$ renewableenergy/wind-energy/offshore-wind/haliade-X-offshore-turbine.

Grue, N., K. Waechter, T. Williams, and J. Lockshin. 2020. Assessment of Wind and Photovoltaic Technical Potential for the Hawaiian Electric Company. Tech. rep. https://www.hawaiianelectric.com/documents/clean_energy_hawaii/ integrated_grid_planning/stakeholder_engagement/stakeholder_council/20200818_sc_heco_tech_potential_final_ report.pdf.

Guillet, J. 2018. Who Will Fund U.S. Offshore Wind - and on What Terms? Teaneck, NJ. https://green-giraffe.eu/ publication/presentation/who-will-fund-us-offshore-wind-and-on-what-terms/.

Hall, R. 2015. Hurricane Design in the Standards - IEC Hurricane Classes and API Hazard Curves. Keystone Engineering. Visited on 10/04/2021. https://zbook.org/read/afee7_iec-hurricane-classes-and-api-hazard-curves.html.

Hawai 'i Department of Business, Economic Development \& Tourism. 2020. 2019 State of Hawai ' $i$ Data Book. Visited on 06/17/2021. http://dbedt.hawaii.gov/economic/databook/db2019/.

- . 2021. Economic Data Warehouse. Visited on 08/19/2021. http://dbedt.hawaii.gov/economic/datawarehouse/.

Hawai 'i House of Representatives. 2015a. Hawai' $i$ Revised Statute 269-92. State of Hawai 'i. https://www.capitol. hawaii.gov/hrscurrent/Vol05_Ch0261-0319/HRS0269/HRS_0269-0092.htm.

- .2015b. House Bill Number 623. State of Hawai' 1 i. https://www.capitol.hawaii.gov/session2015/bills/HB623_CD1_ .pdf.

Hawai 'i State Energy Office. 2018. Hawai ‘ $i$ Clean Energy Initiative. Visited on 10/04/2021. https://energy. hawaii. gov/testbeds-initiatives/hcei.

- . 2021. National Renewable Energy Laboratory Study on Offshore Wind in Hawai' $i$. Visited on 02/2021. https: //energy.hawaii.gov/nrel-study.

Hawaiian Electric. 2020. Power Facts. Visited on 06/29/2021. https://www.hawaiianelectric.com/about-us/powerfacts.

- . 2021. 2020 Renewable Portfolio Standard Status Report. Visited on 10/04/2021. https://dms.puc.hawaii.gov/dms/ DocumentViewer?pid=A1001001A21B16A83544E02195.

Hundleby, G., K. Freeman, A. Logan, and C. Frost. 2017. Floating Offshore: 55 Technology Innovations That Will Have Greater Impact on Reducing the Cost of Electricity from European Floating Offshore Wind Farms. Tech. rep. KiC InnoEnergy and BVG Associates. https://bvgassociates.com/new-floating-offshore-wind-report/\#.

IEC. 2019. IEC 61400-1:2019 Wind energy generation systems - Part 1: Design requirements. Standard. Geneva, CH: International Electrotechnical Commission (IEC). https://webstore.iec.ch/publication/26423.

IEC and DS. 2019. DS/IEC TS 61400-3-2:2019 Wind energy generation systems - Part 3-2: Design requirements for floating offshore wind turbines. Standard. Geneva, CH: International Electrotechnical Commission (IEC) and Danish Standards (DS). https://webstore.iec.ch/publication/29244.

IGP Solution Evaluation and Optimization Working Group. 2021. IGP Solution Evaluation and Optimization Working Group: Offshore Wind Study. https://www.hawaiianelectric.com/documents/clean_energy_hawaii/integrated_grid_ planning/stakeholder_engagement/working_groups/solution_evaluation_and_optimization/20210122_wg_seo_ meeting_summary_notes.pdf. Online; accessed 4 August, 2021.

Jang, S. Y. 2020. POSCO: Carbon Steel Average Selling Price 2019. Visited on 03/11/2021. https://www.statista.com/ statistics/1024083/south-korea-carbon-steel-average-selling-price/.

King, J., P. Fleming, R. King, L. A. Martínez-Tossas, C. Bay, R. Mudafort, and E. Simley. 2020. "Controls-Oriented Model for Secondary Effects of Wake Steering”. Wind Energy Science Discussions. doi:https://doi.org/10.5194/wes2020-3.

Lazard. 2020. Lazard's Levelized Cost of Energy Analysis - Version 14.0. Tech. rep. Lazard. https://www.lazard.com/ media/451419/lazards-levelized-cost-of-energy-version-140.pdf. 
Lee, J. C. Y., and M. J. Fields. 2021. "An overview of wind-energy-production prediction bias, losses, and uncertainties". Wind Energy Science 6:311-365. doi:10.5194/wes-6-311-2021. https://wes.copernicus.org/articles/6/311/ 2021/.

Lester, S., I. Manak, and K. Kim. 2019. Trump's First Trade Deal: The Slightly Revised Korea-U.S. Free Trade Agreement. Visited on 01/19/2021. https://www. cato . org/publications/free-trade- bulletin/trumps - first-trade - dealslightly-revised-korea-us-free-trade.

Louwen, A., and J. Subtil Lacerda. 2019. "The Experience Curve: Concept, History, Methods, and Issues". Chap. 1 in Technological Learning in the Transition to a Low-Carbon Energy System, ed. by M. Junginger, 9-31. Academic Press.

Maness, M., B. Maples, and A. Smith. 2017. NREL Offshore Balance-of-System Model. Tech. rep. NREL/TP-6A2066874. National Renewable Energy Laboratory. https://www.nrel.gov/docs/fy17osti/66874.pdf.

Martin \& Chock, I. 2013. State of Hawai 'i Multi-Hazard Mitigation Plan 2013 Update. Tech. rep. State of Hawaii Department of Defense. https://dod.hawaii.gov/hiema/files/2017/03/2013-Hawaii-State-Mitigation-Plan-FEMAReview-COMPLETE.pdf.

Murcia, J. P. 2017. "Uncertainty Quantification in Wind Farm Flow Models". PhD thesis, Technical University of Denmark. https://orbit.dtu.dk/en/publications/uncertainty-quantification-in-wind-farm-flow-models.

Musial, W., D. Heimiller, P. Beiter, G. Scott, and C. Draxl. 2016. 2016 Offshore Wind Energy Resource Assessment for the United States. Tech. rep. NREL/TP-5000-66599. https://www.nrel.gov/docs/fy16osti/66599.pdf.

Musial, W., R. Robichaud, and S. Tegen. 2016. "Summary of Technical Specifications for Conceptual Offshore Wind Plants in Hawai 'i Call Areas". Unpublished Tech. rep.

Musial, W., P. Beiter, and Nunemaker. 2020. Cost of Floating Offshore Wind Energy Using New England Aqua Ventus Concrete Semisubmersible Technology. Tech. rep. NREL/TP-5000-75618. https://www.nrel.gov/docs/fy20osti/ 75618.pdf.

Musial, W., P. Beiter, J. Nunemaker, D. Heimiller, J. Ahmann, and J. Busch. 2019a. Oregon Offshore Wind Site Feasibility and Cost Study. Tech. rep. NREL/TP-5000-74591. https://www.nrel.gov/docs/fy20osti/74597.pdf.

Musial, W., P. Beiter, P. Spitsen, J. Nunemaker, and V. Gevorgian. 2019b. 2018 Offshore Wind Technology Data Update. Tech. rep. NREL/TP-5000-77411. https://www.nrel.gov/docs/fy19osti/74278.pdf.

Musial, W., P. Spitsen, P. Beiter, P. Duffy, M. Marquis, A. Cooperman, R. Hammond, and M. Shields. 2021. Offshore Wind Market Report: 2021 Edition. Tech. rep. DOE/GO-102021-5614. Washington, D.C.: U.S. Department of Energy. https://www. energy. gov/sites/default/files/2021 - 08/Offshore\% 20Wind\% 20Market\% 20Report\% 202021\%20Edition_Final.pdf.

NREL. 2018. Engage Energy Modeling Tool. Version 0.6.3. https://engage.nrel.gov/.

- . 2021a. 2021 Annual Technology Baseline. Tech. rep. https://atb.nrel.gov: National Renewable Energy Laboratory.

- . 2021b. FLORIS. Version 2.3.0. https://github.com/NREL/floris.

- . 2021c. Marine Energy Atlas. https://maps.nrel.gov/marine-energy-atlas/.

- . 2021d. Offshore Wind Data Release Propels Wind Prospecting. https://www. nrel.gov/news/program/2021/ offshore-wind-data-release-propels-wind-prospecting.html. Online; accessed 30 June, 2021.

- . 2021e. The National Renewable Energy Laboratory Wind Analysis Library (NRWAL). https://github.com/NREL/ NRWAL.

Nunemaker, J., M. Shields, R. Hammond, and P. Duffy. 2020. ORBIT: Offshore Renewables Balance-of-system and Installation Tool. Tech. rep. NREL/TP-5000-77081. https://www. nrel. gov/docs/fy20osti/77081 .pdf: National Renewable Energy Laboratory.

Nygaard, N. 2015. "Systematic quantification of wake model uncertainty". In Proc. of the European Wind Energy Association Offshore Conf. 1-10. EWEA Offshore. http://www.eera-dtoc.eu/wp-content/uploads/files/Nygaard_ Systematic_quantification_of_wake_model_uncertainty_offshore2015presentation.pdf.

Nygaard, N., S. Trads Steen, L. Poulsen, and J. Grønnegaard Pedersen. 2020. "Modelling cluster wakes and wind farm blockage". In Journal of Physics Conference Series, 1618:062072. Journal of Physics Conference Series. doi:10.1088/1742-6596/1618/6/062072.

Optis, M., A. Rybchuk, N. Bodini, M. Rossol, and W. Musial. 2020. 2020 Offshore Wind Resource Assessment for the California Pacific Outer Continental Shelf. Technical Report. Golden, CO. Visited on 03/03/2021. https://www. nrel.gov/docs/fy21osti/77642.pdf. 
Porter, A., and S. Philipps. 2016. Determining the Infrastructure Needs to Support Offshore Floating Wind and Marine Hydrokinetic Facilities on the Pacific West Coast and Hawai' $i$. Tech. rep. OCS Study BOEM 2016-011. Bureau of Ocean Energy Management. https://espis.boem.gov/final\%20reports/5503.pdf.

Rybchuk, A., M. Optis, J. K. Lundquist, M. Rossol, and W. Musial. 2021. "A Twenty-Year Analysis of Winds in California for Offshore Wind Energy Production Using WRF v4.1.2". Geoscientific Model Development Discussions 2021:1-41. doi:10.5194/gmd-2021-50. https://gmd.copernicus.org/preprints/gmd-2021-50/.

Shields, M., P. Beiter, and W. Kleiber. 2021. "Spatial Impacts of Technological Innovations on the Levelized Cost of Energy for Offshore Wind Power Plants in the United States". Sustainable Energy Technologies and Assessments 45. doi:https://dx.doi.org/10.1016/j.seta.2021.101059. https://www.osti.gov/biblio/1774857.

Shields, M., P. Beiter, J. Nunemaker, A. Cooperman, and P. Duffy. 2021. "Impacts of turbine and plant upsizing on the levelized cost of energy for offshore wind". Applied Energy 298:117189. https://doi.org/10.1016/j. apenergy. 2021.117189.

Short, W., D. Packey, and T. Holt. 1995. A Manual for the Economic Evaluation of Energy Efficiency and Renewable Energy Technologies. Tech. rep. NREL/TP-462-5173. Golden, CO: National Renewable Energy Laboratory. https: //www.nrel.gov/docs/legosti/old/5173.pdf.

Siemens Gamesa Renewable Energy. 2019. SG 14-222 DD. https://www.siemensgamesa.com/en-int/products-andservices/offshore/wind-turbine-sg-14-222-dd. Online; accessed 29 June, 2020.

Sirnivas, S., W. Musial, B. Bailey, and M. Filippelli. 2014. Assessment of Offshore Wind System Design, Safety, and Operation Standards. Tech. rep. NREL/TP-5000-60573. https://www.nrel.gov/docs/fy14osti/60573.pdf: National Renewable Energy Laboratory.

Stehly, T., P. Beiter, and P. Duffy. 2020. 2019 Cost of Wind Energy Review. Tech. rep. https://www.nrel.gov/docs/ fy21osti/78471.pdf: National Renewable Energy Laboratory.

The Conference Board. 2016. International Comparisons of Hourly Compensation Costs in Manufacturing, 2016 Summary Tables. Visited on 03/11/2021. https://www.conference-board.org/ilcprogram/index.cfm?id=38269.

- .2018. International Comparisons of Hourly Compensation Costs in Manufacturing Technical Notes. Tech. rep. The Conference Board. https://www.conference-board.org/retrievefile.cfm?filename=ilccompensationtechnicalnotes. pdf\&type $=$ subsite.

Transportation Harbors Division, H. D. of. 2015. Kalaeloa Barbers Point Harbor 2040 Master Plan. Tech. rep. 79 S. Nimitz Highway Honolulu, HI 96813: Hawai'i Department of Transportation - Harbors Division. https://hidot. hawaii.gov/harbors/files/2013/01/2015-06_Kalaeloa-Barbers-Point-Harbor-2040-Master-Plan_Gov-SupportLetter.pdf.

Valpy, B., and P. English. 2014. Future renewable energy costs: Offshore wind. Tech. rep. BVG Associates. https: //bvgassociates.com/publications/.

Valpy, B., G. Hundleby, K. Freeman, A. Roberts, and A. Logan. 2017. Future renewable energy costs: Offshore wind. Tech. rep. BVG Associates. https://bvgassociates.com/publications/.

Vestas. 2021. Vestas launches the V236-15.0 MW to set new industry benchmark and take next step towards leadership in offshore wind. https://www. vestas.com/en/media/company - news? $1=42 \& \mathrm{n}=3886820 \# !$ grid_0_content_0_ Container. Online; accessed April 14, 2021.

Vickery, P., D. Wadhera, M. Powell, and Y. Chen. 2009. "A Hurricane Boundary Layer and Wind Field Model for Use in Engineering Applications". Journal of Applied Meteorology and Climatology. doi:https://doi.org/10.1175/ 2008JAMC1841.1.

Walker, K., et al. 2016. "An evaluation of the predictive accuracy of wake effects models for offshore wind farms". Wind Energy 19:979-996. https://onlinelibrary.wiley.com/doi/epdf/10.1002/we.1871.

Weber, C. 2020. Making floating wind bankable. https://green-giraffe.eu/article/making-floating-wind-bankable.

Wiser, R., K. Jenni, J. Seel, E. Baker, M. Hand, E. Lantz, et al. 2016. "Expert elicitation survey on future wind energy costs". Nature Energy 1:16135. https://doi.org/10.1038/nenergy.2016.135.

Wiser, R., J. Rand, J. Seel, P. Beiter, E. Baker, E. Lantz, et al. 2021. "Experts predict 37\% to $49 \%$ declines in wind energy costs by 2050”. Nature Energy. https://doi.org/10.1038/s41560-021-00810-z. 


\section{A Assessing the Need for Typhoon-Class Turbines}

Hawai' $i$ can be subjected to hurricanes that have the potential to bring extreme wave heights and wind speeds. The concern is that hurricane intensity could exceed design criteria to resist extreme loads prescribed by the governing standards.

An offshore wind system is designed by coupling the support structure with the wind turbine. Although offshore wind turbines in Hawai ' $\mathrm{i}$ will be mounted on floating foundations, the design process will be similar to fixed-bottom offshore wind turbines. For fixed-bottom designs, the support structures use the American Petroleum Institute (API) RP 2A standard. This standard depends on regionally specific "hazard curves" (API 2019). The steepness of the regional hazard curves (e.g., the coefficient of variation) must satisfy the API robustness criteria for determining hurricane risk, requiring understanding of return periods for 50, 100, and 500 years at the project site (IEC and DS 2019; Hall 2015). The support structure, which includes the tower, floating platform, mooring system, and anchors, will need to comply with the IEC 61400-3-2 standard and the ACP OCRP-2 recommended practice that is still under development and scheduled to be published in June 2022. These standards are the most current best practices for floating wind turbines and have adopted many of the best practices from the oil and gas industry, which has had decades of experience in the Gulf of Mexico with hurricane design for floating structures. They are used as companions with the basic wind turbine design standards IEC 61400-01. All offshore wind energy projects will be designed using their respective site-specific conditions in the design basis for the support structure. API standards are limited to static structures, such as oil and gas platforms, and do not cover the wind turbine itself.

Unlike the support structure, wind turbines are not custom designed for site conditions. They are type-certified to IEC standards that specify design classes defined in the governing IEC 61400-1 and 61400-3-2 standards (IEC 2019; IEC and DS 2019). The most robust design class in earlier editions of IEC 61400-01 is a Class 1A turbine with a defining load case specified for an extreme 3 -s gust of $70 \mathrm{~m} / \mathrm{s}$ with high turbulence intensity. The existing Class $1 \mathrm{~A}$ design extremes already cover maximum gust criteria for hurricane-prone sites that do not experience major hurricanes (Category 4 and 5 by National Hurricane Center criteria). The IEC design standards have begun to recognize hurricane design, and some turbine manufacturers are now developing typhoon-class turbines. If the site conditions are determined to exceed IEC extreme limit state design conditions, the turbine design class must be increased, and the support structure design must be upgraded to the appropriate level. In the most recent edition of IEC 61400-01, a new typhoon-class turbine was specified that uses an extreme 3 -s gust condition of $80 \mathrm{~m} / \mathrm{s}$ rather than $70 \mathrm{~m} / \mathrm{s}$. This higher gust criterion would dictate a more robust turbine design and a commensurate upgrade of the support structure.

For sites in Hawai ' $i$, the hurricane risk has not been fully evaluated in the literature, and a full evaluation is beyond the scope of this report. However, drawing from the available data, the risk of exceeding IEC design criteria is low within the return periods of 50 and 100 years established by the governing standards, but additional factors such as possible increasing hurricane severity and frequency due to climate change should be taken into account. As a recommendation, significant caution should be taken to mitigate extreme loads if possible and to actively control offshore wind farms even during power grid failures. Most notably, in 1992, Category 4 Hurricane Iniki made landfall on Kaua 'i, becoming a storm that would challenge current design conditions. However, using best practices for hurricane severity and probability prediction, the documented existence of a hurricane that exceeds the design conditions does not require that all systems must withstand that hurricane. A more rigorous approach must be taken to determine the probability of that storm hitting a given location within the specified return period. A full treatment of this site-specific analysis is beyond the scope of this study but is recommended for any future project development. If this more rigorous analysis reveals the potential for design limit state exceedence at the project site, a typhoon-class turbine may be warranted. Additionally, hurricane load mitigation strategies (e.g., auxiliary on-board power supplies to maintain yaw authority during hurricanes) should probably be implemented.

We did a preliminary assessment of the need for a typhoon-class wind turbine in the $\mathrm{O}$ 'ahu region using existing data available in the literature. We obtained a hazard curve developed for the State of Hawai'i Multi-Hazard Mitigation Plan in 2013 (Martin \& Chock 2013). This curve is reprinted in Figure A.1 and shows that the magnitude of a 3-s gust with a 500-year return period at $10 \mathrm{~m}$ above sea level is $54 \mathrm{~m} / \mathrm{s}$. This result needs to be scaled to a hub height of $150 \mathrm{~m}$ to determine if if a typhoon-class wind turbine is necessary. As we are not aware of a data source providing 
the average wind speeds (either at hub height or sea level) for the Hawai 'i region, we assess the IEC design standards using only the 3-s gust limit state; further analysis would be required to ensure that the average hub height wind speeds are within the Class $1 \mathrm{~A}$ design conditions.

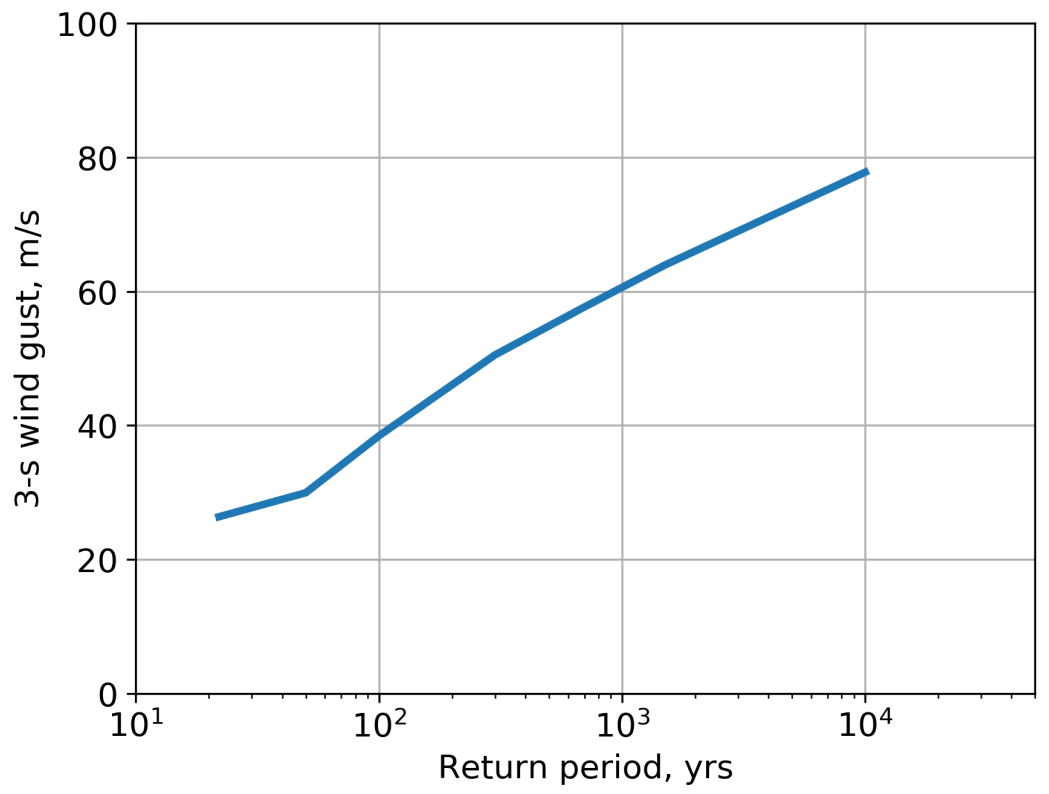

Figure A.1. Wind speed recurrence intervals in Hawai'i with the return period shown on the $x$-axis and the magnitude of the 3-s gust at $10 \mathrm{~m}$ height on the y-axis. Data taken from Martin \& Chock (2013).

In order to scale the 3-s gust data from Figure A.1 to hub height, we use a hurricane boundary layer approximation developed by Vickery et al. (2009). The authors used empirical data to show that the hurricane boundary layer can be well approximated by a simple logarithmic profile up to heights of $400-500 \mathrm{~m}$ above mean sea level. This profile is defined by Equation A.1:

$$
U(z)=\frac{u_{*}}{k} \ln \left(\frac{z}{z_{0}}\right)
$$

where $U(z)$ is the velocity at a height of $z \mathrm{~m}$ above sea level, $u_{*}$ is the friction velocity at the sea surface, $k$ is the von Karman coefficient (a value of 0.4 ), and $z_{0}$ is the surface roughness. The friction velocity is determined as a function of the surface drag coefficient $\left(C_{D}\right)$ and wind speed at $10 \mathrm{~m}\left(U_{10}\right)$ :

$$
u_{*}=C_{D} U_{10}^{2}
$$

Vickery et al. (2009) provide ranges of values for the surface drag coefficient and surface roughness as a function of distance from the eye of the hurricane. We selected the most conservative values of $z_{0}=0.003$ and $C_{D}=0.0022$, which lead to the highest shear profile and hub height wind speed. We also use the hub height $(150 \mathrm{~m})$ of the 15-MW reference wind turbine, which is the highest distance above mean sea level of the wind turbines considered in this study. The scaling parameters and results are listed in Table A.1. Using these parameters to scale the hazard curve shown in Figure A.1 yields a 3-s gust magnitude of $68.6 \mathrm{~m} / \mathrm{s}$ with a return period of 500 years. This preliminary estimate of the maximum gust is slightly under the $70 \mathrm{~m} / \mathrm{s}$ threshold specified by the 64000-1 design standard and indicates that an IEC Class 1A turbine would be satisfactory for the $\mathrm{O}^{\text {' }}$ ahu region assuming stationary wind statistics.

Although the simplified approach described here suggests that a hurricane resilient turbine may not be necessary in the $\mathrm{O}$ 'ahu region, the margin between the IEC design standards and the calculated hub height wind speed is narrow, 
Table A.1. 3-s gust scaling parameters and values at hub height for Hawai‘i adapted from Vickery et al. (2009).

\begin{tabular}{|c|c|c|}
\hline & $50-\mathrm{yr}$ conditions & 500-yr conditions \\
\hline 3 -s gust at $10 \mathrm{~m}(\mathrm{~m} / \mathrm{s})$ & 30.0 & 54.1 \\
\hline Surface roughness & \multicolumn{2}{|c|}{0.003} \\
\hline Surface drag coefficient & \multicolumn{2}{|c|}{0.0022} \\
\hline Specified hub height (m) & \multicolumn{2}{|c|}{150} \\
\hline 3 -s gust at hub height $(\mathrm{m} / \mathrm{s})$ & 38.0 & 68.6 \\
\hline
\end{tabular}

and the uncertainty is much greater. As a result, we impose an additional $10 \%$ cost premium on the capital cost of the wind turbines we use in this study to account for mitigation strategies that are not standard on existing designs, such as battery banks for yaw systems that would allow the turbines to turn into the wind during an extreme event. The uncertainty surrounding the performance of wind turbines in hurricane environments requires further research into characteristics of the hurricane boundary layer, load mitigation techniques on existing Class 1 wind turbines, and how climate change may impact the return period and magnitude of future extreme weather events. 


\section{B Sizing Export Cables}

As we describe in Section 6.2, Hawaiian Electric (HE) has specified that the maximum interconnection capacity will be $135 \mathrm{MW}$ in the upcoming Integrated Grid Planning process. This constraint is designed to reduce the amount of spinning (firm) reserve generation required on $\mathrm{O}^{`}$ ahu, which is expensive and incompatible with the Hawaiian Clean Energy Initiative 100\% renewable energy target. Limiting the interconnection capacity of different variable generation power plants means that the loss of a single source would not be catastrophic for the island. The export cable costs calculated in the ORCA cost model assume a $220-\mathrm{kV}$ cable that can transmit upwards of $300 \mathrm{MW}$ of electricity; this type of cable is oversized for the needs of HE. In order to address the grid planning needs on $\mathrm{O}^{\text {' }}$ ahu, we developed a cost correction factor to account for different types of cables that would be used for offshore wind in the region.

We assume that the export system would still be rated at $220 \mathrm{kV}$, reflecting the most commonly made cables and accessories in the industry (Musial et al. 2021); however, the cable cross section and corresponding ampacity would be reduced to restrict the total power capacity to $135 \mathrm{MW}$ per cable. The physical properties of these smaller cables are readily available through component catalogs from cable manufacturers; however, the unit costs are not public. In order to obtain a rough order of magnitude of the cost of the smaller cable, we assume that cost scales linearly with the mass of the cable. We then used the following process to estimate the cost difference between an industry standard export cable and the 135 capacity cables that would be used in O'ahu based on ABB's three-core XLPE subsea cables (ABB). The costs of the default cable are based on the industry-reviewed, generic export cable costs used in ORBIT (Nunemaker et al. 2020).

1. Assign the default export cable cost from the ORBIT cost model to the $1000 \mathrm{~mm}^{2}$ conductor size ABB cable.

2. Select a smaller cable ampacity for use as an $\mathrm{O}^{\prime}$ ahu export cable.

3. Interpolate cable densities from the ABB catalog to estimate the density and mass of the $\mathrm{O}$ 'ahu export cable.

4. Use the scaling ratio between the density of the $1,000 \mathrm{~mm}^{2}$ cable and the $\mathrm{O}^{\text {' }}$ ahu export cable to scale the ORBIT cable costs.

Following this process identifies a $300 \mathrm{~mm}^{2}, 530$ A cable with a cost of $\$ 533 / \mathrm{m}$ that would be appropriate for offshore wind in $\mathrm{O}^{`}$ ahu. The relevant properties are listed in Table B.1.

Table B.1. Scaled parameters for a 135-MW export cable. ABB cable data taken from ABB.

\begin{tabular}{ccccc}
\hline Property & Default cable value & Source & O`ahu cable value & Source \\
\hline Conductor size, $\mathrm{mm}^{2}$ & 1,000 & $\mathrm{ABB}$ & 300 & $\mathrm{ABB}$ \\
Voltage, $\mathrm{kV}$ & 220 & $\mathrm{ABB}$ & 220 & $\mathrm{ABB}$ \\
Amperage, $\mathrm{A}$ & 825 & $\mathrm{ABB}$ & 530 & $\mathrm{ABB}$ \\
Density, $\mathrm{kg} / \mathrm{m}$ & 104 & $\mathrm{ABB}$ & 71 & Interpolated from ABB \\
Cost, $\$ \mathrm{~m}$ & 800 & ORBIT & 533 & Scaled from ORBIT \\
\hline
\end{tabular}

Although the smaller $\mathrm{O}^{\prime}$ ahu cables will be individually cheaper than the default cables in the ORCA cost model, a 600-MW project will require more cables to offtake the full capacity of the offshore wind power plant. This will increase export system cost CapEx and installation costs. We used ORBIT to evaluate the export system procurement and installation costs of a representative project in the $\mathrm{O}$ 'ahu region located at varying distances from shore using both default and $530 \mathrm{~A}$ cables. We then used the relative differences in costs to derive a scaling factor that we applied to the baseline ORCA export system equations to estimate the regionally specific costs in $\mathrm{O}^{\prime}$ ahu. The results of the scaling exercise are provided in Table B.2.

The greater number of smaller export cables leads to a $73 \%$ increase in cable procurement costs and a $40-78 \%$ increase in installation costs. The increase in installation costs does not necessarily increase proportionally with the cable procurement costs as vessel mobilization is held constant for the baseline and small cable scenarios. The variance based on distance from shore is due to the capacity limits of the cable lay vessel and the number of times it needs 
Table B.2. Scaling factors for export cable procurement and installation as a function of distance to shore for $530 \mathrm{~A}$ export cables relative to the default cable type.

\begin{tabular}{ccc}
\hline Site distance from shore, $\mathrm{km}$ & Export cable & Export cable installation \\
\hline 20 & 1.73 & 1.43 \\
40 & 1.73 & 1.40 \\
60 & 1.73 & 1.78 \\
80 & 1.73 & 1.70 \\
100 & 1.73 & 1.77 \\
\hline
\end{tabular}

to return to port to collect a new cable carousel. In this analysis, each export cable is installed individually. A more detailed analysis is required to understand the full implications of constraining the export cable capacity to $135 \mathrm{MW}$, which could also impact the cost of transformers and other electrical infrastructure at the onshore substation as well as the permitting process for additional cable routes to shore. 
This report is available at no cost from the National Renewable Energy Laboratory at www.nrel.gov/publications. 
C Full Page Heat Maps

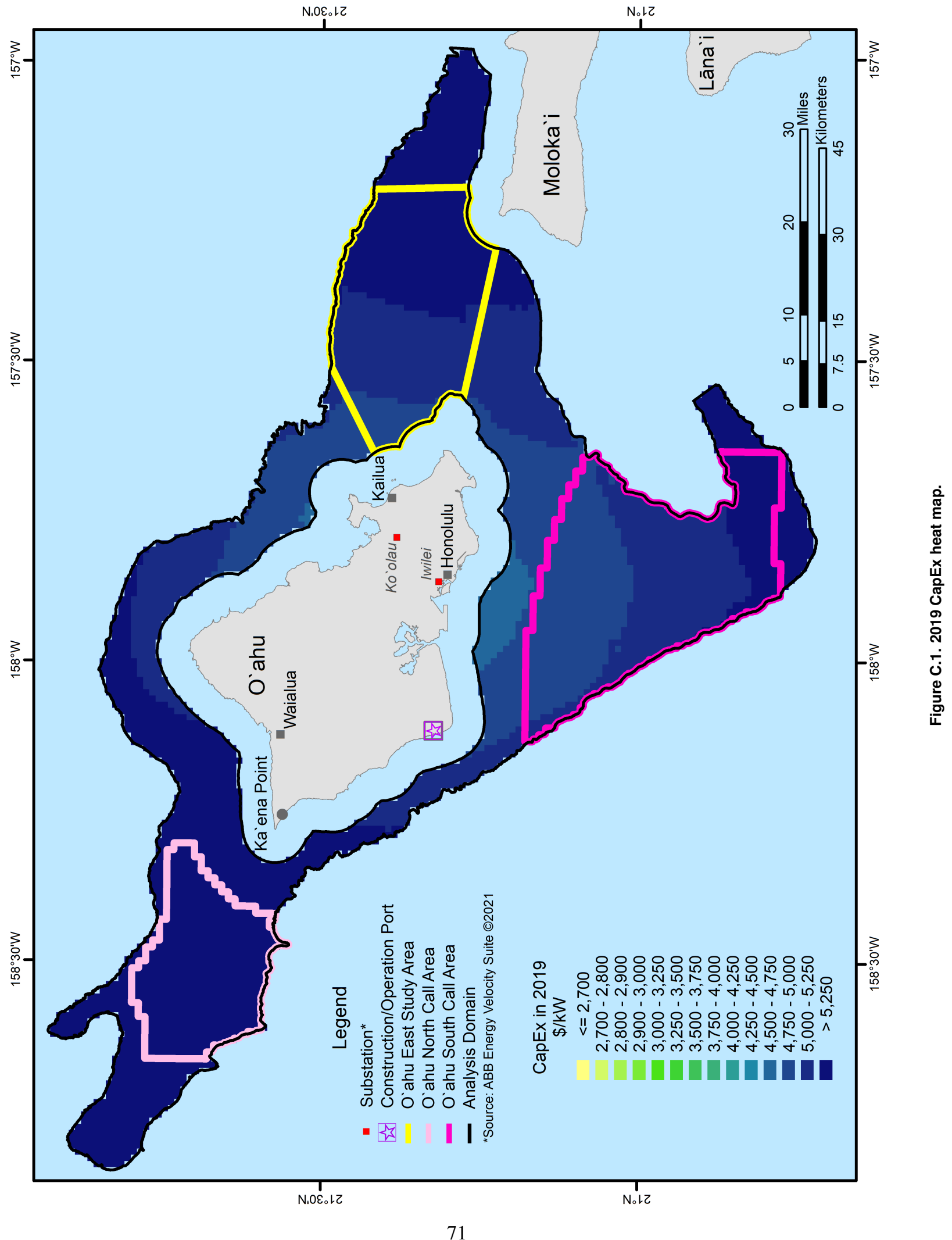

This report is available at no cost from the National Renewable Energy Laboratory at www.nrel.gov/publications. 


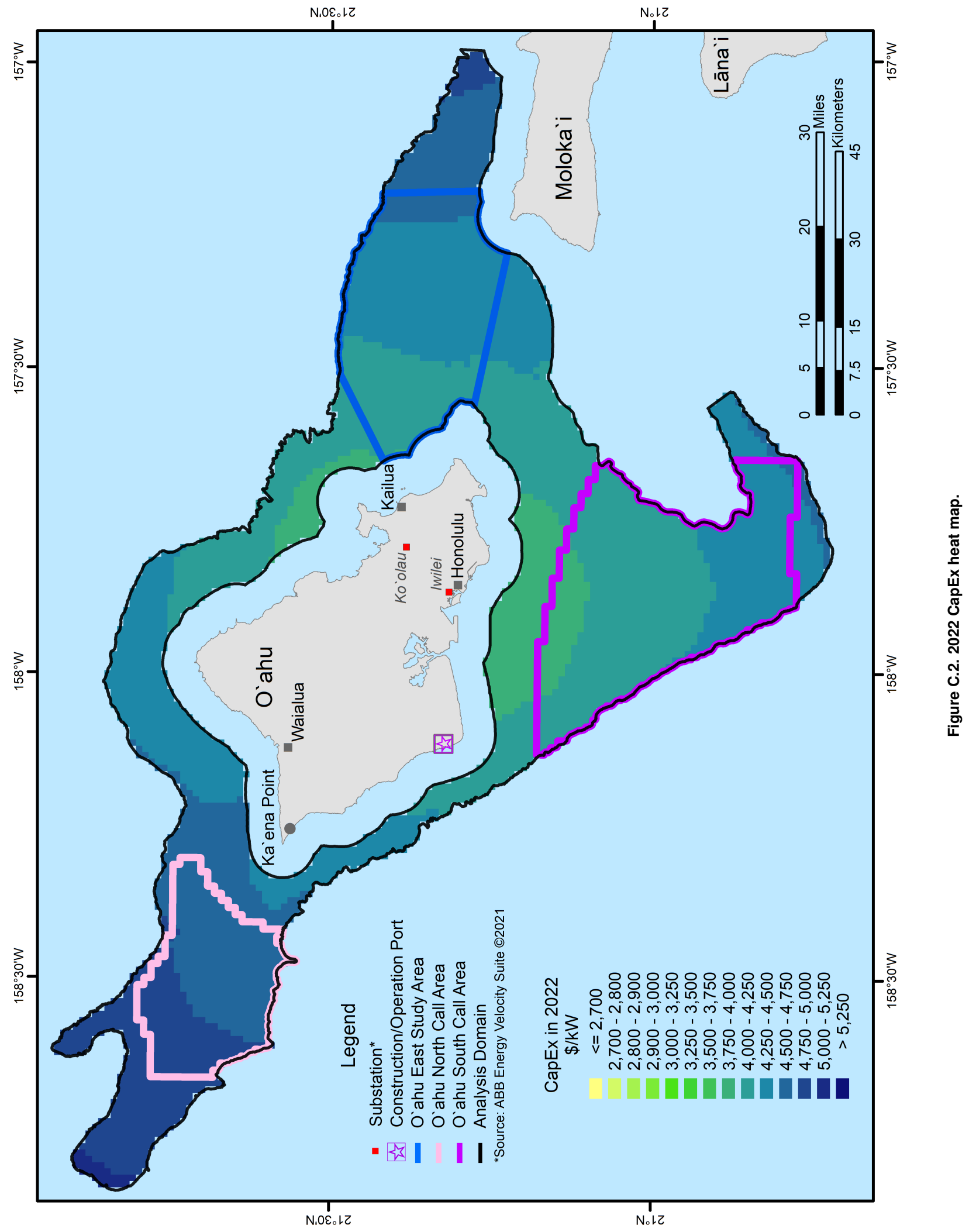




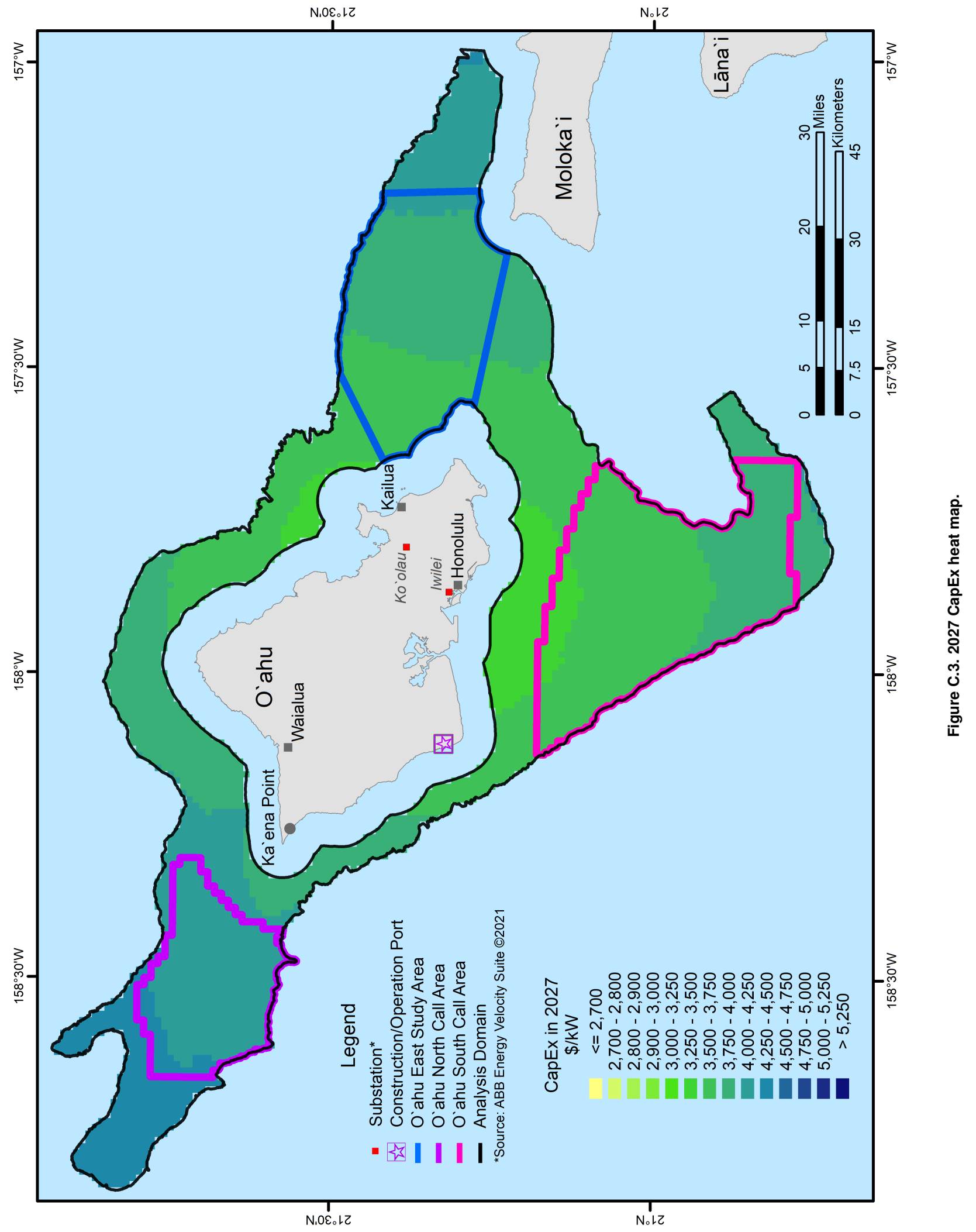




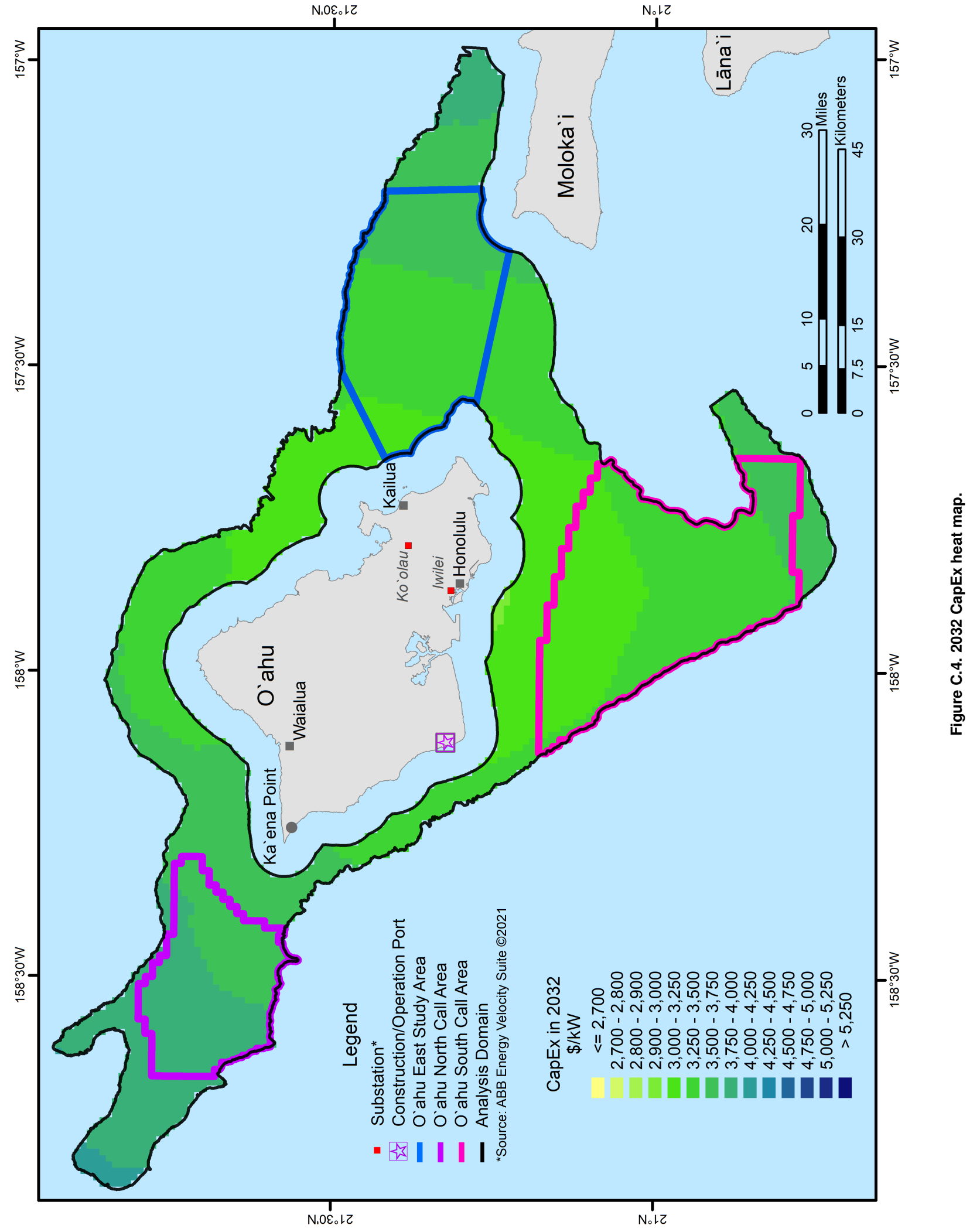




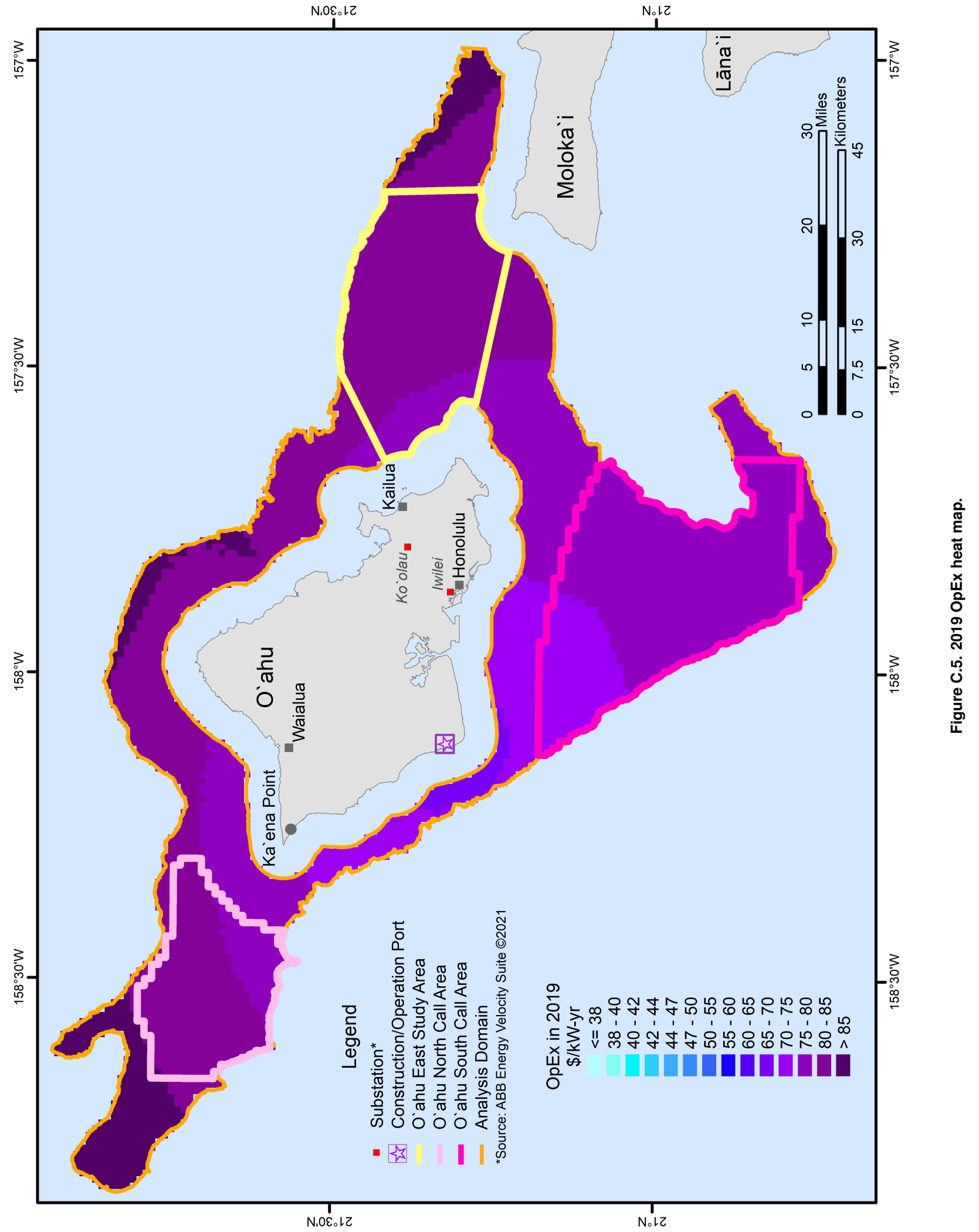




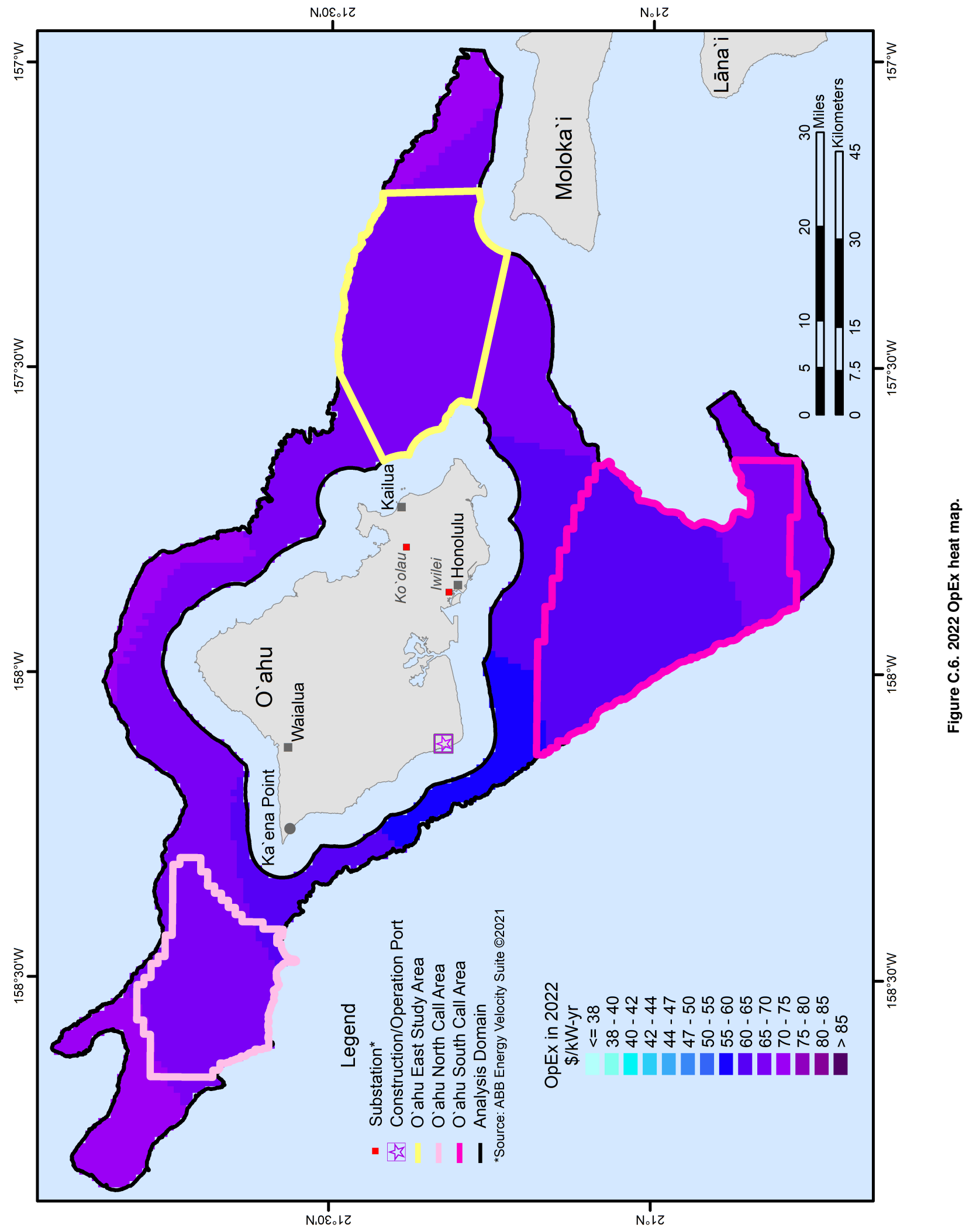




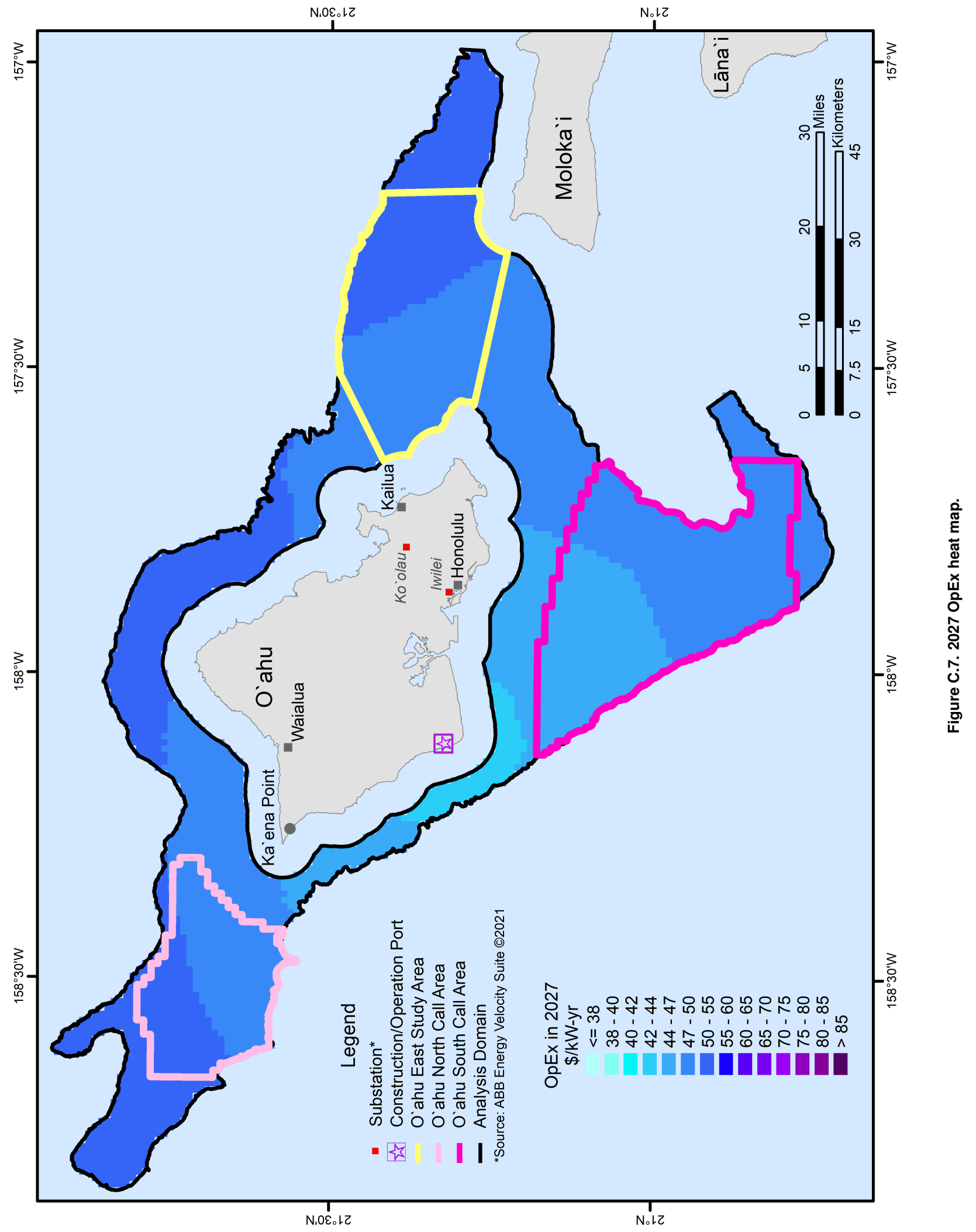




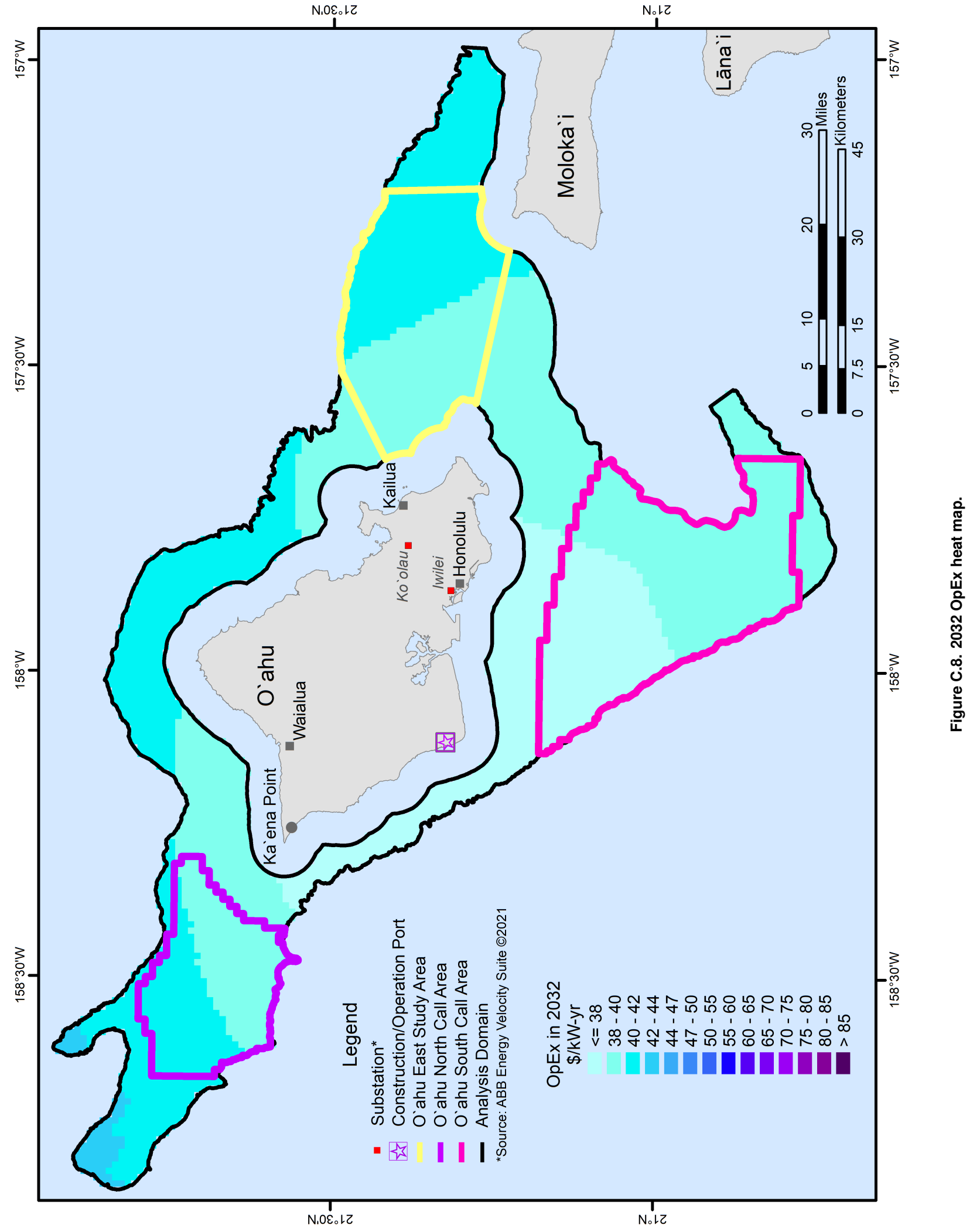




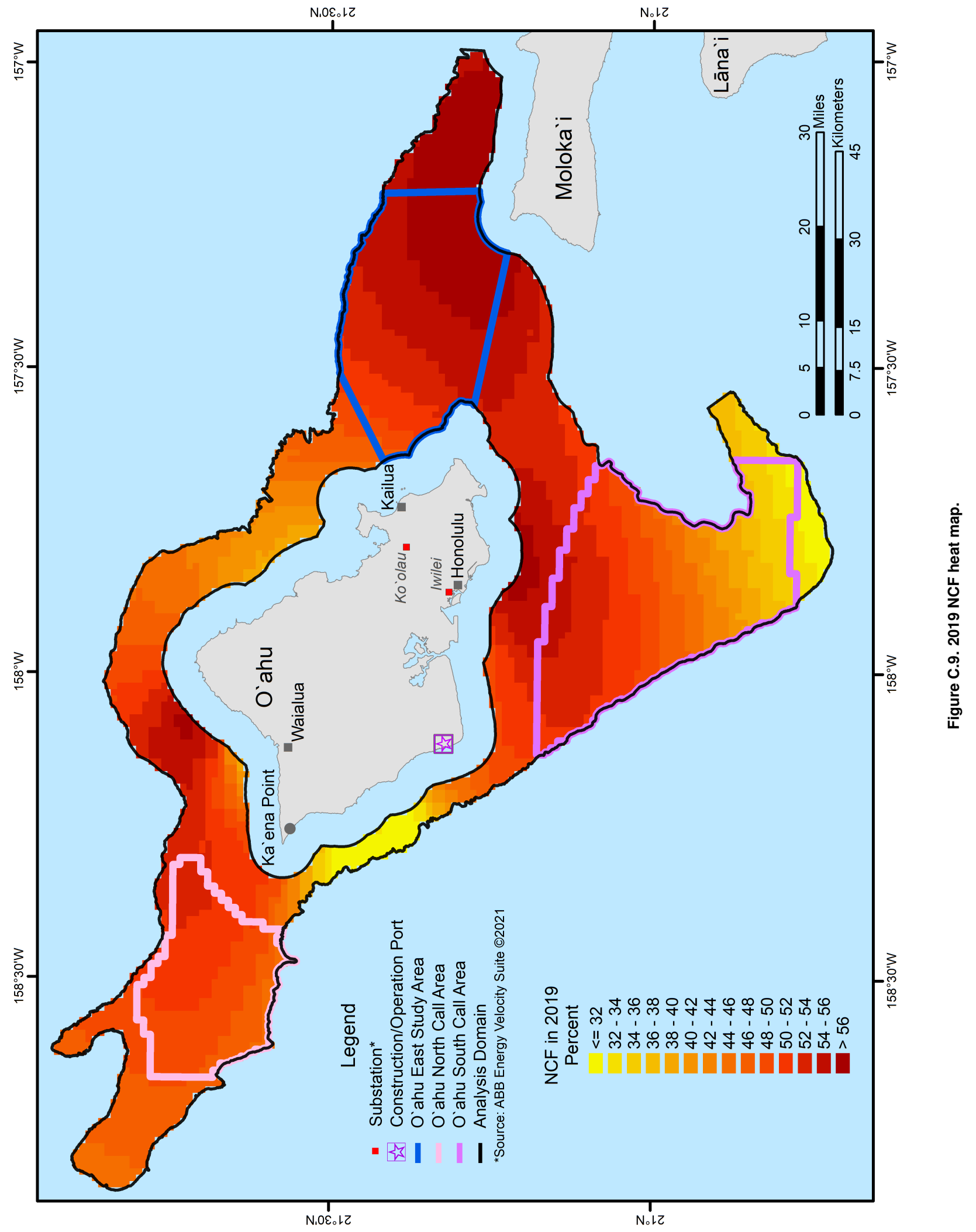




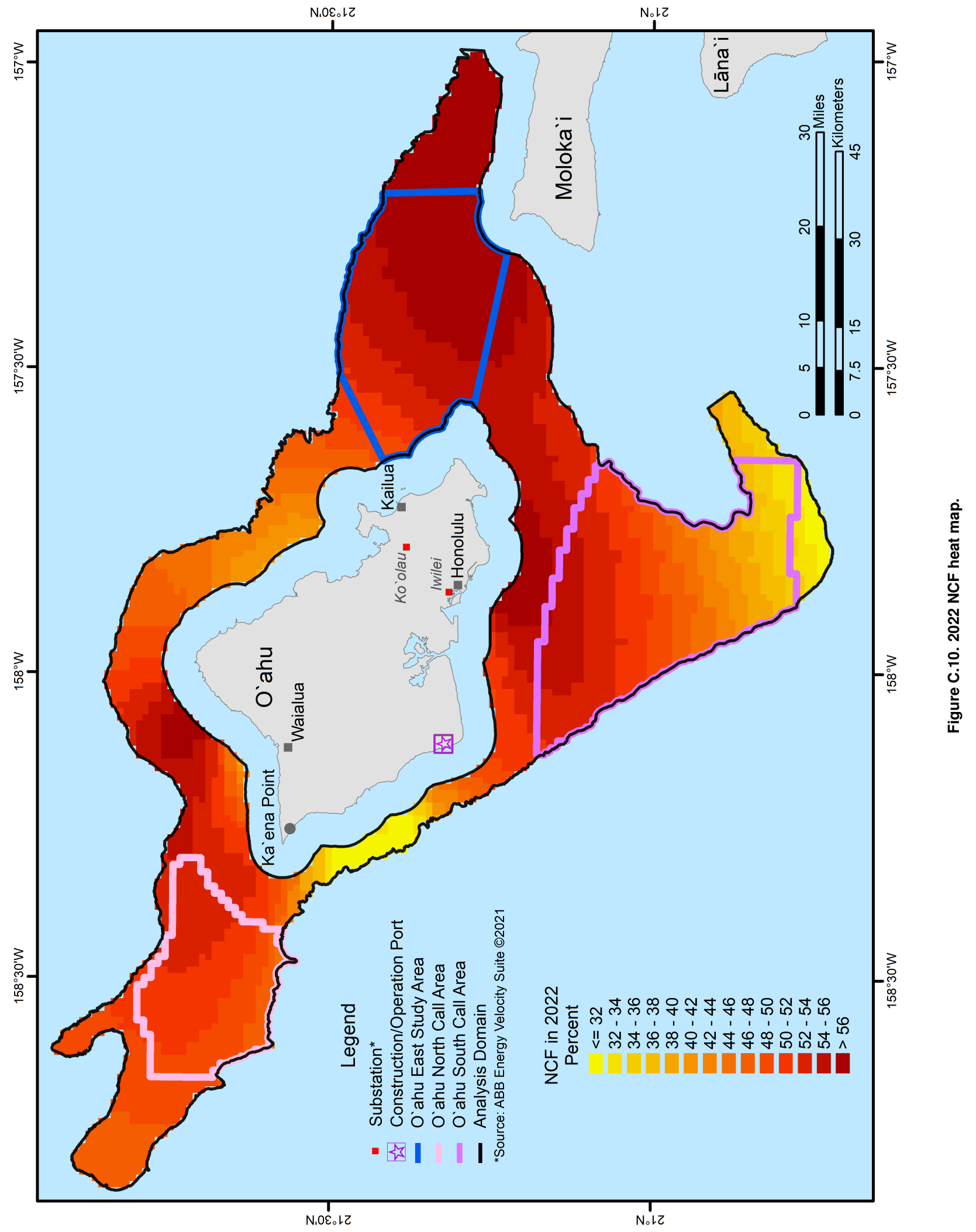




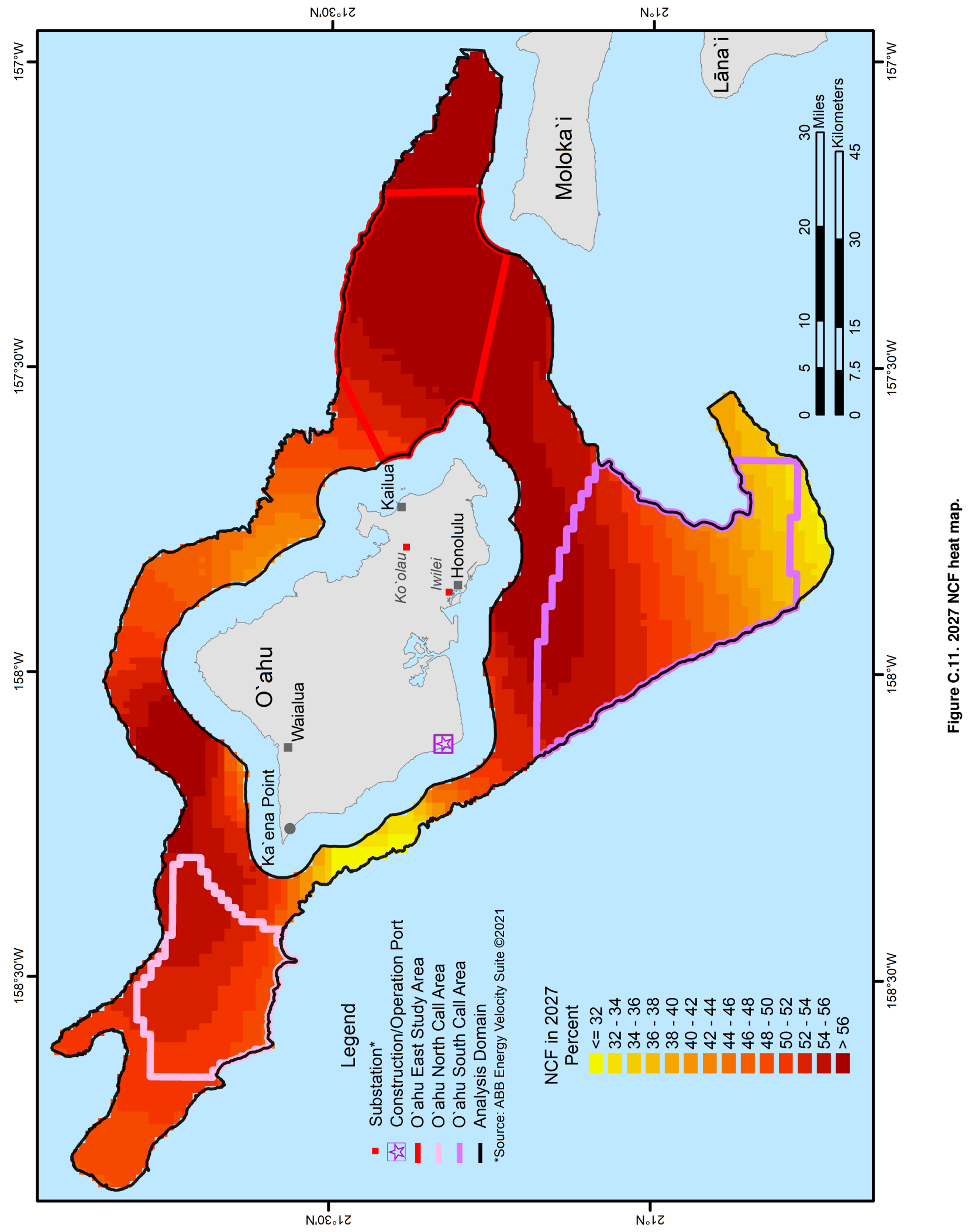




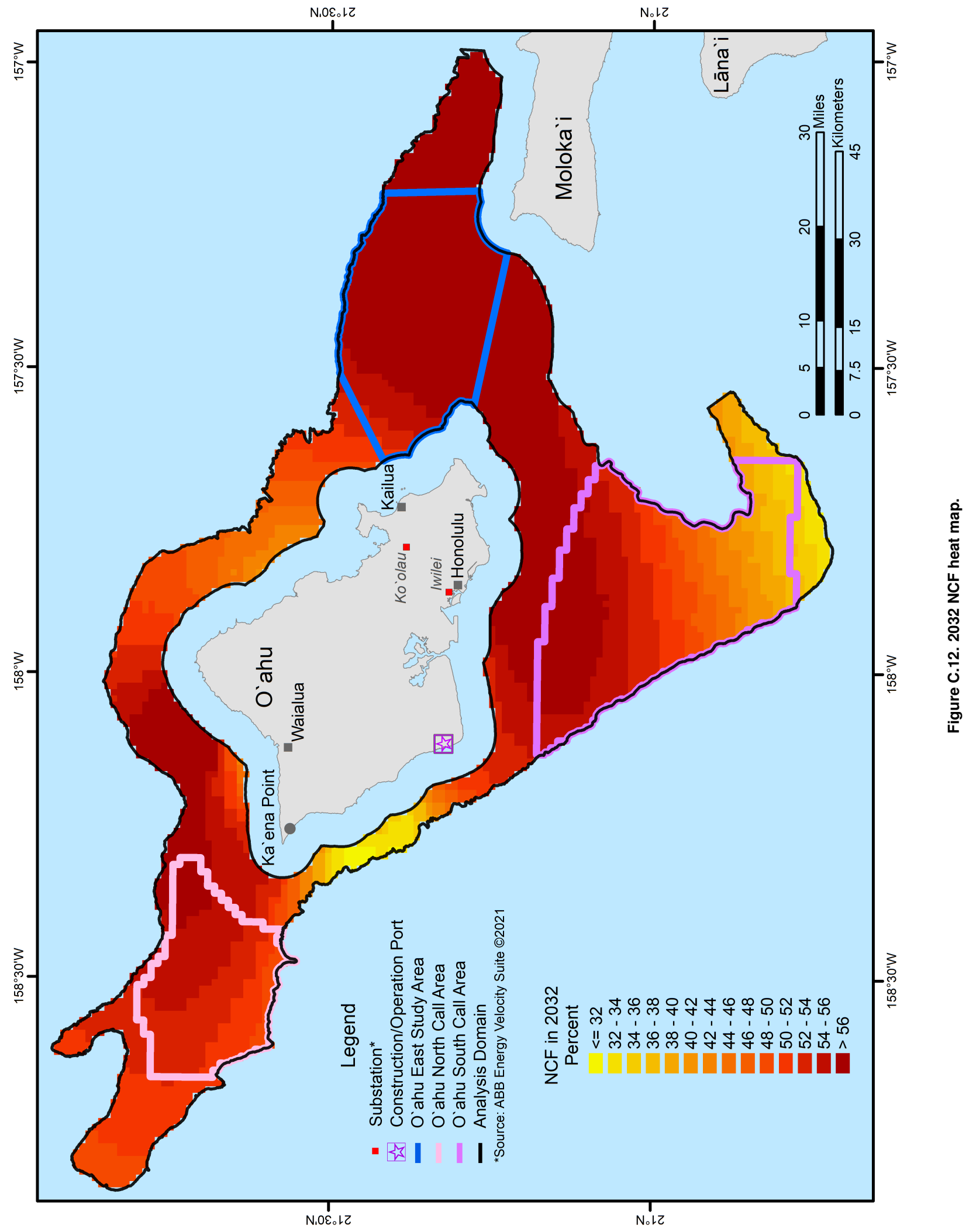




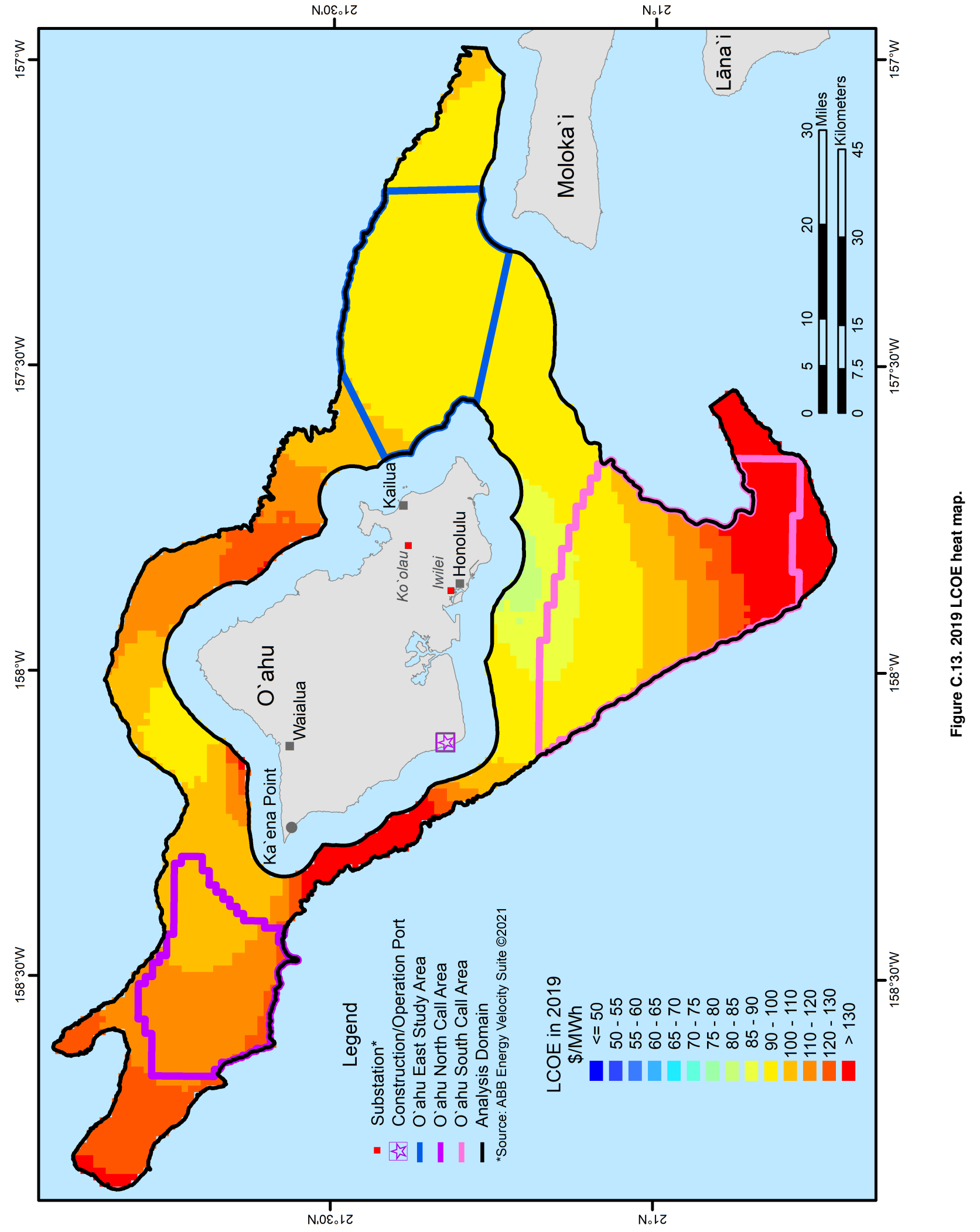




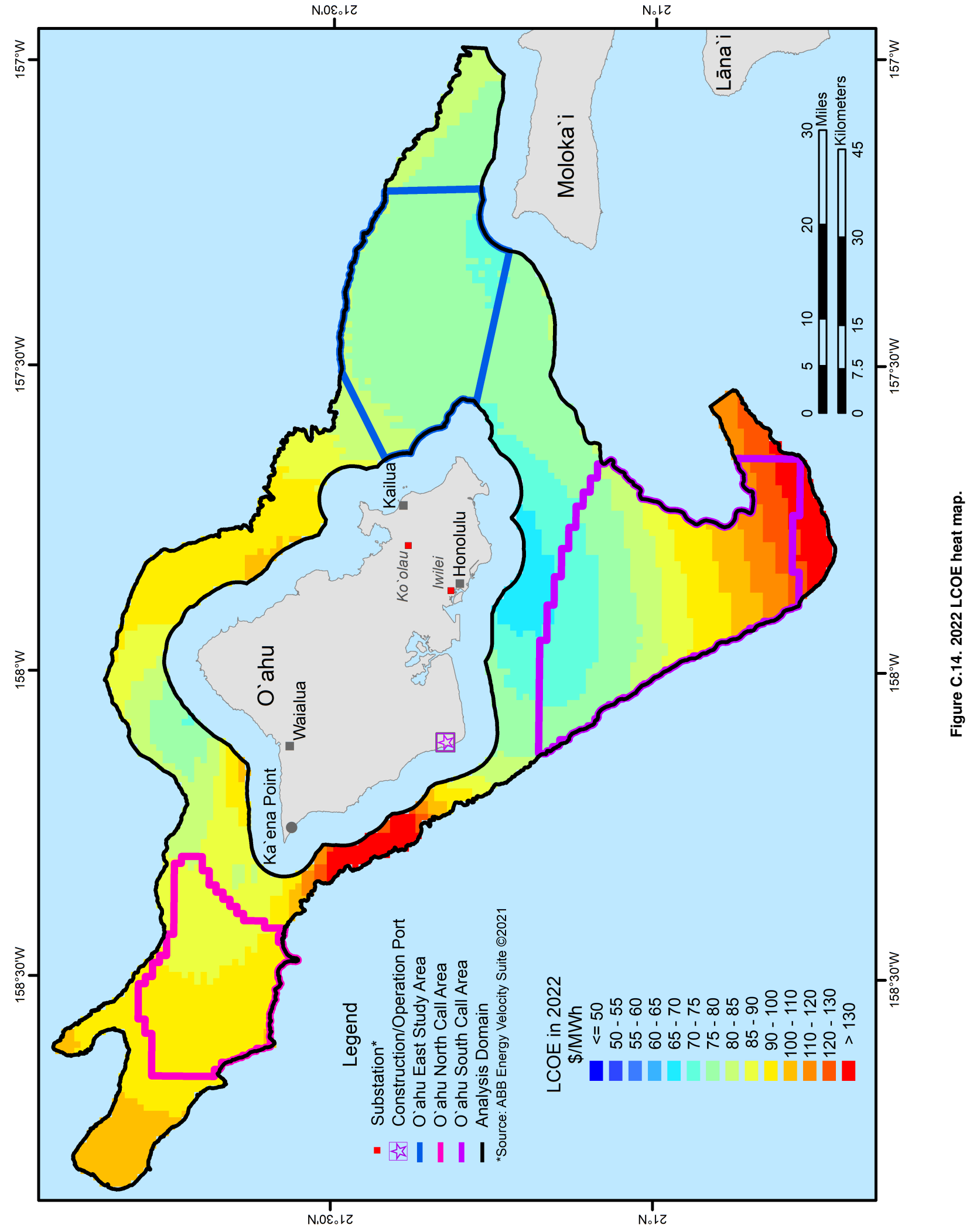




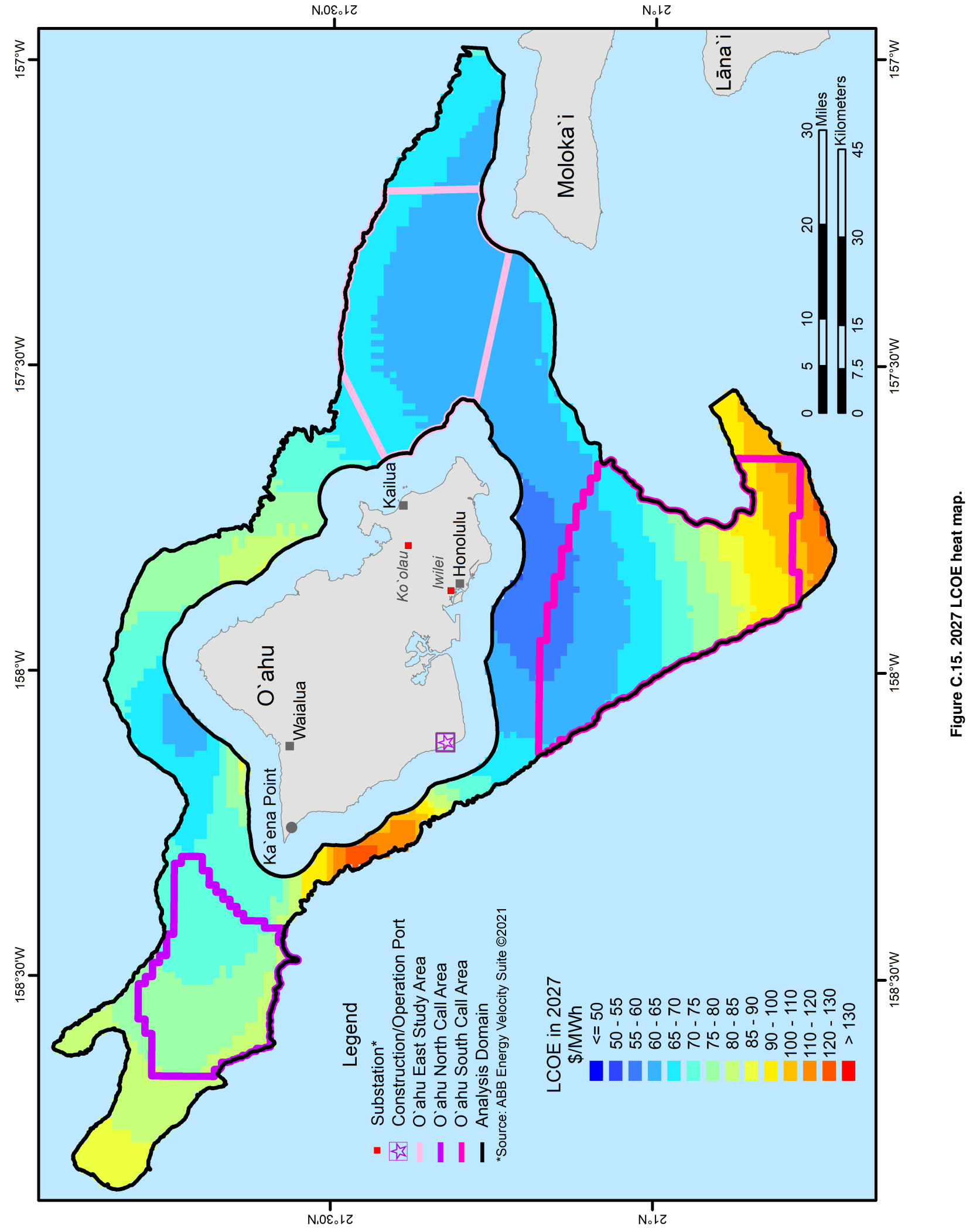




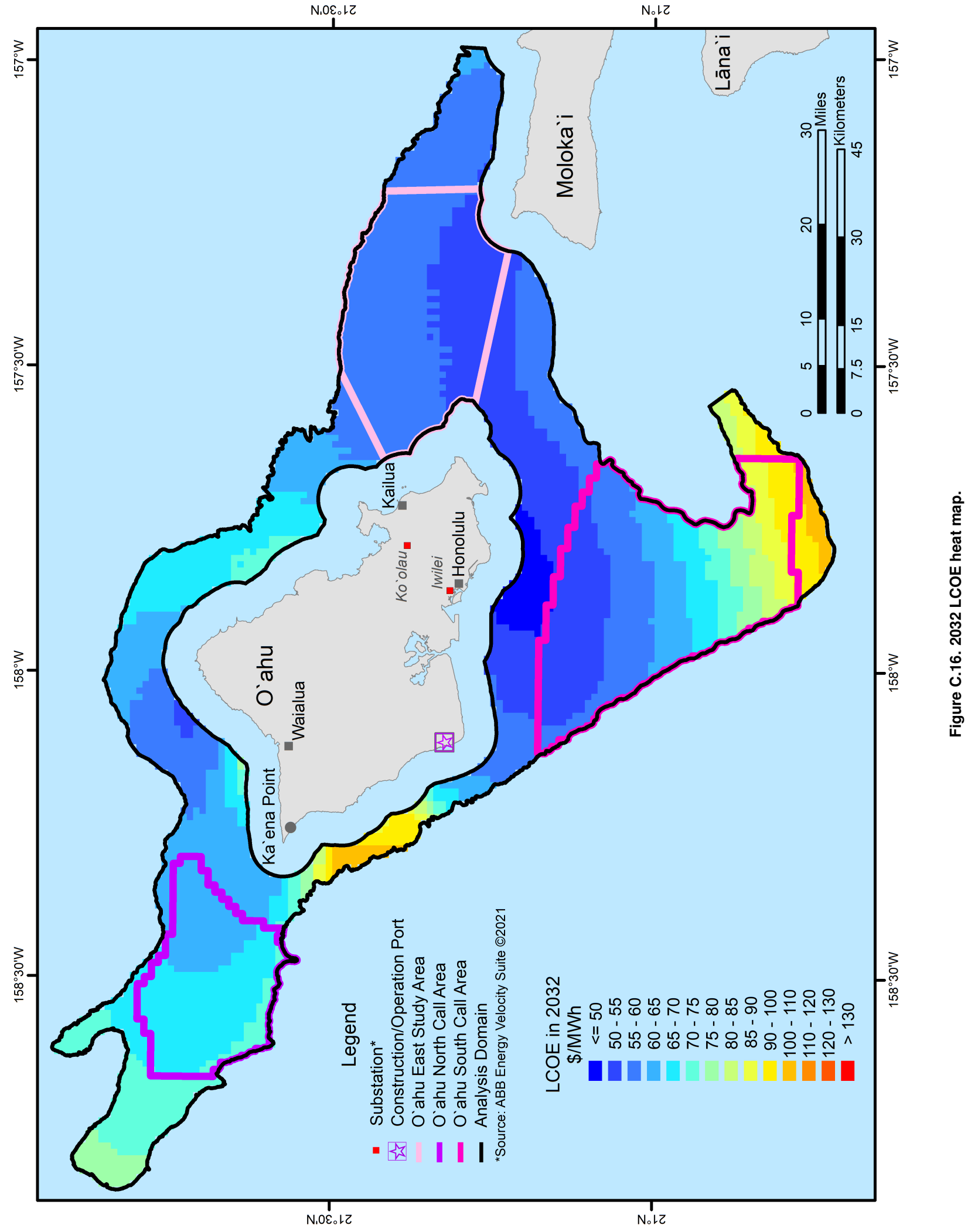




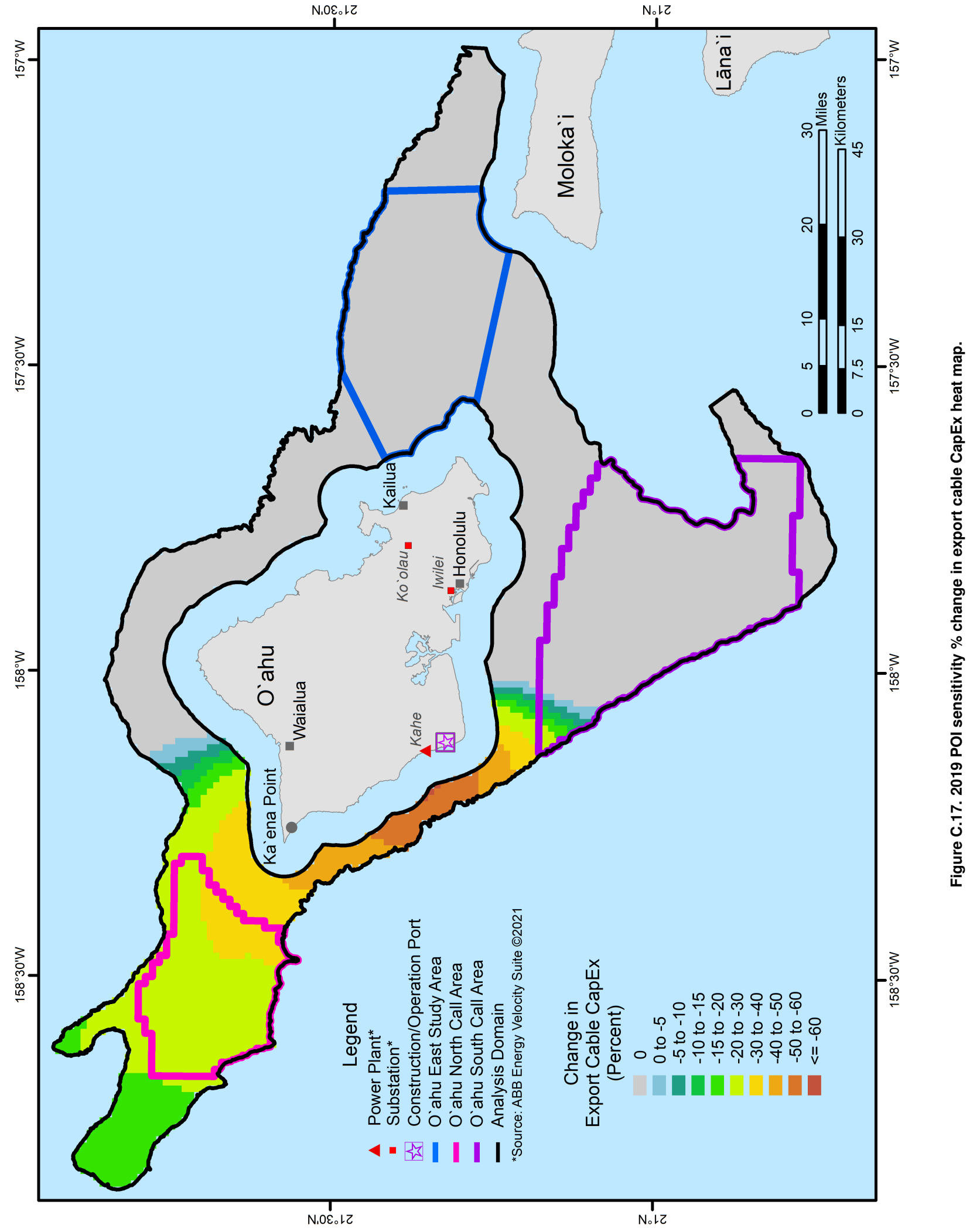




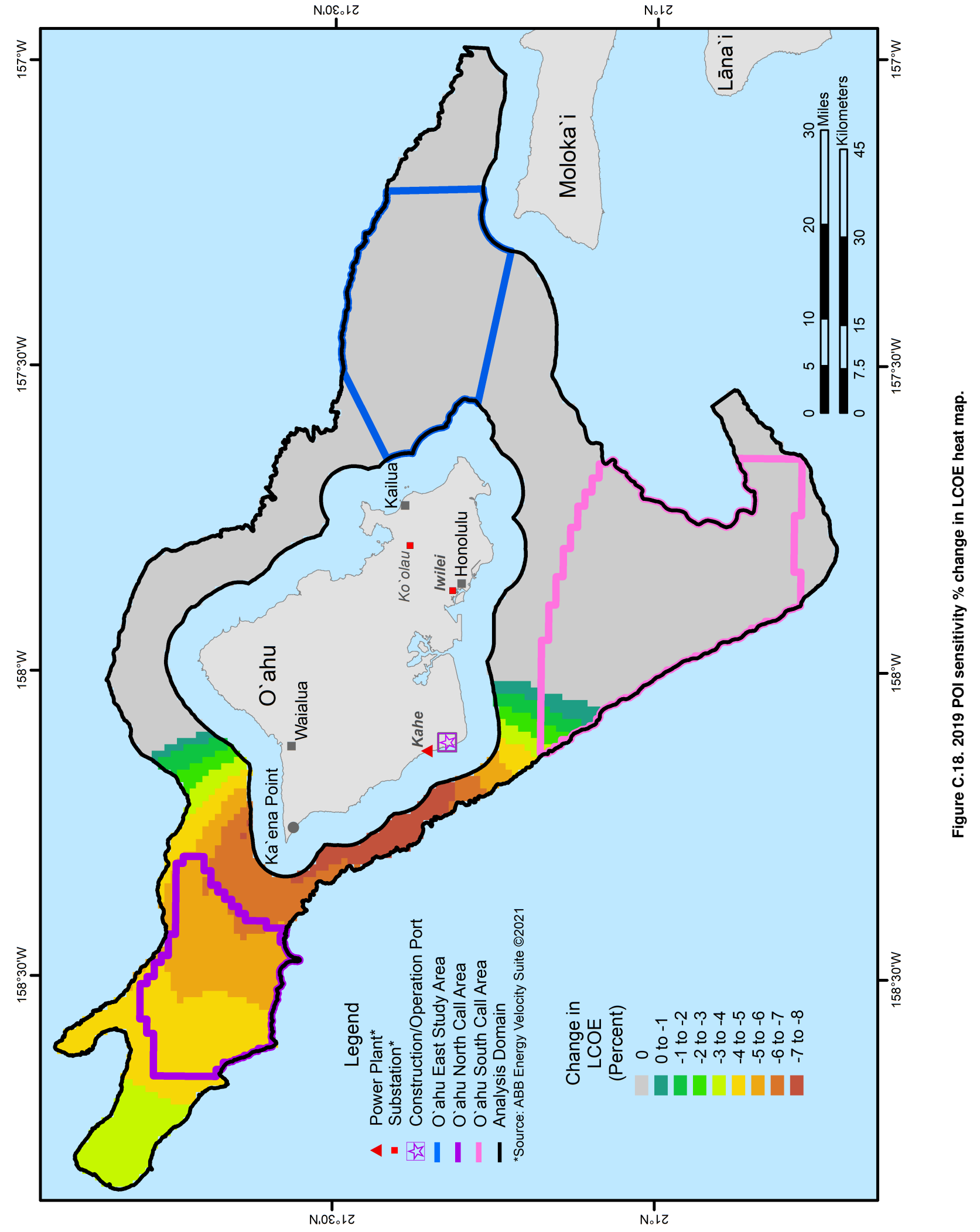

